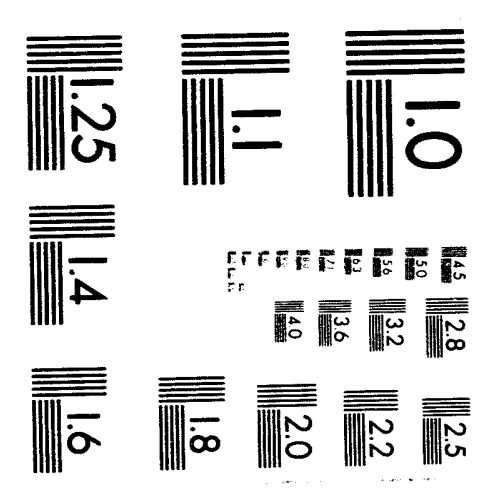



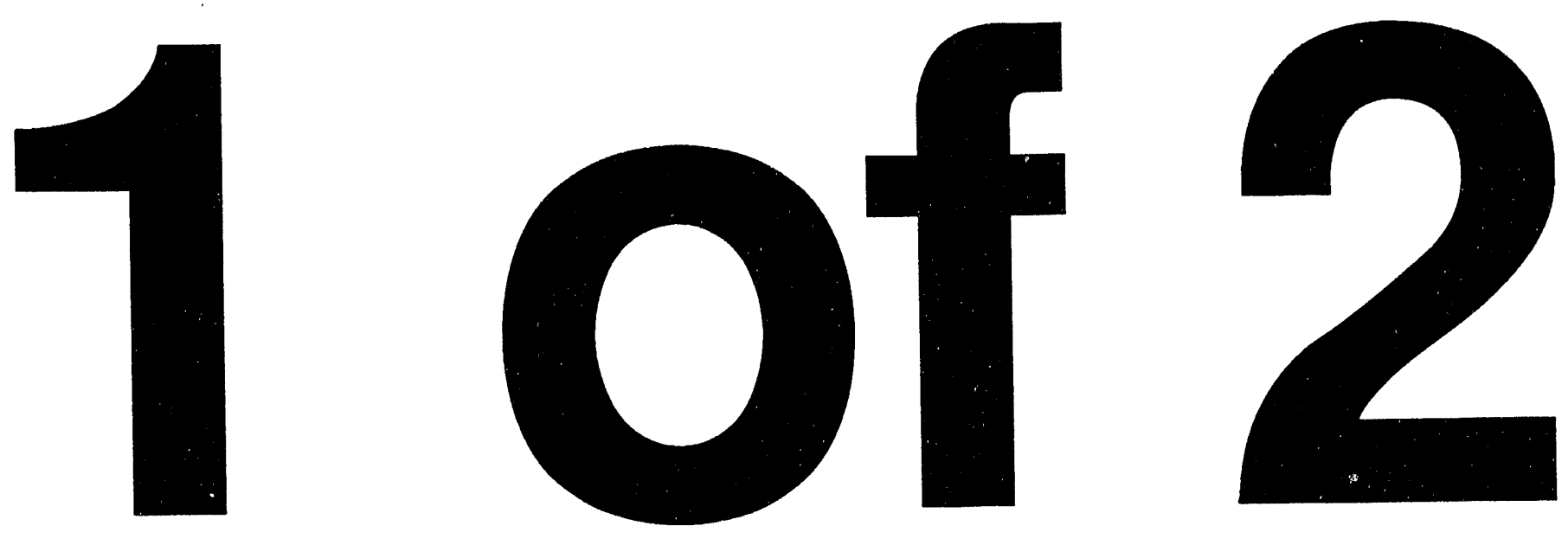
NUREG/CR-6076

ORNL/TM-12415

\section{TR-EDB: Test Reactor Embrittlement Data Base, Version 1}

Manuscript Completed: December 1993

Date Published: January 1994

Prepared by

F. W. Stallmann, J. A. Wang, F. B. K. Kam

Oak Ridge National Laboratory

Operated by Martin Marietta Energy Systems, Inc.

Oak Ridge National Laboratory

Oak Ridge, TN 37831

Prepared for

Division of Engineering

Office of Nuclear Regulatory Research

U.S. Nuclear Regulatory Commission

Washington, DC 20555-0001

NRC FIN B0415

Under Contract No. DE-AC05-84OR21400

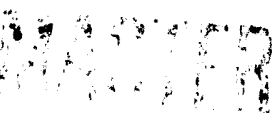




\section{AVAILABILITY NOTICE}

Availability of Reference Materials Cited in NRC Publications

Most documents cited in NRC publications will be available from one of the following sources:

1. The NRC Public Document Room, $2120 \mathrm{~L}$ Street, NW., Lower Level, Washington, DC 20555-0001

2. The Superintendent of Documents, U.S. Government Printing Office, Mail Stop SSOP, Washington, DC 20402-53?8

3. The National Technical Information Service, Springfield. VA 22161

Although the listing that follows represents the majority of documents cited in NRC publications, it is not intended to be exhaustive.

Referenced documents available for inspection and copying for a fee from the NRC Public Document Room include NRC correspondence and internal NRC memoranda: NRC bulletins, circulars, information notices, inspection and investigation notices: licensee event reports; vendor reports and correspondence: Commission papers; and applicant and licensee documents and correspondence.

The following documents in the NUREG series are available for purshase from the GPO Sales Program: formal NRC staff and contractor reports. NRC-sponsored conference proceedings, international agreement reports. grant publications, and NRC booklets and brochures. Also available are regulatory guides, NRC regulations in the Code of Federal Regulations, and Nuclear Regulatory Commission Issuances.

Documents available from the National Technical Information Service include NUREG-series reports and technical reports prepared by other Federal agencies and reports prepared by the Atomic Energy Commission. forerunner agency to the Nuclear Regulatory Commission.

Documents available from public and special technical libraries include all open literature items, such as books. journal articles, and transactions. Federal Register notices. Federal and State legislation, and congressional reports can usually be obtained from these libraries.

Documents such as theses, dissertations, foreign reports and translations, and non-NRC conference proceedings are available for purchase from the organization sponsoring the publication cited.

Single copies of NRC draft reports are available fiee, to the extent of supply. upon written request to the Office of Administration. Distribution and Mail Services Section, U.S. Nuclear Regulatory Commission. Washington, DC 20555-0001.

Copies of industry codes and standards used in a substantive manner in the NRC regulatory process are maintained at the NRC Library, 7920 Norfolk Avenue. Bethesda. Maryland, for use by the public. Codes and standards are usually copyrighted and may be purchased from the originating organization or, if they are American National Standards, from the American National Standards Institute, 1430 Broadway, New York, NY 10018.

\section{DISCLAIMER NOTICE}

This report was prepared as an account of work sponsored by an agency of the United States Government. Neither the United States Government nor any agency thereof, or any of their employees, makes any warranty, expressed or implied, or assumes any legal liability of responsibility for any third party's use, or the results of such use, of any information, apparatus, product or process disclosed in this report, or represents that its use by such third party would not infringe privately owned rights. 


\begin{abstract}
The Test Reactor Embrittlement Data Base (TR-EDB) is a collection of results from irradiations in materials test reactors. It complements the Power Reactor Embrittlement Data Base (PR-EDB), whose data are restricted to the results from the analysis of surveillance capsules in commercial power reactors. The rationale behind this restriction was the assumption that the results of test reactor experiments may not be applicable to power reactors and could, therefore, be challenged if such data were included. For this very reason the embrittlement predictions in the Reg. Guide 1.99, Rev. 2, were based exclusively on power reactor data. However, test reactor experiments are able to cover a much wider range of materials and irradiation conditions that are needed to explore more fully a variety of models for the prediction of irradiation embrittlement. These data are also needed for the study of effects of annealing for life extension of reactor pressure vessels that are difficult to obtain from surveillance capsule results.

The current data collection of the TR-EDB contains primarily Charpy test data, which are accompanied in most cases by tensile tests for the same irradiation conditions. Information is available for 1,230 different irradiated sets, 797 of which are from base material (plates and forgings), 378 from welds, and 55 from heat-affected-zone materials. The chemistries of the investigated materials span also a fairly wide range, particularly in the content of copper and nickel, which are considered the most important contributors to embrittlement sensitivity. Complete chemistry information is available for 1,095 of the 1,230 samples (after discarding the HAZ information).

The architecture of the TR-EDB is fully compatible with that of the PR-EDB so that the data from both databases can be easily merged, if desired. The data files are given in dBASE format and can be accessed with any personal computer using the DOS operating system. "User-friendly" utility programs have been written to investigate the radiation embrittlement using this data base. The utility programs are used to retrieve and select specific data, manipulate data, display data to the screen or printer, and to fit and plot Charpy impact data.
\end{abstract}




\section{CONTENTS}

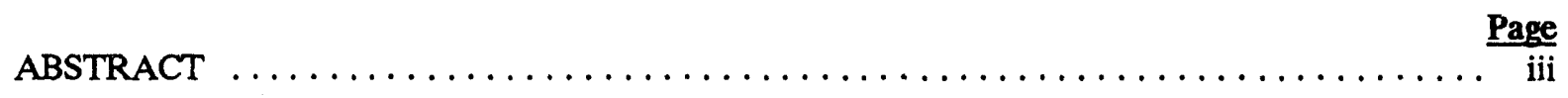

LIST OF FIGURES $\ldots \ldots \ldots \ldots \ldots \ldots \ldots \ldots \ldots \ldots \ldots \ldots \ldots \ldots \ldots \ldots \ldots \ldots \ldots \ldots$

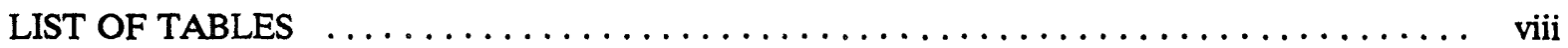

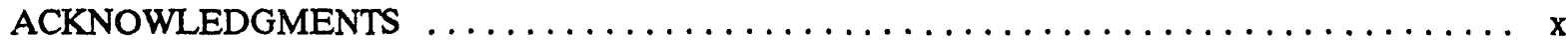

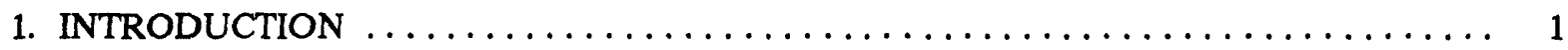

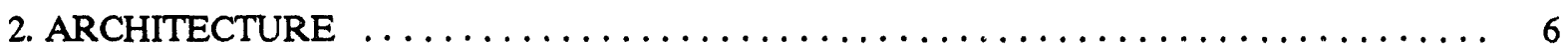

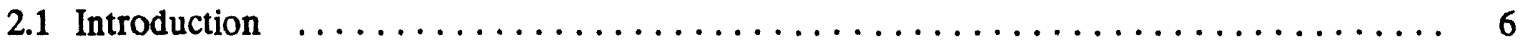

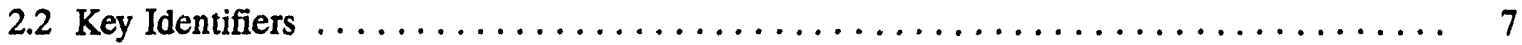

2.3 Organization of the TR-EDB Raw Data Files $\ldots \ldots \ldots \ldots \ldots \ldots \ldots \ldots \ldots \ldots \ldots \ldots$

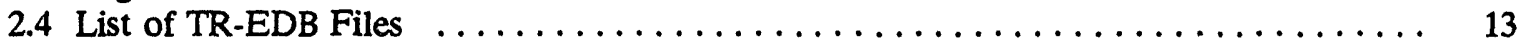

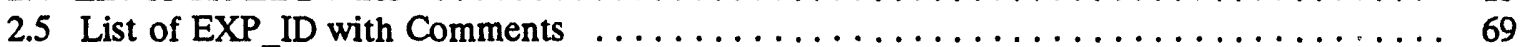

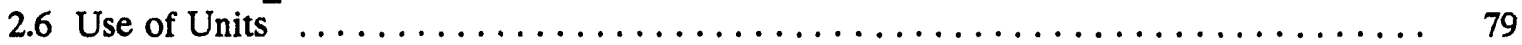

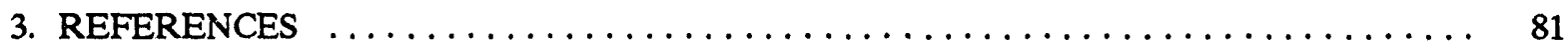

APPENDIX A. CUSTOM SOFTWARE FOR PROCESSING OF THE TR-EDB $\ldots \ldots \ldots \ldots 83$

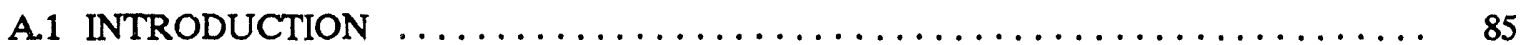

A.2 EDB-UTILITIES SOFTWARE PACKAGE $\ldots \ldots \ldots \ldots \ldots \ldots \ldots \ldots \ldots \ldots \ldots \ldots$

A.3 FILE MANIPULATION PROCEDURES $\ldots \ldots \ldots \ldots \ldots \ldots \ldots \ldots \ldots \ldots \ldots$

A.3.1 General Consideration $\ldots \ldots \ldots \ldots \ldots \ldots \ldots \ldots \ldots \ldots \ldots \ldots \ldots \ldots \ldots$

A.3.2 Retrieve of Files for Manipulation $\ldots \ldots \ldots \ldots \ldots \ldots \ldots \ldots \ldots \ldots \ldots \ldots \ldots$

A.3.3 Addition or Deletion of Fields $\ldots \ldots \ldots \ldots \ldots \ldots \ldots \ldots \ldots \ldots \ldots \ldots$

A.3.4 Addition or Deletion of Records $\ldots \ldots \ldots \ldots \ldots \ldots \ldots \ldots \ldots \ldots \ldots$

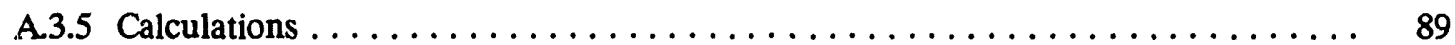

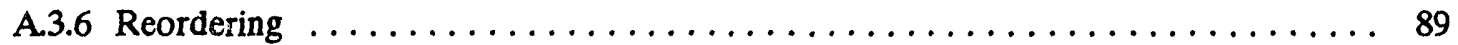

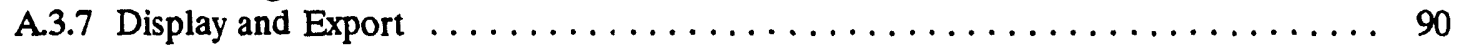

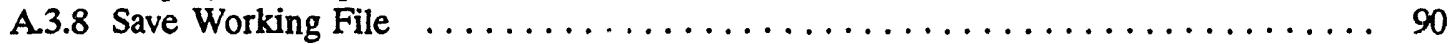

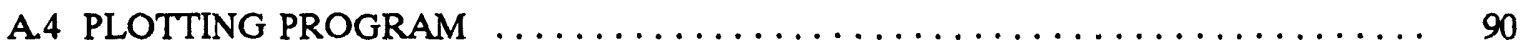

A.5 CHARPY FITTING AND PLOTTING $\ldots \ldots \ldots \ldots \ldots \ldots \ldots \ldots \ldots \ldots \ldots \ldots$

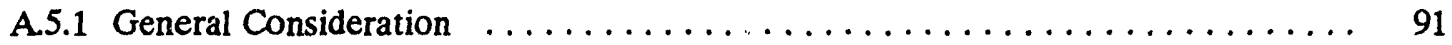

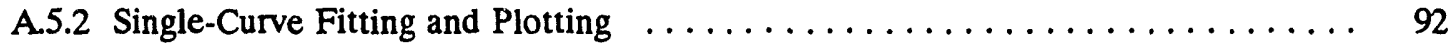

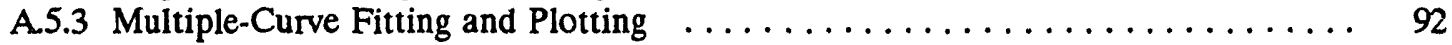

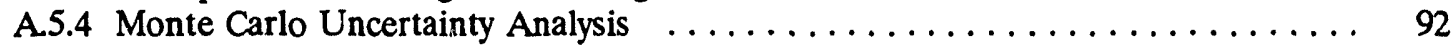

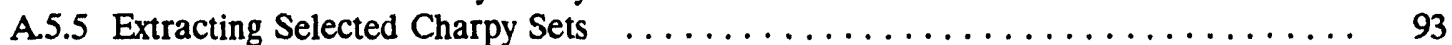

A.5.6 Selection of Input Fields and Data Sets $\ldots \ldots \ldots \ldots \ldots \ldots \ldots \ldots \ldots \ldots$ 
CONTENTS

(continued)

$\underline{\text { Page }}$

A.6 INSTALLATION AND EXECUTION $\ldots \ldots \ldots \ldots \ldots \ldots \ldots \ldots \ldots \ldots \ldots \ldots \ldots \ldots$

APPENDIX B. DIFFERENCES BETWEEN CURRENT VERSIONS OF THE PR-EDB

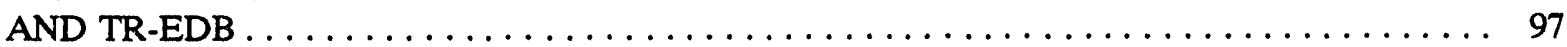

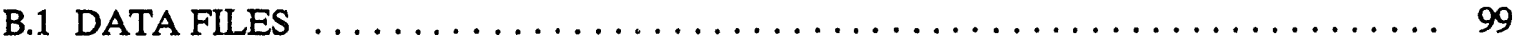

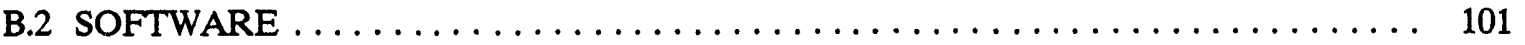

APPENDIX C. LIS ^ OF FILES INCLUDED IN THE TR-EDB AND SOFTWARE $\ldots \ldots \ldots$

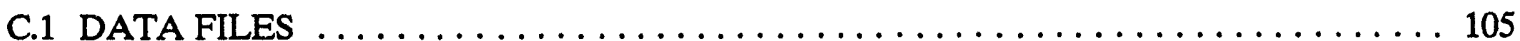

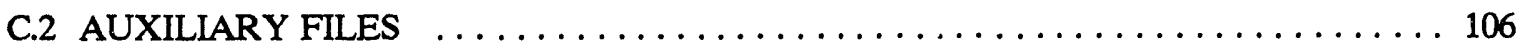

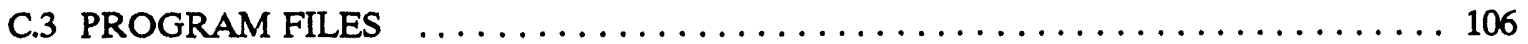

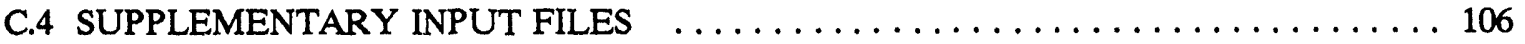




\section{LIST OF FIGURES}

1. Distribution of charpy irradiations in fluence and irradiation temperature $\ldots \ldots \ldots \ldots \ldots \ldots \frac{\text { Page }}{4}$

2. Distribution of charpy irradiations in copper and nickel content $\ldots \ldots \ldots \ldots \ldots \ldots \ldots \ldots$

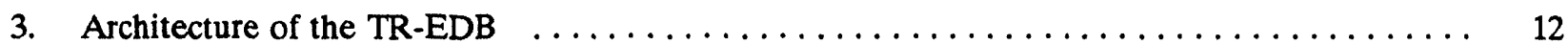

A.1 Major options selected from first menu $\ldots \ldots \ldots \ldots \ldots \ldots \ldots \ldots \ldots \ldots \ldots \ldots$

A.2. File-manipulation procedures $\ldots \ldots \ldots \ldots \ldots \ldots \ldots \ldots \ldots \ldots \ldots \ldots \ldots \ldots \ldots \ldots$ 


\section{LIST OF TABLES}

Page

1. Structure file for E-LST_TR.dbf $\ldots \ldots \ldots \ldots \ldots \ldots \ldots \ldots \ldots \ldots \ldots \ldots \ldots \ldots \ldots \ldots \ldots \ldots \ldots \ldots$

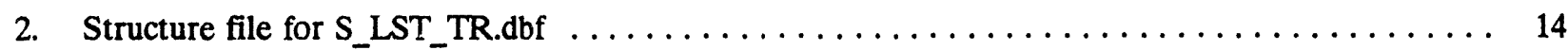

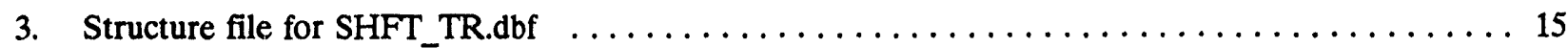

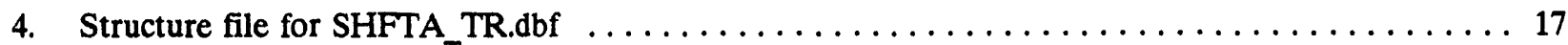

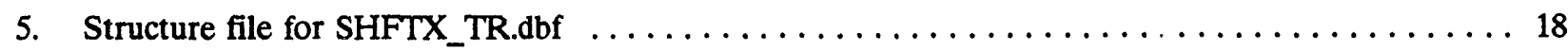

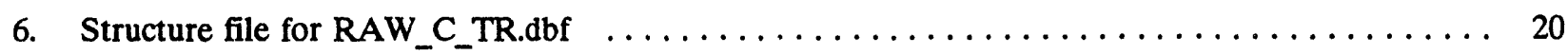

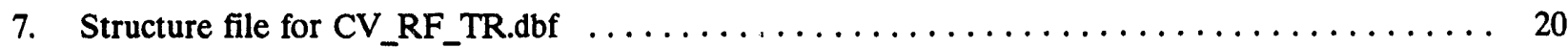

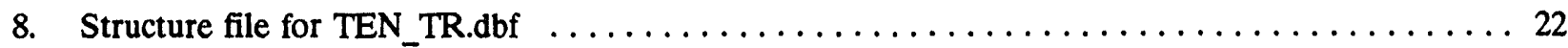

9. Structure file for $R_{-}$LST_TR.dbf $\ldots \ldots \ldots \ldots \ldots \ldots \ldots \ldots \ldots \ldots \ldots \ldots \ldots \ldots \ldots \ldots \ldots \ldots$

10. Structure file for REAC_TR $_{-}$dbf $\ldots \ldots \ldots \ldots \ldots \ldots \ldots \ldots \ldots \ldots \ldots \ldots \ldots \ldots \ldots \ldots \ldots$

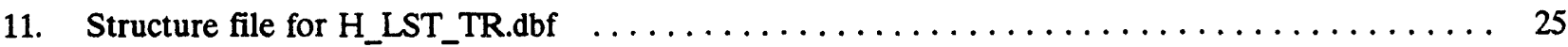

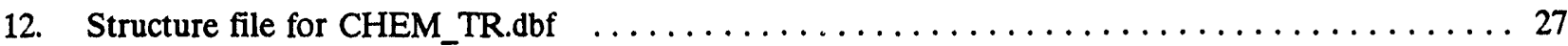

13. Structure file for HEAT_TR.dbf $\ldots \ldots \ldots \ldots \ldots \ldots \ldots \ldots \ldots \ldots \ldots \ldots \ldots \ldots \ldots \ldots \ldots$

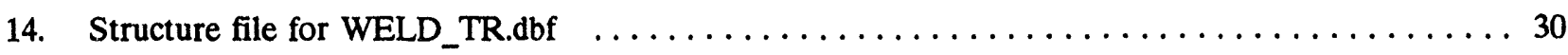

15. Structure file for $\mathrm{HAZ}_{-} \mathrm{TR} . \mathrm{dbf} \ldots \ldots \ldots \ldots \ldots \ldots \ldots \ldots \ldots \ldots \ldots \ldots \ldots \ldots \ldots \ldots \ldots \ldots \ldots \ldots$

16. Structure file for TITL $\mathrm{TR}$.dbf $\ldots \ldots \ldots \ldots \ldots \ldots \ldots \ldots \ldots \ldots \ldots \ldots \ldots \ldots \ldots \ldots \ldots \ldots$

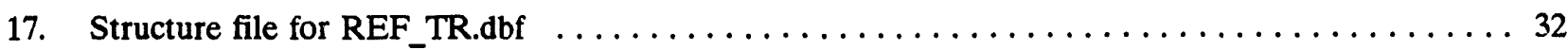

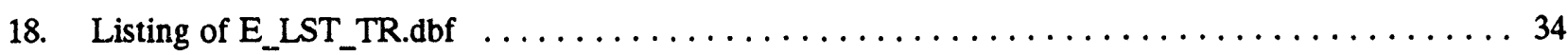

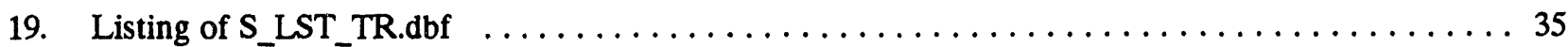

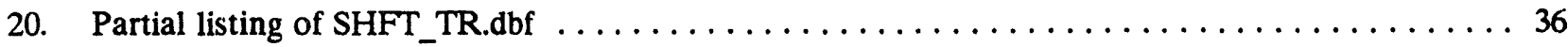

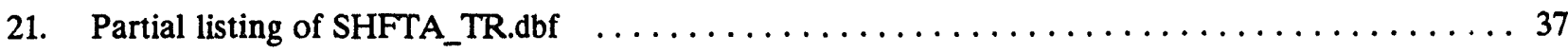

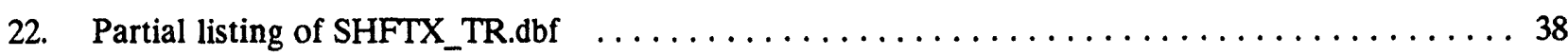

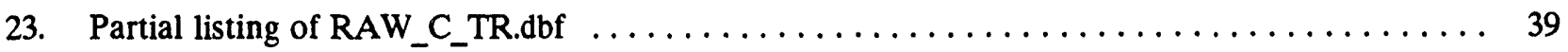




\section{LIST OF TABLES}

(continued)

$\underline{\text { Page }}$

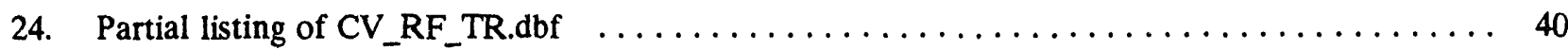

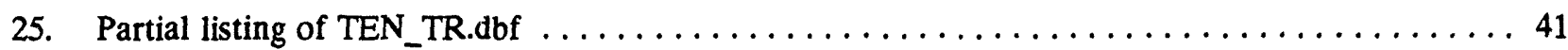

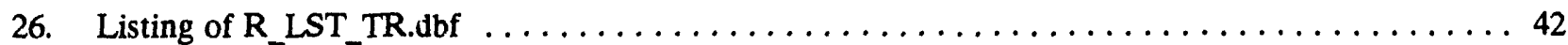

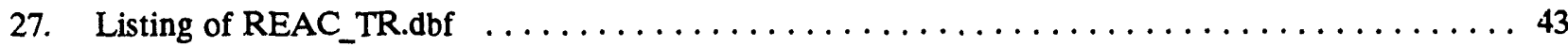

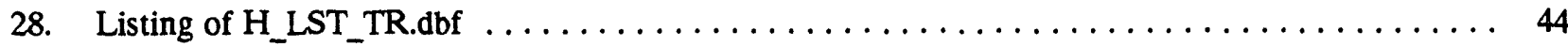

29. Partial listing of CHEM TR.dbf $\ldots \ldots \ldots \ldots \ldots \ldots \ldots \ldots \ldots \ldots \ldots \ldots \ldots \ldots \ldots$

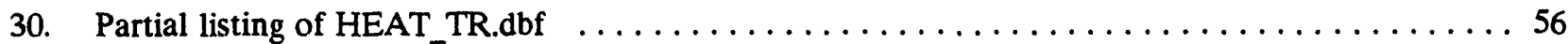

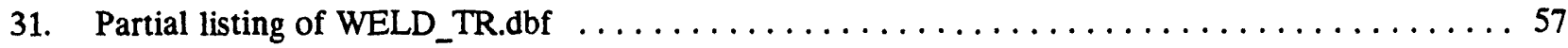

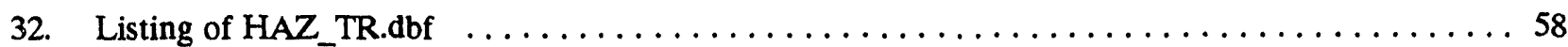

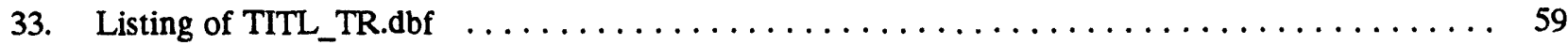

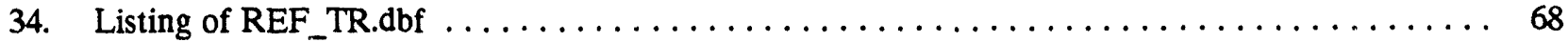

35. Units used in TR-EDB files $\ldots \ldots \ldots \ldots \ldots \ldots \ldots \ldots \ldots \ldots \ldots \ldots \ldots \ldots \ldots$ 


\section{ACKNOWLEDGMENT}

The authors gratefully acknowledge E. Sajo and E. Eason for their valuable suggestions in reviewing this report; L. P. Hileman and M. A. Bunch for preparing this manuscript; C. H. Shappert for editing, and C. Z. Serpan and Al Taboada of the U.S. Nuclear Regulatory Commission for their financial support and guidance. 


\section{INTRODUCTION}

The Test Reactor Embrittlement Data Base (TR-EDB) is a collection of results from irradiations in materials test reactors. It complements the Power Reactor Embrittlement Data Base ${ }^{1}$ (PR-EDB), whose data are restricted to the results from the analysis of surveillance capsules in commercial power reactors. The rationale behind this restriction was the assumption that the results of test reactor experiments may not be applicable to power reactors, and regulatory decisions could, therefore, be challenged if such data were included. For this very reason the embrittlement predictions in the Reg. Guide 1.99, Rev. 2 (ref. 2) were based exclusively on power reactor data. However, test reactor experiments are able to cover a much wider range of materials and irradiation conditions that are needed to explore more fully a variety of models for the prediction of irradiation embrittlement. These data are also needed for the study of effects of annealing for life extension of reactor pressure vessels that are difficult to obtain from surveillance capsule results (see, however ref. 3 ).

The scope and purpose of this program, which is sponsored by the Nuclear Regulatory Commission (NRC), can be summarized as follows:

1. Compile and verify a comprehensive collection of data from test reactor irradiation experiments of pressure vessel materials from U.S. and foreign laboratories.

2. Provide software support for the use of the cata base by furnishing programs and maintaining compatibility with commercially available software.

3. Maintain compatibility with the PR-EDB.

4. Maintain compatibility with U.S. and International Standards.

5. Facilitate the exploration and verification of embrittlement prediction models.

6. Facilitate the exploration and verification of the effects of annealing for pressure vessel life extension.

The data collections for both data bases originated from the Material Properties Council (MPC) data base, which contains both power and test reactor data. From this collection a first (unpublished) version of the embrittlement data base (EDB) was constructed and augmented with more recently reported data. For the reasons stated above a restricted version containing only surveillance data the PR-EDB - was assembled under NRC sponsorship to be used primarily for regulatory purposes. The data in the PR-EDB were subsequently reviewed and verified by reactor vendors and utilities and released to the public as Version 1 in July 1991. An updated Version 2 is currently being released. $^{4}$ In the meantime the assembly and review of the MPC and other test reactor results were continued, tracing them to the original reports and adding more data. Significant additions came from NRC-sponsored investigations at Materials Engineering Associates, Inc. (MEA) and Oak Ridge National Laboratory (ORNL), the International Atomic Energy Commission (IAEA)-sponsored program, and a variety of other irradiation experiments at laboratories in France, Germany, Japan,

*Martin Prager, Final Report Evaluation, Analysis and Transfer of Materials Property Data, The Materials Properties Council, Inc.. 
and the United Kingdom. Release of research data from other countries is being negotiated. The origin of each data point is, of course, identified by reference in the data files. The authors of the TR-EDB were provided with copies of the raw data sheets used for the MPC data base. These sheets that were prepared by the original investigators contain some unpublished material, such as identification of the irradiation facility and pre-irradiation test data. Such data are included in the TR-EDB and identified in the NOTES in addition to the referenced data.

The current data collection of the TR-EDB contains primarily Charpy test data that are accompanied in most cases by tensile tests for the same irradiation conditions. Information is available for 1,230 different irradiated sets, 797 of which are from base material (plates and forgings), 378 from welds, and 55 from heat-affected-zone materials. The distribution of fluences $(E>1.0 \mathrm{MeV})$ and irradiation temperatures over these experiments is shown in Figure 1. Not surprisingly, most irradiations were performed at the typical operating temperature of power reactors around $550^{\circ} \mathrm{F}$, but enough information for other temperatures is available to investigate in detail the influence of irradiation temperature on embrittlement. The chemistries of the investigated materials span also a fairly wide range, particularly in the content of copper and nickel, which are considered the most important contributors to embrittlement sensitivity. Complete chemistry information is available for 1,095 of the 1,230 samples (after discarding the HAZ information). The distribution in copper and nickel is shown in Figure 2. Several studies whose results are included in the TR-EDB deal specifically with the influence of chemical composition on embrittlement, primarily copper, nickel, and phosphorus. Section 2.5 lists all irradiation experiments that are currently included in the TR-EDB and gives a detailed description of facilities, methods, and goals. A summary of this information can also be found in the file E_LST_TR.dbf.

The data format that was chosen for both, the TR-EDB and PR-EDB is dBASE; this format was initially introduced by Ashton-Tate and is now the virtual standard for relational data bases. This format allows queries and data processing not only with the current dBASE software but also with any of the now numerous "Xbase" developer tools, such as Clipper or Foxpro. The dBase files can also be imported into most other data base, spreadsheet, and word processing programs that run in the DOS or WINDOWS environment. The more recent versions of these programs contain extensive facilities for generating reports including statistic, curve fitting, and graphic programs. For often-performed tasks a customized EDB software based on Clipper and FORTRAN has been written originally for the PR-EDB, which can be utilized with both data bases. An updated version of these programs is included in the current version of the TR-EDB (see Appendix A). No effort is being made to extend the scope of this software any further since commercially available sof tware can be readily applied to the data bases for any conceivable application and can also be more readily adapted to Windows and other platforms.

The architecture of the TR-EDB is fully compatible with that of the PR-EDB so that the data from both data bases can be easily merged, if desired. (Some overlap does occur; a few data from the PR-EDB appear also in the TR-EDB to make the latter self-consistent.) However, there are some differences; some changes are due to the differences between power reactor surveillance and test reactor experiments while others are improvements on the first design of the PR-EDB and will be beneficial to both data bases. None of these changes affect the data themselves and the ability to combine and select corresponding data from both data bases. These changes will also not prevent the use of the EDB software package provided for both versions of the EDB. A complete and detailed discussion of the architecture and data structures of the TR-EDB will be given in the next section. A list of differences between the PR-EDB and the TR-EDB is given in Appendix B. 
An important difference between surveillance capsule and test reactor experiments is the way the results are reported. A surveillance capsule report is part of a legal requirement that assures some degree of uniformity and consistency in its content. Test reactor experiments, on the other hand, are designed for specific investigations and the reports, particularly the older ones, present only the data that are deemed relevant to particular questions, without regard to their possible use in other research. This is quice understandable given the effort and cost involved in publications but results in incomplete information about the reported data sets; for instance, raw Charpy data are usually presented only as graphs, if at all. Additional difficulties arise whenever the results of the same experiment are reported in different publications without clearly indicating this fact. Frequently, different codes are used for the same material or experimental capsule, and a considerable amount of detective work is necessary to identify each single experiment or material. (Duplicate entries of this type have been identified in the original MPC Data Base.) For the reasons stated abr,ve, verification of the TR-EDB data is difficult and cannot be as thorough and comprehensive as in the PR-EDB. An additional problem is that laboratories and researchers responsible for the published data are often no longer available or cannot be funded for the considerable work involved for outside reviews. All data have been, of course, checked internally for correctness and consistency, and all unresolved problems are reported in the "NOTES." Every effort is being made to resolve discrepancies by contacting the original investigators.

The user of the TR-EDB is expected to have some familiarity with the dBASE philosophy and software to take full advantage of the information contained in the data base. Many simple inquiries and investigations can be handled, however, with the custom software supplied with the data. This program is menu-driven and self-explanatory requiring no special training. A description is given in Appendix A. It should be noted that the data in the TP.-EDB (and the PR-EDB) are taken directly from the quoted documents without any interpretation or evaluation. All numerical values are given in the units of the original documents. All data from any particular record in a TR-EDB file are obtained only from the document quoted in REF_ID, except as noted. More than one record of the same quantities may be included in the files if different documents report different evaluations of the same data. For instance, several determinations of the chemistry of the same material may be performed or fluences may have been updated based on improved methodology or cross section data. It is left to the user to select or, perhaps, average the different values for the same quantity. Automated analysis of the raw data files in the TR-EDB (and the PR-EDB) is not recommended; additional evaluation, selection, and unit conversion will be necessary whenever these data are to be used for critical investigations and as support for the analysis of reactor safety issues. The creation of evaluated data files for such purposes is being considered for future releases.

The distribution diskette of TR-EDB, Version 1, which is in compressed format, can be ordered from Energy Science and Technology Software Center, P.O. Box 1020, Oak Ridge, TN 37831, Tel. (615) 576-2606. 


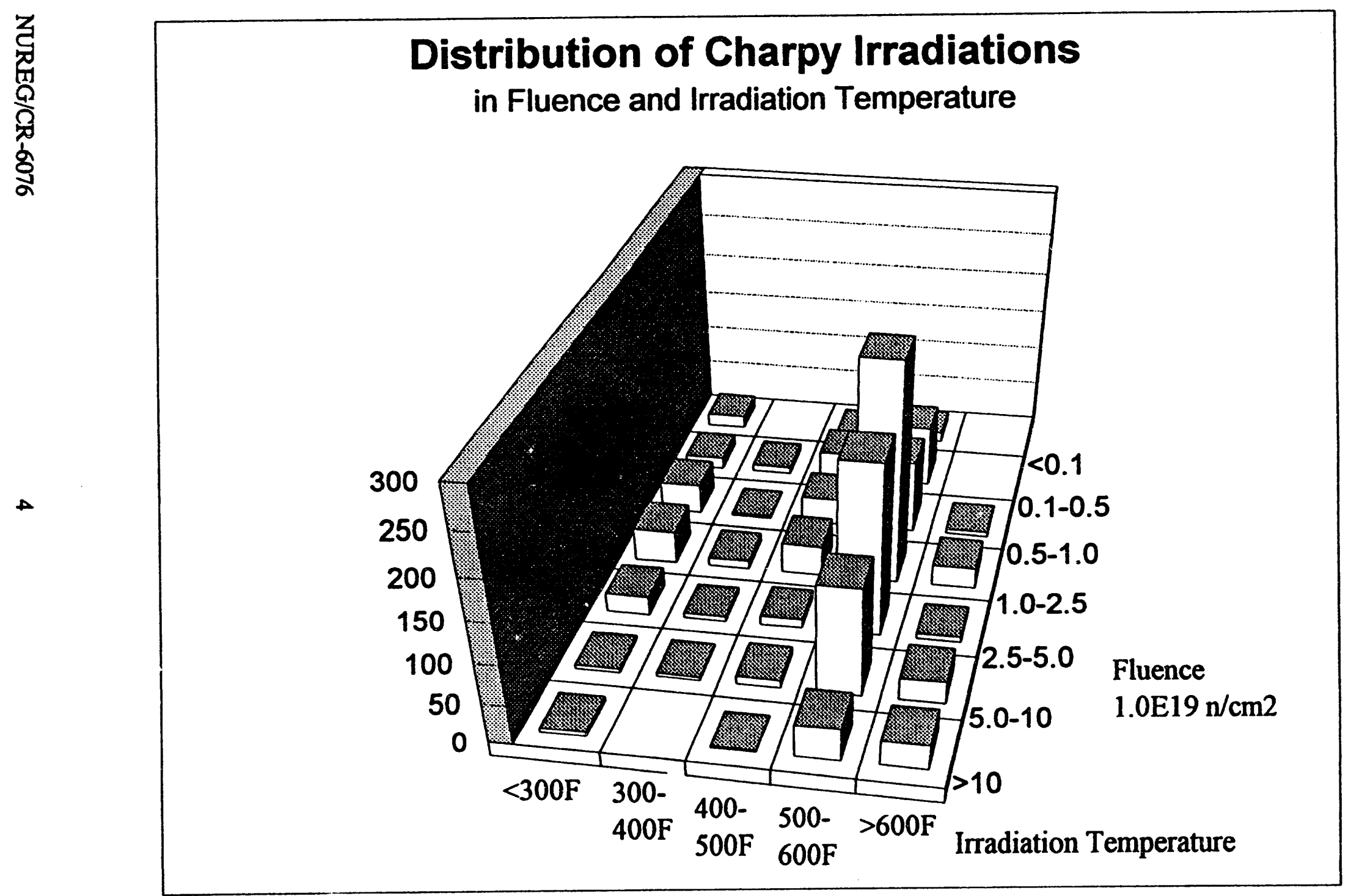

Fig. 1 Distribution of Charpy irradiations in fluence and irradiation temperature 


\section{Distribution of Charpy Irradiations in Copper and Nickel Content}

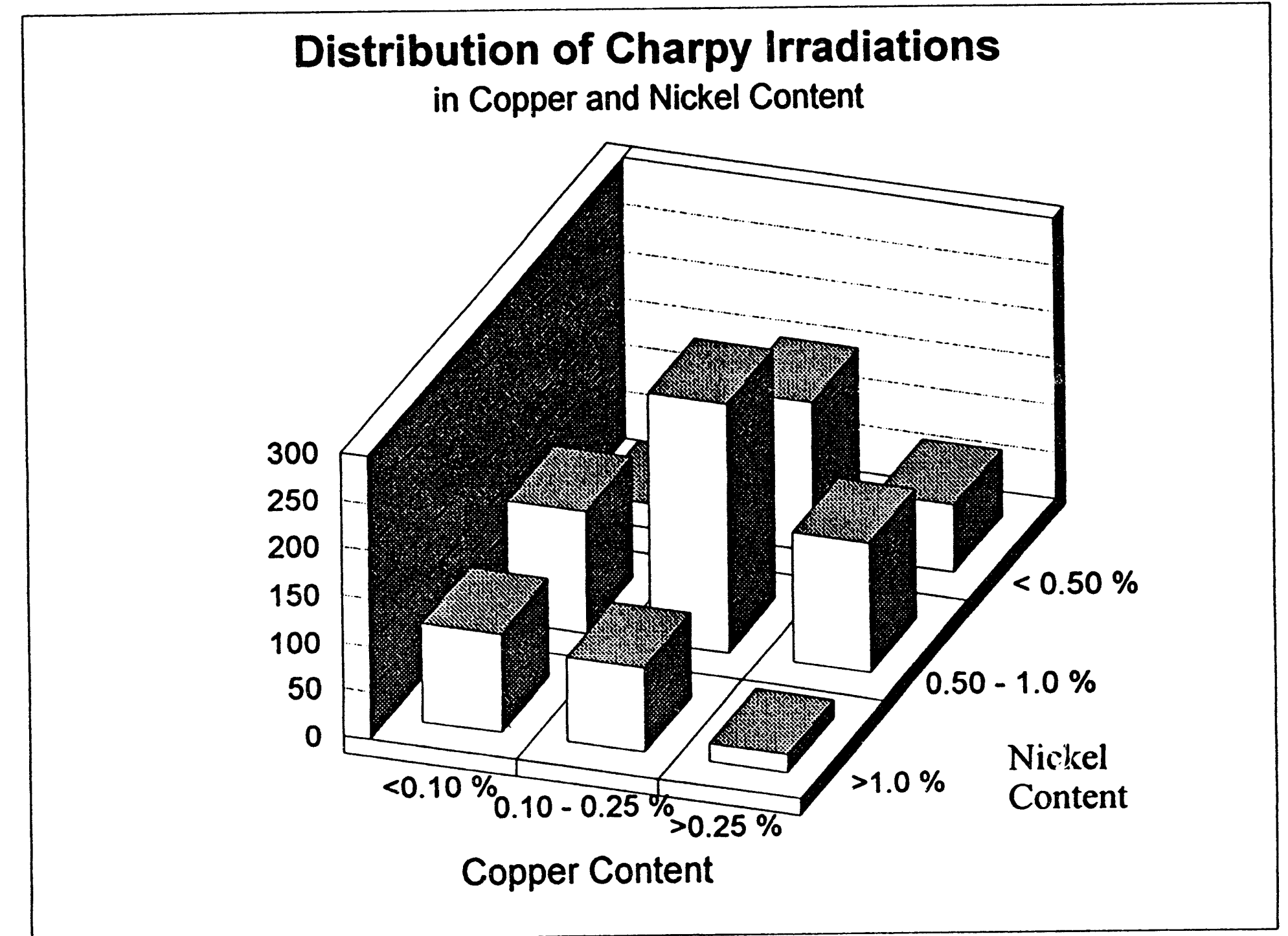

Fig. 2 Distribution of Charpy irradiations in copper and nickel content 


\section{ARCHITECTURE}

\subsection{Introduction}

Most data collections are composed of one or more tables that are two-dimensional arrangements with rows called "records" and the columns designated as "fields." Each record represents an individual (person, test, reactor, etc.), and each field, a particular attribute. For example, a table for persons may list name, age, height, weight, etc., each in its designated field. A data base that consists of only one table is called "flat," and this is the format that was used for the older collections, including the MPC Data Base. This approach makes data retrieval easy, requiring no special software, but ignores completely any connections that may exist between different types of data. For instance, chemistry data are common to a particular material and must be repeated for every record that contains the same material. Also, more than one chemistry determination may be made for the same material such that not only the same chemistry is repeated over several records, but each record must provide room for several different chemistries. (This was actually the case in the MPC Data Base.) These requirements make a flat data base unwieldy and error prone and has led to the introduction of "relational" data bases. In a relational data base the information is split into several different tables (files), each of which contains only related data. Data from different files are connected (related) with each other by means of unique identifiers that are common to the related tables. For instance, all chemistry data are collected in a chemistry file, where each chemistry record contains a unique material identifier. The same material identifier is contained in each test record for that material so that test results can be combined with chemistry. In this way duplications are avoided, and it is also possible to list any number of different chemistry determinations for the same material. The lownside is that several files must be linked together to extract the desired information, and considerable software support is necessary to do this effectively. Such software support is now widely available as is the use of relational data bases for all but the very simplest data base applications. For the Embrittlement Data Base, both PR-EDB and TR-EDB, the relational data base format has the following significant advantages:

1. The structure of the data files need not be predetermined; the data files are designed according to what is available in the original reports, and new data files can be added without disturbing the existing ones.

2. Because every record in a data file originates from a single report, and in most cases, from a single table in this report, a unique reference, including page number(s), can be given for each record. This feature allows the user to go back to the source of the data whenever questions arise.

3. Multiple determinations of the same quantity are given in different records, each with its proper references. Such multiple determinations occur, for instance, if the chemistry is determined by the manufacturer of the material as well as from broken specimens. Also, fluence determinations are frequently updated in subsequent reports using improved neutron physics calculations. All different determinations are kept in the TR-EDB, and the user must decide which determination to use for a particular application or, perhaps, calculate averages from several of them. (For statistical evaluations and model fittings only one value can be used for any given quantity; for these applications "evaluated" data files need to be created that contain only unique data obtained from different reports by averaging or related procedures.) 
The process in the construction of relational data bases by which data are distributed over different files is known in the data base literature as "normalization." A relational data base is considered normalized if no data are repeated, except key identifiers. Full normalization is a desirable goal for aesthetic as well as practical reasons, but it may lead to an unnatural separation of connected data. For instance, results of Charpy tests for irradiated materials are never considered in isolation but are always related to the same data for unirradiated material (baseline data) to determine the changes due to radiation. On the other hand, baseline data are the same for all irradiations of the same material and should, therefore, be listed in a separate file to avoid duplications. However, the file SHFT_TR.dbf for evaluated Charpy tests contains both irradiated and baseline data in the same record and also the differences (shifts) between the two, although shift values can be obtained by simple arithmetic. This was done to simplify the eventual use of the data, although strict normalization was not performed in this case. In addition, fluences and irradiation temperatures are also listed with each data set although the same data are also collected in the file REAC_TR.dbf. (However, in this case fluences and temperatures are relative to the specimen or sets of specimen which may be different from the values for the whole capsule that are listed in REAC_TR.dbf.)

All data in the TR-EDB are given in character format, that is, numerical data are represented internally in the dBASE files by the ASCII characters representing the numbers. This policy which was also adopted for the PR-EDB provides the freedom to represent the data exactly as reported. For instance, prefixes, such as, >, <, or , can be included in the data fields. Missing clata are repre ented as blank fields and not with some fictitious, impossible numerical value as it is necessary if the data are coded internally as numerical fields. The disadvantage is that special conversion procedures are necessary if comparisons or numerical manipulations are to be performed on the data. Such procedures are included in the custom software described in Appendix A. Also required are additional structure files (identified with the extension *.str) that identify the numerical (and date) fields in the TR-EDB files since this information is no longer contained in the regular dBASE structure files.

A detailed description of the data files and the connecting key identifiers is given in the next two sections of this report. It is important to remember that this structure can easily be extended to accommodate additional types of data without change in the existing structure. Most of the files have a counterpart in the PR-EDB with essentially the same set of fields, including field names. A few fields have been added that were not needed in the PR-EDB, such as EXP_ID, or to remove ambiguities, such as the addition of a field for nominal temperature which was previously listed under maximum or minimum temperature. All these changes in the field structure have advantages for the PR-EDB also and will eventually be incorporated. Some changes in the naming of the files were also necessary to distinguish between the PR-EDB and TR-EDB, for instance, HEAT_LST.dbf is H_LST_TR.dbf in the TR-EDB and will eventually be renamed H_LST_PR.dbf for the PR-EDB. (See Appendix B.)

\subsection{Key Identifiers}

One or more fields in each data file are occupied by "key identifiers," which provide the means for combining data from several files through "relations" that link the corresponding records in these files. These key identifiers are assigned by the manager of the data base in a manner that guarantees the 
unique labeling of experiments, materials, or source documents. The identifiers used in the reports do not always provide such unambiguous labeling. The following key identifiers are used in the current version of the TR-EDB:

\section{EXP_ID}

The data that are included in the TR-EDB were originally generated by specific experiments or groups of experiments that were designed to answer some specific questions. Accordingly, choice of irradiation conditions, types of specimen investigated, evaluation methods, and related aspects differ considerably from one experiment to another, and these differences have to be considered in the use of the data. For that reason a key identifier EXP_ID has been added to every record in almost all data files. EXP ID is not primarily intended for linking the information between two or more data files; it's main link is to give a detailed description of each experiment in the file E_LST_TR.dbf and the related table in this report. Note that the identifier PLANT_ID in the material files in the PR-EDB, such as HEAT_LST.dbf, CHEM_PR.dbf, etc., is replaced by EXP_ID in the corresponding files H_LST_TR.dbf, CHEM_TR.dbf. For test reactor experiments that were performed in support of a power reactor surveillance program, the PLANT_ID of the power reactor is used as EXP_ID. This policy will be extended to the PR-EDB in future releases. However, this key identifier is not presently used in the PR-EDB. The file REF_TR.dbf links references with experiments. Note that any given experiment is usually described in more than one reference and that the same reference may also report more than one experiment.

\section{PLANT_ID}

Up to six characters may be used in PLANT_ID to identify the reactor in which the irradiation was performed. This key also identifies in the PR-EDB the surveillance program of the specified commercial power reactor. (Only the first three characters in PLANT_ID are used for this purpose.) No comparable link exits in the TR-EDB between the irradiation facility and materials or experiment. PLANT_ID links, therefore, only irradiation environments to test data and does not appear in any of the materials files, such as CHEM_TR.dbf. Detailed information about the reactors identified by PLANT_ID is given in the file R_LST_TR.dbf.

\section{CAPSULE}

Up to six characters are used to identify the irradiation capsule. As far as practical, the capsule identifications of the original reports were used. Sometimes specimens are lumped together which come from different capsules with similar fluences, and in these cases special identifiers for data sets from combined capsules are assigned.

\section{HEAT_ID}

The material identifier can have up to ten characters. A simple scheme was devised for the PR-EDB and has been extended to the TR-EDB. It works as follows: The coding assigns the first letter to the material type, namely $\mathrm{P}$ _late, F_orging, W_eldment, H_eat-affected-zone material, or $\mathrm{S}_{-}$tandard reference material. The next three characters contain a general code related to the origin of the material with two additional characters to distinguish between 
different materials of the same origin. If practical, some correspondence between the HEAT_ID and report identifications is retained (e.g., the forging KS01 used in the Komponentsicherheits Program in Germany is named FKS_01). The last four letters are reserved to distinguish between different parts of the same material if different parts show markedly different material properties from those properties documented in the reports. For instance, SASTM S1 to SASTM S4 denote different sections of the 6-in. ASTM A302B reference plate, whose baseline properties vary considerably. The code SASTM without appendix will be reserved for the A302B correlation material that is used in Westinghouse reactors to avoid possible confusion with the PR-EDB; any other material from this plate of unidentified provenance is coded as SASTM X. The four-character appendix is also used to identify material that has been annealed after irradiation. The "anneal tag" has the form "Axy" for the first-time anneal and "Rxy" for any subsequent re-anneal. Details are given in the description of the file SHFTA_TR.dbf. The file H_LST_TR.dbf gives a comiplete list of identifiers used as HEAT_ID, together with the corresponding identifiers in the referenced reports.

The HEAT_ID provides the link between the material test data on the left side of Fig. 3 (e.g., SHFT_TR.dbf) and the fabrication and chemistry data on the right side (e.g., CHEM_TR.dbf). Chemistry and fabrication data are in many cases only available for the "generic" material, that is, for the plate or weldment as a whole, and not for a particular section dept as identified by the last four characters in the HEAT_ID. Thus, linkage may be possible only by restricting it to the first six characters of HEAT_ $\overline{\mathrm{ID}}$ whenever no link exists for the full 10-character identifier. To find the chemistry data for annealed material it is necessary to go back to the parent material or, again, the first 6 characters of HEAT_ID. A similar situation exists for the HAZ materials; their chemistry is rarely determined separately, thus the data from the parent (plate) material must be used. The parent material for each $\mathrm{HAZ}$ is listed in the file HAZ_TR.dbf.

\section{SPEC_ORI}

Different orientations of the material test specimens may lead to substantially different property test results, thus this identifier is needed to correctly link the properties of irradiated specimens to the corresponding baseline values.

Orientations are assigned in the now customary T-L-S system as described in ASTM Standard E399*, with $L$ the primary rolling or forging direction, or for welds and HAZ, the direction of the weld seam; $T$ is perpendicular to $L$ and parallel to the plate surface, and $S$ is perpendicular to the plate surface. The first letter describes the longitudinal direction of the specimen (perpendicular to the crack surface, if any), and the second letter describes the direction of the crack propagation (perpendicular to the notch). The orientation for each specimen set was determined as well as possible, preferably from drawings, making sure that the same orientations are assigned to corresponding specimen sets. SPEC_ORI is left blank if no information is available.

*Standard E399 applies formally only to CT specimens, but the extension to other types of specimens is straightforward. 


\section{REF_ID}

In most files, each record is assigned a reference that indicates the source of the data. This is done by means of a 20 -character field REF_ID. This identifier is usually a report number or a similar code that links it uniquely to the complete bibliographic information (i.e., author, title, and time of publication) which is given in the file TITL_TR.dbf. The linkage between experiments (EXP_ID) and reports (REF_ID) is given in the file REF_TR.dbf. The starting page of articles in a larger volume is included if this volume contains other, unrelated, material.

\section{Organization of the TR-EDB Data Files}

The current version of the TR-EDB is organized in a manner similar to the PR-EDB, as shown in Fig. 3. On top is the file E_LST_TR.dbf (Table 1) which contains a complete list of all experiments whose results are included in the TR-EDB. This file can be linked via the key identifier EXP_ID with any other TR-EDB file, except the reactor list, R LST TR.dbf, that does not refer to any particular experiment. Immediately below is the file S_LST_TR.dbf (Table 2) containing a complete list of test specimen sets which are used in the test reactor experiments. Spe simen sets are characterized by type of the specimen, such as Charpy, Tensile, and the various forms of fracture mechanics specimen listed in the field SPEC_TYPE, and the five key identifiers EXP_ID, PLANT_ID, CAPSULE, HEAT_ID, and SPEC_ORI, which link the sets to the other data files.

(Fracture mechanics test data are not currently included in the TR-EDB for lack of time and manpower but listed in many irradiation capsules in S_LST_TR.dbf). Specimen sets for testing of the baseline properties of unirradiated materials are characterized by leaving the PLANT_ID field blank.

The data that are relevant for radiation embrittlement are distributed over three groups of data files. For each test listed in the specimen file, actual data from three groups of data can be obtained by linking via the appropriate key identifier. The first group, on the left of Fig. 3, consists of results of material property tests. Charpy, both individual tests and results of curve fittings, and tensile data are currently available (SHFT_TR.dbf, SHFTX_TR.dbf, SHFTA_TR.dbf, RAW_C_TR.dbf, and CV_RF_TR.dbf, for Charpy data and TEN_TR.dbf for tensile, Tables $2 \overline{0}$ through 25). (SHFTA_TR.dbf contains summaries of anneal experiments and SHFTX_TR.dbf unconventional measures of Charpy transition temperature). Each record in these files is uniquely characterized by the combination PLANT_ID, CAPSULE, HEAT_ID, and SPEC_ORI. Baseline data, which have no entries in PLANT ID and CAPSULE (blank field), may also need an additional characterization through EXP ID. (Different experiments for the same material have sometimes performed different tests for baseline values, though theoretically the same values may differ somewhat due to statistical fluctuations.)

The second group, in the middle of Fig. 3, contains data describing the reactor and radiation environment for each surveillance capsule. The file REAC_TR.dbf contains a detailed description of the fluence, irradiation temperature and irradiation time for each irradiation capsule. The file REAC_TR.dbf is linked with the others via the key identifiers PLANT_ID and CAPSULE. This linkage will not be needed in most cases because fluence and irradiation temperature are also given in the test data files, such as, SHFT_TR.dbf and TEN_TR.dbf. Note that the fluence values given in REAC_TR.dbf apply only for the capsule as a whole (i.e., average or capsule center), which is not 
necessarily the same as for the individual specimen or group of specimen, listed in the test data files. However, many details, such as, values for fluence (E > $0.1 \mathrm{MeV})$ or dpa are listed - whenever available - in REAC_TR.dbf. The file R_LST_TR.dbf is a list of irradiation facilities used in the experiments, similar to REAC_LST.dbf in the PR-EDB. In contrast to power reactor surveillance there is no particular link between test reactor facilities and the experiments performed there. Thus, the only key identifier field in this file is PLANT_ID.

The third group on the right of Fig. 3 contains the information about the chemistry and fabrication of the materials used in the experiments. H_LST_TR.dbf lists all HEAT_IDs with reported codes, and CHEM_TR.dbf, HEAT_TR.dbf, WELD_TR.dbf, and HAZ_TR.dbf the actual chemistry and fabrication data. All these files are linked via HEAT_ID with the rest of the TR-EDB files. The key identifier EXP_ID is also included but is not specifically needed for linkage; it only identifies the experiment for which the listed data were reported.

Any record in most of the TR-EDB files has a reference in the field REF_ID and one or more page numbers which allows to verify the sources from where the data were collected and, perhaps, to find additional information. Exceptions are again the file R_LST_TR.dbf and also E_LST_TR.dbf whose information comes from many different sources. References are also not listed in RÄW_C_TR.dbf because the associated file CV_RF_TR.dbf has the necessary references. A detailed list of all reference with complete title, authors, time of publication is given in the file TITL_TR.dhf. The linkage to the other files is, of course, via REF_ID. The associated file REF_TR.dbf links all REF_IDs with the EXP_IDs (i.e., experiments with publications). 


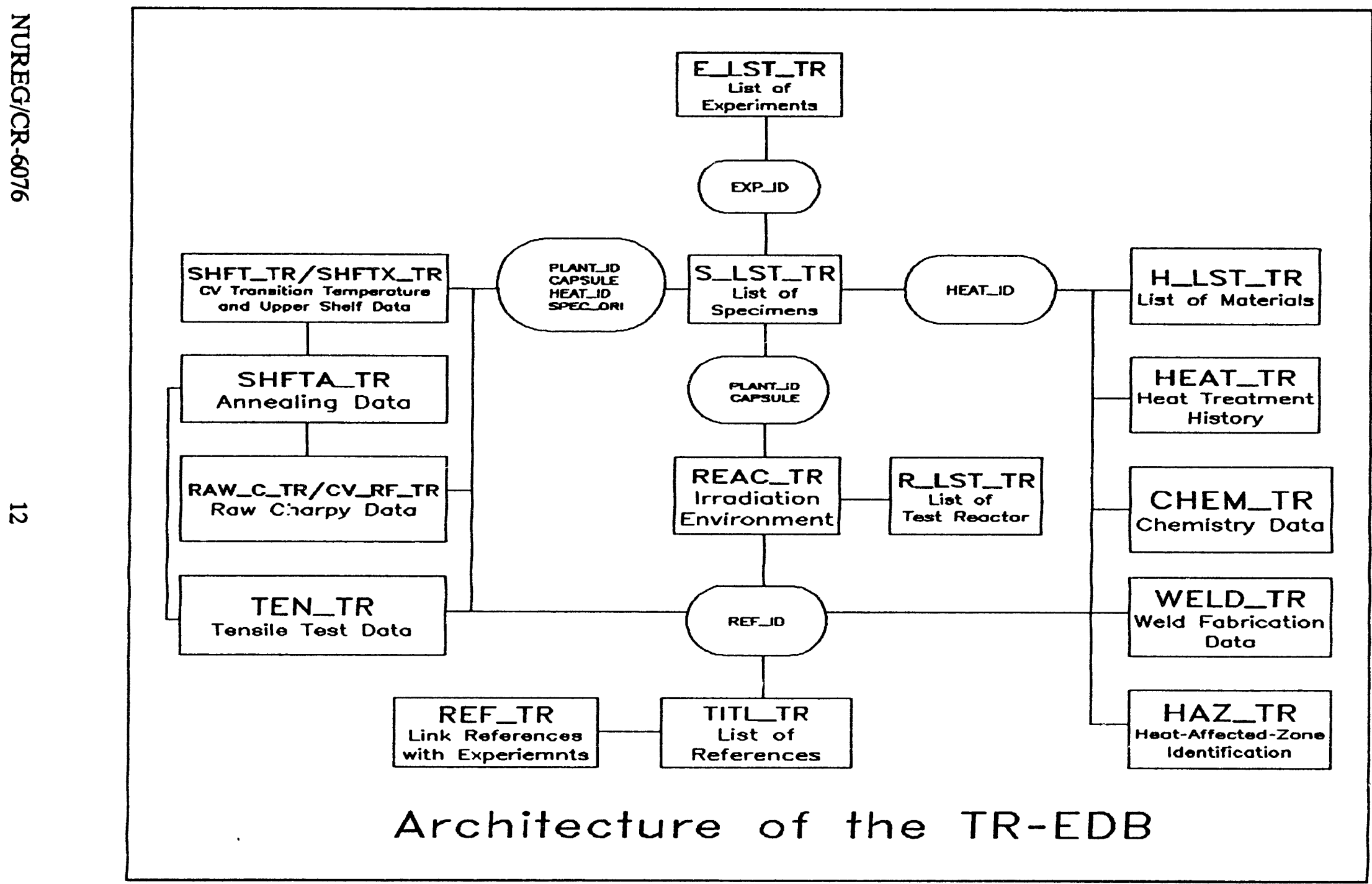

Fig. 3 Architecture of the TR-EDB 


\section{List of TR-EDB Files}

\section{E_LST_TR.dbf}

This file lists all EXP_ID with brief descriptions of the experiment or group of experiments, the laboratory, authors, and irradiation facilities involved. A detailed description of the experiments included is given in Section 2.5. It is intended to include this information in the file in the form of memo fields, but the current software does not support this extersion.

Table 1 Structure file for E_LST_TR.dbf

\begin{tabular}{|c|c|c|}
\hline $\begin{array}{l}\text { Field } \\
\text { name }\end{array}$ & $\begin{array}{l}\text { No. } \\
\text { chrs. }\end{array}$ & Description \\
\hline TAG & 1 & Used for Internal Operation \\
\hline EXP ID & 6 & Experiment Identification \\
\hline EXP_DESCR & 80 & Description of Experiment \\
\hline LABŌRATORY & 30 & Laboratory Responsible for the Experiment and Evaluation \\
\hline AUTHORS & 50 & List of Principal Investigators \\
\hline REACTORS & 30 & List of Reactors used in the Experiment \\
\hline
\end{tabular}

\section{S_LST_TR.dbf}

The object of this file is to provide a complete list of all specimen sets whose test data are contained in the other TR-EDB files. (A "set" is here defined as a group of test specimens that share the same combination of EXP_ID, PLANT_ID, CAPSULE, HEAT_ID, and SPEC_ORI, and are of the same specimen type, such as Charpy, tensile, etc.) The information given in the reports is often sketchy in contrast to the surveillance reports which contain detailed lists and capsule drawings. A new field, REPORT_TAG, has been added to the old structure of SPEC_LST.dbf to indicate in what form the test results are reported: " $R$ " indicates that individual test results are given instead of just averages ("A"), " $G$ " means that plots of the Charpy fits are reported containing individual test results, and " $L "$ if only lines without points are presented in the graph. A blank field means that just numerical summaries are provided. The field SPEC_SIZE which was part of the file SPEC_LST.dbf in the PR-EDB has been removed from this file. This field cannot properly contain all the relevant dimensions for all possible test specimen and was, therefore, moved in extended form to the files containing the test results, such as, TEN_TR.dbf. 
Table 2 Structure file for S_LST_TR.dbf

\begin{tabular}{|c|c|c|}
\hline $\begin{array}{l}\text { Field } \\
\text { name }\end{array}$ & $\begin{array}{l}\text { No. } \\
\text { chrs. }\end{array}$ & Description \\
\hline TAG & 1 & Used for Internal Operation \\
\hline EXP ID & 6 & Experiment Identification \\
\hline PLAÑTT ID & 6 & Reactor Identification \\
\hline CAPSUL̃E & 6 & Surveillance or Experiment Capsule Identification \\
\hline HEAT_ID & 10 & Identification Code for Given Material \\
\hline SPEC_TYPE & 3 & $\begin{array}{l}\text { Type of Specimen: Charpy (CV) TEN_sile, C_ompact } \\
\text { T_ension, WOL }\end{array}$ \\
\hline SPEC_ORI & 2 & Specimen Orientation: TL, LT, TS, etc. \\
\hline SPEC_POS & 10 & Specimen Position: $1 / 4 \mathrm{~T}, 1 / 2 \mathrm{~T}, 3 / 4 \mathrm{~T}$, etc. \\
\hline NO_OF_SPEC & 3 & Number of Specimen in Capsule or Experimental Set \\
\hline REP̄ORT_TAG & 1 & $\begin{array}{l}\text { Type of Reporting: } R_{-} \text {aw data, A_verages, G_raphs, } \\
\text { L_ine Drawings }\end{array}$ \\
\hline REF ID & 20 & Réference Identifier \\
\hline PAGES & 20 & Page Number(s) \\
\hline NOTES & 30 & Pertinent Information Related to Data Entries, If Needed \\
\hline
\end{tabular}

\section{File SHFT_TR.dbf}

SHFT_TR.dbf (Table 3) lists transition temperatures and upper shelf energies as determined by the evaluator of the report. It lists $30 \mathrm{ft}-\mathrm{lb}, 50 \mathrm{ft}-\mathrm{lb}$, and 35 -mil transition temperatures (irradiated and unirradiated), and shift (difference between the two), whatever is listed in the report, and similarly for the upper shelf energy with both absolute and relative shift values. The tags U_FIT and I_FIT were added to indicated the type of fitting procedure used to determine transition temperature and upper shelf values for un-irradiated and irradiated data, respectively. Also included are the data describing the irradiation as applied to the Charpy specimen set. These include fluences $(\mathrm{E}>1.0 \mathrm{MeV}$ ) and irradiation temperature at the location of the specimen, taking into account the differences within the capsule between different specimen sets. Further included is the available information concerning the fluence rate since the rate effect appears to be quite important, especially if test reactor data are to be applied to embrittlement predictions in power reactors, which have much lower fluence rates. The rates are sometimes given directly and can in other cases be determined from the equivalent full-power irradiation time; fields are provided in the file to contain either or both types of information. Not included is the transition temperature at $50 \%$ shear since it is seldom reported and is difficult to be determined reliably. It can also be readily reconstructed from the individua! Charpy test data, whenever available. Also not included are transition temperatures at other energy levels or lateral expansion such as $15 \mathrm{it}-\mathrm{lb}$ or $3 \mathrm{kgm}$ (see Section 2.6 for units), which are sometimes listed in older reports. These data are relegated to the special file SHFTX_TR.dbf. 
Table 3 Structure file for SHFT_TR.dbf

\begin{tabular}{|c|c|c|}
\hline $\begin{array}{l}\text { Field } \\
\text { name }\end{array}$ & $\begin{array}{l}\text { No. } \\
\text { chrs. }\end{array}$ & Description \\
\hline TAG & 1 & Used for Internal Operation \\
\hline EXP_ID & 6 & Experiment Identification \\
\hline PLAN̄TIID & 6 & Reactor Identification \\
\hline CAPSUĪE & 6 & Surveillance or Experiment Capsule Identification \\
\hline HEAT ID & 10 & Identification Code for Given Material \\
\hline PROD_ID & 3 & Material Type: $P$ late, $F$ orging, W eld, HAZ, or SRM \\
\hline SPEC_ŌRI & 2 & Specimen Orientation: $\overline{\mathrm{TL}}, \mathrm{LT}, \mathrm{TS}$, etc. \\
\hline CSP_F̄ 1 & 10 & Fluence $>1 \mathrm{MeV}$ at Charpy Specimen Location $\left[\mathrm{n} / \mathrm{cm}^{2}\right.$ ] \\
\hline FLU_TAG & 1 & $\begin{array}{l}\text { Tag for Fluence Determination: } F_{-} \text {ission, } S_{-} \text {caling, } \\
\text { A_djustment }\end{array}$ \\
\hline EFP_TIME & 10 & Effective Full Power Time of Irradiation \\
\hline TIME_U & 1 & Unit of Time: $S$ _econds, $M$ inutes, $H_{-}$ours, $D_{-}$ays, $Y_{-}$ears \\
\hline F1_RĀTE & 10 & Fluence Rate $>-1 \mathrm{MeV}$ at Capsule Center $\left[\mathrm{n} /\left(\mathrm{cm}^{2} \mathrm{~s}\right)\right]$ \\
\hline CSPי_TEMP & 4 & Irradiation Temperature of Charpy Specimen \\
\hline UTT30 & 5 & CVT at $30 \mathrm{ft}-\mathrm{lb}$, Unirradiated Charpy Specimen \\
\hline UTT50 & 5 & CVT at $50 \mathrm{ft}-\mathrm{lb}$, Unirradiated Charpy Specimen \\
\hline ULE35 & 5 & CVT at Lateral Expansion $=35$ mils, Unirrad. Charpy Spec. \\
\hline UUSE & 5 & Upper Shelf Energy, Unirradiated Charpy Specimen \\
\hline U_FIT & 1 & $\begin{array}{l}\text { Tag for Fitting (Unirr. Data): } H_{-} \text {and drawn, hyp. } T_{-} \text {angent, } \\
O_{\text {ther }}\end{array}$ \\
\hline ITT30 & 5 & $\mathrm{CV} T$ at $30 \mathrm{ft}-\mathrm{lb}$, Irradiated Charpy Specimen \\
\hline ITT50 & 5 & CVT at $50 \mathrm{ft}-\mathrm{lb}$, Irradiated Charpy Specimen \\
\hline ILE35 & 5 & CVT at Lateral Expansion $=35$ mils, Irrad. Charpy Spec. \\
\hline IUSE & 5 & Upper Shelf Energy, Irradiated Charpy Specimen \\
\hline I_FIT & 1 & $\begin{array}{l}\text { Tag for Fitting (Irr. Data): } H_{-} \text {and drawn, hyp. T_angent, } \\
O \text { ther }\end{array}$ \\
\hline DTT30 & 5 & CV̄T Shift at $30 \mathrm{ft}-\mathrm{lb}$ (ITT30 - UTT30) \\
\hline DTT50 & 5 & CVT Shift at $50 \mathrm{ft}-\mathrm{lb}$ (ITT50 - UTT50) \\
\hline DLE35 & 5 & CVT Shift at Lateral Expansion $=35$ mils (ILE35 - ULE35) \\
\hline DUSE_ABS & 5 & Absolute Drop in Upper Shelf Energy (UUSE - IUSE) \\
\hline DUSE- REL & 5 & Percent Drop in Upper Shelf Energy \\
\hline TEMP_U & 1 & Unit used for Temperature Data \\
\hline USE_U & 5 & Unit used for Energy Data (in Upper Shelf Energy) \\
\hline REF_ID & 20 & Reference Identifier \\
\hline PAGES & 20 & Page Number(s) \\
\hline NOTES & 30 & Pertinent Information Related to Data Entries, If Needed \\
\hline
\end{tabular}




\section{SHFTA_TR.dbf}

The information in SHFTA_TR.dbf (Table 4) provides a summary of the annealing processes studied in the experiments included in the TR-EDB. In order to fit the results of annealing experiments into the existing framework of the TR-EDB, it was decided to identify annealed material by changing the last three characters in the HEAT_ID. Any steel that was irradiated and annealed is distinguished from the parent material through an "anneal tag" which has the form Axy, where $\mathrm{x}$ and $\mathrm{y}$ are each some digit or letter, with $\mathrm{x}$ characterizing the irradiation and $\mathrm{y}$ the annealing procedure. Any subsequent re-annealing is indicated by a tag Rxy. This tag replaces any other appendix in the last four characters of HEAT_ID. This procedure allows the listing of the test results from annealing experiments without changing the file structures by just considering material as a newly created steel. Both raw Charpy and tensile data are listed in this manner in the respective files RAW_C_TR.dbf and TEN_TR.dbf.

The study of annealing effects requires, of course, the information about how each annealed material came into being, and this is the primary content of the file SHFTA_TR.dbf. This file gives a complete list of all anneal tags that are used with any parent material together with fluence, irradiation temperature, anneal temperature and anneal duration together with the reactor and capsuie identification, PLANT_ID and CAPSULE, respectively. Because the anneal tags are unique, the information in SHFTA_TR.dbf allows the tracing of the HEAT_ID of any annealed material (i.e., any HEAT_ID containing an anneal tag) to the parent material and to reconstruct the irradiation and anneal history.

To make the file more or less self-contained, information from Charpy tests was added, which is the predominant means for assessing annealing effects. (However, anneal conditions, for which only tensile data are available, are also listed in this file.) Also included are the data for re-irradiation after anneal, if applicable. Listed are the transition temperature at $30 \mathrm{ft}-\mathrm{lb}(41 \mathrm{~J})$ and upper shelf energy for each stage of the baseline-irradiation-annealing-re-irradiation cycle together with the shifts in these parameters, depending on what is reported. Re-annealing after re-irradiation is placed in a second record in which the material with the first anneal tag serves as parent material and a new tag Rxy is defined for the second cycle. This procedure can be repeated as often as necessary. Frequently whole capsules filled with specimen were irradiated and subsequently annealed (and sometimes re-irradiated, etc.) without determining embrittlement status after irradiation. Irradiated values before anneal are then determined in a separate irradiation run that is included in the file even though no annealing is connected with that particular run. These and other Charpy data in the file that are related to the first irradiation are duplicated (with some addition, such as, transition temperatures at $50 \mathrm{ft}-\mathrm{lb}$ and 35 mil lateral expansion) in the file SHFT_TR.dbf. 
Table 4 Structure file for SHFTA_TR.dbf

\begin{tabular}{|c|c|c|}
\hline $\begin{array}{l}\text { Field } \\
\text { name }\end{array}$ & $\begin{array}{l}\text { No. } \\
\text { chrs. }\end{array}$ & Description \\
\hline TAG & 1 & Used for Internal Operation \\
\hline EXP_ID & 6 & Experiment Identification \\
\hline PLAN̄TT ID & 6 & Reactor Identification \\
\hline CAPSUL̃E & 6 & Surveillance or Experiment Capsule Identification \\
\hline HEAT ID & 10 & Identification Code for Given Material \\
\hline PROD_ID & 3 & Material Type: P_late, F_orging, W_eld, HAZ, or SRM \\
\hline SPEC_ORI & 2 & Specimen Orientation: $\overline{\mathrm{T}} \mathrm{L}, \mathrm{LT}, \mathrm{TS}$, etc. \\
\hline CSP_F1 & 10 & Fluence > $1 \mathrm{MeV}$ at Charpy Specimen Location $\left[\mathrm{n} / \mathrm{cm}^{2}\right.$ ] \\
\hline CSP_TEMP & 4 & Irradiation Temperature of Charpy Specimen \\
\hline ANN_TAG & 4 & Tag Added to the HEAT_ID to Identify Annealed Material \\
\hline ANN_TEMP & 3 & Annealing Temperature \\
\hline ANN_HRS & 4 & Duration of Annealing in Hours [ hours ] \\
\hline PLAÑT_ID_R & 6 & Reactor Identification for $\mathrm{Re}$-irradiation \\
\hline CAPSULEE_R & 6 & Capsule Identification for $\mathrm{Re}$-irradiation \\
\hline CSP_F1_R & 10 & Fluence $>1.0 \mathrm{MeV}$ During Re-irradiation [ $\mathrm{n} / \mathrm{cm}^{2}$ ] \\
\hline CSP_TEMP_R & 4 & Irradiation Temperature During Re-irradiation \\
\hline UTT30 & 5 & CVT at $30 \mathrm{ft}-\mathrm{lb}$, Unirradiated Charpy Specimen \\
\hline ITT30 & 5 & CVT at $30 \mathrm{ft}-\mathrm{lb}$, Irradiated Charpy Specimen \\
\hline DTT30 & 5 & CVT Shift at $30 \mathrm{ft}-\mathrm{lb}($ ITT30 - UTT30) \\
\hline IATT30 & 5 & CVT at $30 \mathrm{ft}-\mathrm{lb}$, After Annealing \\
\hline RTT30 & 5 & Recovery of TT30 After Annealing (ITT30 - IATT30) \\
\hline IARTT30 & 5 & CVT at $30 \mathrm{ft}-\mathrm{lb}$, After Annealing and Re-irradiation \\
\hline UUSE & 5 & Upper Shelf Energy, Unirradiated Charpy Specimen \\
\hline IUSE & 5 & Upper Shelf Energy, Irradiated Charpy Specimen \\
\hline DUSE_ABS & 5 & Absolute Drop in Upper Shelf Energy (UUSE - IUSE) \\
\hline IAUSE & 5 & Upper Shelf Energy, After Annealing \\
\hline RUSE_ABS & 5 & Recovery of Upper Shelf Energy (IAUSE -IUSE) \\
\hline IARUS̄E & 5 & Upper Shelf Energy, After Annealing and Re-irradiation \\
\hline TEMP_U & 1 & Unit used for Temperature Data \\
\hline USE_Ū & 5 & Unit used for Energy Data (in Upper Shelf Energy) \\
\hline REF_ID & 20 & Reference Identifier \\
\hline PAGĒES & 20 & Page Number(s) \\
\hline NOTES & 30 & Pertinent Information Related to Data Entries, If Needed \\
\hline
\end{tabular}




\section{File SHFTX_TR_dbf (Table 5)}

This file lists the non-standard determinations for Charpy transition temperature before and after irradiation with appropriate definitions for the non-standard data. The fluence data are the same as in SHFT_TR.dbf.

Table 5 Structure file for SHFTX_TR.dbf

\begin{tabular}{|c|c|c|}
\hline $\begin{array}{l}\text { Field } \\
\text { name }\end{array}$ & $\begin{array}{l}\text { No. } \\
\text { chrs. }\end{array}$ & Description \\
\hline TAG & 1 & Used for Internal Operation \\
\hline EXP_ID & 6 & Experiment Identification \\
\hline PLANT_ID & 6 & Reactor Identification \\
\hline CAPSUL̄E & 6 & Surveillance or Experiment Capsule Identification \\
\hline HEAT_ID & 10 & Identification Code for Given Material \\
\hline PROD_ID & 3 & Material Type: P_late, F_orging, W_eld, HAZ, or SRM \\
\hline SPEC_ŌRI & 2 & Specimen Orientation: $\overline{\mathrm{TL}}, \mathrm{LT}, \mathrm{TS}$, etc. \\
\hline CSP_F1 & 10 & Fluence $>1 \mathrm{MeV}$ at Charpy Specimen Location $\left[\mathrm{n} / \mathrm{cm}^{2}\right]$ \\
\hline FLU_TAG & 1 & $\begin{array}{l}\text { Tag for Fluence Determination: } F_{-} \text {ission, } S_{-} \text {caling, } \\
\text { A_djustment }\end{array}$ \\
\hline EFP_TIME & 10 & Effective Full Power Time of Irradiation \\
\hline TMME_U & 1 & Unit of Time: $S_{-}$econds, $M_{-}$inutes, $H_{-}$ours, $D_{-}$ays, Y_ears \\
\hline F1_RĀTE & 10 & Fluence Rate $>1 \mathrm{MeV}$ at Capsule Center $\left[\mathrm{n} /\left(\mathrm{cm}^{2} \mathrm{~s}\right)\right]$ \\
\hline CSP_TEMP & 4 & Irradiation Temperature of Charpy Specimen \\
\hline UTTX & 5 & $\begin{array}{l}\text { CVT at Specified Non-standard Value, Unirradiated Charpy } \\
\text { Specimen }\end{array}$ \\
\hline ITTX & 5 & $\begin{array}{l}\text { CVT at Specified Non-standard Value, Irradiated Charpy } \\
\text { Specimen }\end{array}$ \\
\hline DTTX & 5 & CVT Shift at Specified Non-standard Value (ITTX - UTTX) \\
\hline TT_DEF & 5 & Quantity for which Transition Temperature is Specified \\
\hline TT_DEF_U & 5 & $\begin{array}{l}\text { Unit of Quantity for which Transition Temperature is } \\
\text { Specified }\end{array}$ \\
\hline TEMP_U & 1 & Unit used for Temperature Data \\
\hline REF_ID & 20 & Reference Identifier \\
\hline PAGES & 20 & Page Number(s) \\
\hline NOTES & 30 & Pertinent Information Related to Data Entries, If Needed \\
\hline
\end{tabular}




\section{Files RAW_C_TR.dbf and CV_RF_TR.dbf}

RAW_C_TR.dbf (Table 6) gives a complete list of individual Charpy test results. (See p. 39 at the end of the section for a partial listing.) In addition to the materials test results the key identifiers are listed to link the raw data with the evaluations in SHFT_TR.dbf and related files. Also included are fluence and irradiation temperature that may be different for each specimen. Fields for measuring units permit the entering of data in different units, as reported. Data that share the same combination of key identifiers are considered a "set," and a list of all different sets in RAW_C_TR.dbf is contained in the associated file CV_RF_TR.dbf. This file includes in addition to the key identifiers the references for the raw data that are not part of RAW_C_TR.dbf to save space, since each specimen in the same set has the same reference. Newly added to this file is information about the Charpy test equipment, that is also common to each whole set. The structure of this file is listed below (Table 7), and a partial listing of the records is given at the end of the section (p. 40). Some sets of individual Charpy test data are combined from several irradiation capsules for the determination of transition temperature and upper-shelf energy in different sets since each individual capsule does not contain enough specimens. Different CAPSULE identifications are assigned to those combined sets, and the resulting evaluations are listed in the file SHFT_TR.dbf. However, these combination capsules are not listed in RAW_C_TR to avoid the duplication of data. Instead, these combination sets were placed in a separate file, RAW_FT_TR.dbf, to aid the user in determining their content. These combinations are also contained in the ASCII file RAW_C_TR.dat which is used for the EDB fitting programs. 
Table 6 Structure file for RAW_C_TR.dbf

\begin{tabular}{lcl}
\hline $\begin{array}{l}\text { Field } \\
\text { name }\end{array}$ & $\begin{array}{l}\text { No. } \\
\text { chrs. }\end{array}$ & Description \\
\hline TAG & 1 & $\begin{array}{l}\text { Used for Internal Operation } \\
\text { EXperiment Identificaiion }\end{array}$ \\
PLANT_ID & 6 & Reactor Identification \\
CAPSU_E & 6 & Surveillance or Experiment Capsule Identification \\
HEAT_ID & 10 & Identification Code for Given Material \\
PROD_ID & 3 & Material Type: P_late, F_orging, W_eld, HAZ, or SRM \\
SPEC_ORI & 2 & Specimen Orientation: TL, LT, TS, etc. \\
SPEC_ID & 8 & Specimen Identifier \\
TST_TEMP & 6 & Test Temperature of Specimen \\
TST_TEMP_U & 1 & Unit of Temperature used in TST_TEMP \\
IMP_E & 6 & Impact Energy of Charpy Specimen \\
IMP_E_U & 5 & Unit of Energy used in IMP_E \\
FRACT_APP & 3 & Fracture Appearance Value [ \% shear ] \\
LAT_EXP & 4 & Lateral Expansion of Charpy Specimen \\
LAT_EXP_U & 3 & Unit of Length used in LAT_EXP \\
CSP_F1 & 10 & Fluence > 1 MeV at Charpy Specimen Location [ $\mathrm{n} / \mathrm{cm}^{2}$ ] \\
CSP_TEMP & 4 & Irradiation Temperature of Charpy Specimen \\
CSP_TEMP_U & 1 & Unit of Temperature used in CSP_TEMP \\
\hline
\end{tabular}

Table 7 Structure file for CV_RF_TR.dbf

\begin{tabular}{|c|c|c|}
\hline $\begin{array}{l}\text { Field } \\
\text { name }\end{array}$ & $\begin{array}{l}\text { No. } \\
\text { chrs. }\end{array}$ & Description \\
\hline TAG & 1 & Used for Internal Operation \\
\hline EXP ID & 6 & Experiment Identification \\
\hline PLAN̄T ID & 6 & Reactor Identification \\
\hline CAPSULEE & 6 & Surveillance or Experiment Capsule Identification \\
\hline HEAT ID & 10 & Identification Code for Given Material \\
\hline PROD_ID & 3 & Material Type: P_late, F_orging, W_eld, HAZ, or SRM \\
\hline SPEC_ŌRI & 2 & Specimen Orientation: $\overline{\mathrm{T} L}, \mathrm{LT}, \mathrm{TS}$, etc. \\
\hline TUP TYPE & 1 & Type of Tup Used: A_STM, D_IN, ... \\
\hline TUP VEL & 5 & Velocity of Tup on Impact \\
\hline VEL_U & 5 & Unit used for Tup Velocity \\
\hline $\mathrm{MAX} \bar{X}$ & 4 & Maximum Impact Energy \\
\hline USE $\bar{U}$ & 5 & Unit used for Energy Data (in Upper Shelf Energy) \\
\hline REF_ID & 20 & Reference Identifier \\
\hline PAGES & 20 & Page Number(s) \\
\hline NOTES & 30 & Pertinent Information Related to Data Entries, If Needed \\
\hline
\end{tabular}




\section{File TEN_TR.dbf}

The file TEN_TR.dbf (Table 8) lists the results of tensile tests with separate entries for each indiviaial test. Averages from several experiments are included if no other information is available, but are omitted if individual test data are given. Such cases are indicated by the character @, followed by the number of specimen averaged in the field SPEC_ID. The character $\$$ is used to indicate individual test data if no specimen identification is given. A blank in SPEC_ID means that the report does not indicate whether the test result is from a single specimen or an average. The dimensions of the specimen have been added to the file since a large variety of different diameters are used in the experiments which may influence the measured results. 
Table 8 Structure file for TEN_TR.dbf

\begin{tabular}{lcl}
\hline $\begin{array}{l}\text { Field } \\
\text { name }\end{array}$ & $\begin{array}{c}\text { No. } \\
\text { chrs. }\end{array}$ & Description \\
\hline TAG & 1 & Used for Internal Operation \\
EXP_ID & 6 & Experiment Identification \\
PLANT_ID & 6 & Reactor Identification \\
CAPSULE & 6 & Surveillance or Experiment Capsule Identification \\
HEAT_ID & 10 & Identification Code for Given Material \\
PROD_ID & 3 & Material Type: P_late, F_orging, W_eld, HAZ, or SRM \\
SPEC_ORI & 2 & Specimen Orientation: TL, LT, TS, etc. \\
TSP_F_ & 10 & Fluence > 1 MeV at Tensile Specimen Location [ $\mathbf{n} / \mathrm{cm}^{2}$ ] \\
TSP_TEMP & 4 & Irradiation Temperature of Tensile Specimen \\
SPEC_ID & 8 & Specimen Identifier \\
TST_TEMP & 4 & Test Temperature of Spcimen \\
TEMP_U & 1 & Unit used for Temperature Data \\
YSL & 5 & Lower Yield Strength of Tensile Specimen \\
YSU & 5 & Upper Yield Strength of Tensile Specimen \\
UTS & 5 & Ultimate Tensile Strength \\
STRESS_U & 6 & Unit of Stress \\
ULG & 4 & Ultimate Elongation of Tensile Specimen [\% ] \\
TLG & 4 & Total Elongation of Tensile Specimen [ \% ] \\
RA & 4 & Reduction in Area of Tensile Specimen [ \% ] \\
SPEC_DIAM & 4 & Diameter (or Cross Section) of Tensile Specimen \\
GAGE_LEN & 4 & Gage Length of Tensile Specimen \\
TOTAL_LEN & 4 & Total Length of Tensile Specimen \\
LENGTH_U & 3 & Unit of Length \\
REF_ID & 20 & Reference Identifier \\
PAGES & 20 & Page Number(s) \\
NOTES & 30 & Pertinent Information Related to Data Entries, If Needed \\
& & \\
\hline
\end{tabular}

\section{File R_LST_TR.dbf}

There are substantial differences between material test reactors and commercial power reactors; however, the structure of the PR-EDB file REAC_LST.dbf has been retained with a few additions to retain compatibility between the two data bases. The NOTES field has been added to augment the information about the reactor and two fields concerning the power output, both thermal and electric. The same structure will be used for future releases of the PR-EDB file, R_LST_PR.dbf (Table 9), which is also included in the TR-EDB since some materials tests (as opposed to the mandated pressure vessel surveillance) have been performed in power reactors. 
Table 9 Structure file for R_LST_TR.dbf

\begin{tabular}{|c|c|c|}
\hline $\begin{array}{l}\text { Field } \\
\text { name }\end{array}$ & $\begin{array}{l}\text { No. } \\
\text { chrs. }\end{array}$ & Description \\
\hline TAG & 1 & Used for Internal Operation \\
\hline PLANT_ID & 6 & Reactor Identification \\
\hline REAC TYPE & 3 & Reactor Type: PWR, BWR, or TR \\
\hline REAC NAME & 50 & Reactor Name \\
\hline LOCATION & 30 & Reactor Location \\
\hline PLANT_OP & 50 & Reactor Operator or Utility \\
\hline PLANT DES & 25 & Reactor Designer or Vendor \\
\hline ARCH ENG & 50 & Reactor Architect/Engineer \\
\hline VESSEL MFG & 50 & Reactor Vessel Manufacturer \\
\hline OUTPUT̄_TH & 5 & Thermal Output of the Reactor [ $\mathrm{Mw}$ ] \\
\hline OUTPUT ${ }^{-} \mathrm{E}$ & 5 & Electricity Output of the Reactor [ Mw ] \\
\hline NOTES & 30 & Pertinent Information Related to Data Entries, If Needed \\
\hline
\end{tabular}

\section{File REAC_.TR.dbf (Table 10)}

The fluence determination in test reactor experiments is much more varied than in power reactors whose surveillance programs are subject, regulation by NRC or the equivalent authorities in countries outside the United States. In addition to the standard fluence $\mathrm{E}>1.0 \mathrm{MeV}$, $\mathrm{E}>0.1 \mathrm{MeV}$, and dpa, "fission equivalent fluence" is often reported in early experiments. Fission fluences are determined directly from dosimetry, mostly assuming a 68 milli barn (mb) cross section of the ${ }^{54} \mathrm{Fe}(\mathrm{n}, \mathrm{p})$ reaction. Conversion to the standard damage fluences is done by scaling the fission fluences with a factor that is determined by comparing the fission spectrum with that of a neutron transport calculation. This factor is listed, whenever it is reported, together with the standard damage fluences with uncertainties. The field FLU_TAG is used to indicate the type of fluence determination: The character $F$ indicates that only fission fluence is reported, $S$ indicates the scaling procedure described above, and A stands for a full fledged neutron physics calculation with adjustment for dosimetry data. Also included are the fluence rates at full power, full-power-equivalent irradiation times, and start-up and removal dates of the experiment capsules. In some cases, the capsules have been irradiated more than once and annealed in between; the different irradiations are listed in separate records with the same CAPSULE identification; the sequence of irradiations is indicated in the CONFIG field. Irradiation temperatures within the capsule are reported either as maxima and minima or as a nominal (target) value, sometimes with a temperature range. Included in the temperature data is a TEMP_TAG which indicates how the irradiation tcmperature was determined. This field was also included in the REAC_PR.dbf file of the PR-EDB; however, instead of numbers a letter is used for test reactors with $\mathrm{C}$ for calculated (or estimated) temperatures, $M$ for melt wires, and $T$ for thermocouples, the most frequently used technique in test reactor experiments. 
Table 10 Structure file for REAC_TR.dbf

\begin{tabular}{|c|c|c|}
\hline $\begin{array}{l}\text { Field } \\
\text { name }\end{array}$ & $\begin{array}{l}\text { No. } \\
\text { chrs. }\end{array}$ & Description \\
\hline TAG & 1 & Used for Internal Operation \\
\hline EXP_ID & 6 & Experiment Identification \\
\hline PLANTT_ID & 6 & Reactor Identification \\
\hline CAPSUL̄E & 6 & Surveillance or Experiment Capsule Identification \\
\hline START_DATE & 10 & Data at Start of Irradiation [ MM/DD/YYYY ] \\
\hline STOP D̄ATE & 10 & Date at End of Irradiation [ MM/DD/YYYY] \\
\hline CONFIG & 6 & Indicator for Change in Irradiation Environment \\
\hline EFP_TIME & 10 & Effective Full Power Time of Irradiation \\
\hline TIME U & 1 & Unit of Time: $S$ _econds, $M$ _inutes, $H_{-}$ours, $D_{-}$ays, $Y$ _ears \\
\hline CAP_T_MIN & 4 & Minimum Irradiation Temperature at Capsule Center \\
\hline CAP_T_MAX & 4 & Maximum Irradiation Temperature at Capsule Center \\
\hline CAP_T_NOM & 4 & Nominal Irradiation Temperature for Capsule \\
\hline TEMP_RANGE & 4 & Temperature Variations within the Capsule \\
\hline TEMP_U & 1 & Unit used for Temperature Data \\
\hline TEMP_TAG & 1 & $\begin{array}{l}\text { Irr. Temp. Determination: } C_{-} \text {alcul., } T_{-} \text {hermocouples, } \\
\text { M_elt wires }\end{array}$ \\
\hline CAP_F1 & 10 & Fluence $>1 \mathrm{MeV}$ at Capsule Center $\left[\mathrm{n} / \mathrm{cm}^{2}\right]$ \\
\hline F1_UNC & 3 & Uncertainty of Fluence $>1.0 \mathrm{MeV}$ [ \% Standard Deviation ] \\
\hline FLU_TAG & 1 & $\begin{array}{l}\text { Tag for Fluence Determination: } F_{-} \text {ission, } S_{-} \text {caling, } \\
\text { A_djustment }\end{array}$ \\
\hline F1_RATE & 10 & Fluence Rate $>1 \mathrm{MeV}$ at Capsule Center $\left[\mathrm{n} /\left(\mathrm{cm}^{2} \mathrm{~s}\right)\right]$ \\
\hline CAP FP1 & 10 & Fluence $>0.1 \mathrm{MeV}$ at Capsule Center $\left[\mathrm{n} / \mathrm{cm}^{2}\right]$ \\
\hline FP1 TO F1 & 4 & Ratio of Fluence $\mathrm{E}>0.1 \mathrm{MeV}$ to Fluence $\mathrm{E}>1.0 \mathrm{MeV}$ \\
\hline FP1_UNC & 3 & Uncertainty of Fluence $>0.1 \mathrm{MeV}$ [ \% Standard Deviation ] \\
\hline CAP_FISS & 10 & $\begin{array}{l}\text { Equivalent Fission Fluence } \mathrm{E}>1 \mathrm{Mev} \text { as Determined from } \\
\text { Dosimetry }\end{array}$ \\
\hline F1_TO_FISS & 4 & $\begin{array}{l}\text { Ratio of Calculated to Equivalent Fission Spectrum } \\
\mathrm{E}>1.0 \mathrm{MeV}\end{array}$ \\
\hline CAP_DPA & 10 & Displacements per Atom of Iron at Capsule Center \\
\hline DPA_TO_F1 & 10 & Ratio of dpa to Fluence $\mathrm{E}>1.0 \mathrm{MeV}$ \\
\hline DPA_UNC & 3 & $\begin{array}{l}\text { Uncertainty of Displacements per Atom } \\
\text { [\% Standard Deviation ] }\end{array}$ \\
\hline REF ID & 20 & Reference Identifier \\
\hline PAGES & 20 & Page Number(s) \\
\hline NOTES & 30 & Pertinent Information Related to Data Entries, If Needed \\
\hline
\end{tabular}




\section{File H_LST_TR.dbf}

The file H_LST_TR.dbf (Table 11) relates the material codes given in HEAT_ID to the descriptions and heat numbers given in the reports and in the MPC data base. It also includes the ASTM (or European standard) material classification, the supplier of the material, and the thickness. SOURCE gives specific information about the origin of the material (if available), namely SCR-ap, if it was obtained from excess material during the fabrication of a pressure vessel (this applies also to welds), CUTOUT for nozzle cutouts, and SIM-ulated welds, if the material was not obtained from an actual weld seam but fabricated from excess plate material using the same filler and flux. Finally, FABR icated means, that the material was fabricated exclusively for irradiation experiments. (A complete listing is given on p. 44 at the end of the section.)

Table 11 Structure file for H_LST_TR.dbf

\begin{tabular}{|c|c|c|}
\hline $\begin{array}{l}\text { Field } \\
\text { name }\end{array}$ & $\begin{array}{l}\text { No. } \\
\text { chrs. }\end{array}$ & Description \\
\hline TAG & 1 & Used for Internal Operation \\
\hline EXP_ID & 6 & Experiment Identification \\
\hline HEAT_ID & 10 & Identification Code for Given Material \\
\hline RPT_ID & 20 & Material Identifier Used in Referenced Reports \\
\hline HEĀT_NO & 10 & Heat Number of Material Used by Supplier \\
\hline PROD_ID & 3 & Material Type: P_late, F_orging, W_eld, HAZ, or SRM \\
\hline MAT_ID & 10 & Material Classification: $\overline{\mathrm{A}} 302 \mathrm{~B}, \mathrm{~A} 5082$, A533B1, etc. \\
\hline SUPPLIIER & 20 & Supplier of Material \\
\hline THICKNESS & 6 & Thickness of Base Material \\
\hline LENGT_U & 3 & Unit of Length \\
\hline $\begin{array}{l}\text { SOURCE } \\
\text { CUTOUT }\end{array}$ & 10 & Source of Material: FABR_icated, SCR_ap, SIM_ulated Weld \\
\hline MPC_ID & 5 & Reference Number Assigned by Combustion Engineering (MPC) \\
\hline MPC_HEAT & 7 & Material Heat Number (MPC) \\
\hline REF_ID & 20 & Reference Identifier \\
\hline PAGES & 20 & Page Number(s) \\
\hline NOTES & 30 & Pertinent Information Related to Data Entries, If Needed \\
\hline
\end{tabular}




\section{File CHEM_TR.dbf}

The file CHEM_TR.dbf (Table 12) lists the chemistries for the given materials together with information about the laboratory and method used, if reported, and whether it is derived from test specimens or represents generic values given by the supplier of the material. Generic values are identified in SPEC_ID as LADLE, CHECK, or just HEAT, depending on what is revealed in the reports. The term WIRE is used if the chemistry of the filler wire, rather than that of the actual weld material, has been reported. Other terms listed in SPEC_ID are the identifiers of the test specimen whose chemistry was determined. All different chemistry determinations for the same material are listed as reported, but duplications are omitted. (A partial listing is given on p. 55 at the end of the section.) 
Table 12 Structure file for CHEM_TR.dbf

\begin{tabular}{|c|c|c|}
\hline $\begin{array}{l}\text { Field } \\
\text { name }\end{array}$ & $\begin{array}{l}\text { No. } \\
\text { chrs. }\end{array}$ & Description \\
\hline TAG & 1 & Used for Internal Operation \\
\hline EXP ID & 6 & Experiment Identification \\
\hline HEATT_ID & 10 & Identification Code for Given Material \\
\hline PROD_ID & 3 & Material Type: $P_{\text {_late, }} \mathrm{F}_{\text {_orging, }} \mathrm{W}_{\text {eld }}$, HAZ, or SRM \\
\hline MAT_ID & 10 & Material Classification: $\overline{\mathrm{A}} 302 \mathrm{~B}, \mathrm{~A} 5 \overline{8} \mathrm{z} 2$, A533B1, etc. \\
\hline CHEM_LAB & 15 & Chemistry Laboratory or Procedure Identification \\
\hline METHŌD & 30 & Method for Determining the Chemistry \\
\hline SPEC_ID & 8 & Specimen Identifier \\
\hline C & 5 & Weight Percent Carbon \\
\hline MN & 5 & Weight Percent Manganese \\
\hline $\mathbf{P}$ & 5 & Weight Percent Phosphorus \\
\hline $\mathrm{s}$ & 5 & Weight Percent Sulfur \\
\hline SI & 5 & Weight Percent Silicon \\
\hline NI & 5 & Weight Percent Nickel \\
\hline CR & 5 & Weight Percent Chromium \\
\hline MO & 5 & Weight Percent Molybdenum \\
\hline $\mathrm{CU}$ & 5 & Weight Percent Copper \\
\hline V & 5 & Weight Percent Vanadium \\
\hline B & 5 & Weight Percent Boron \\
\hline CS & 5 & Weight Percent Cesium \\
\hline $\mathrm{TI}$ & 5 & Weight Percent Titanium \\
\hline $\mathrm{CO}$ & 5 & Weight Percent Cobalt \\
\hline $\mathrm{N}$ & 5 & Weight Percent Nitrogen \\
\hline 0 & 5 & Weight Percent Oxygen \\
\hline SB & 5 & Weight Percent Antimony \\
\hline AS & 5 & Weight Percent Arsenic \\
\hline ZR & 5 & Weight Percent Zirconium \\
\hline $\mathrm{AL}$ & 5 & Weight Percent Aluminum \\
\hline AL_SOL & 5 & Weight Percent Aluminum in Solution \\
\hline $\mathrm{AL} I \mathrm{INT}$ & 5 & Weight Percent Aluminum Interstitial \\
\hline $\mathrm{PB}^{-}$ & 5 & Weight Percent Lead \\
\hline W & 5 & Weight Percent Tungsten \\
\hline SN & 5 & Weight Percent Tin \\
\hline ZN & 5 & Weight Percent Zinc \\
\hline TA & 5 & Weight Percent Tantalum \\
\hline $\mathrm{H}$ & 5 & Weight Percent Hydrogen \\
\hline NB & 5 & Weight Percent Niobium \\
\hline REF_ID & 20 & Reference Identifier \\
\hline PAGES & 20 & Page Number(s) \\
\hline NOTES & 30 & Pertinent Information Related to Data Entries, If Needed \\
\hline
\end{tabular}




\section{File HEAT_TR.dbf}

The file HEAT_TR.dbf (Table 13) lists up to eight different steps of heat treatment with temperature ranges, duration, quench method, and an indication of whether the particular step was intended for normalizing, austenizing, tempering, or stress relief, as far as reported. The supplier of the material and the facility performing the heat treatment, plus the identification used for the ingot (HEAT_NO) and the code used for the finished material (SUPPL_ID), are also included. A new field, NOMTEMP_ $x$, is added to the old HEAT_PR.dbf file in the PR-EDB to indicate the nominal temperature of the treatment step, if no MAXTEMP_ $x$ and MINTEMP_ $x$ is reported. RANGE, if reported, indicates then the deviation from the nominal temperature (in both directions if \pm is attached). (A partial listing is given on p. 56 at the end of the section.)

Table 13 Structure file for HEAT_TR.dbf

\begin{tabular}{|c|c|c|}
\hline $\begin{array}{l}\text { Field } \\
\text { name }\end{array}$ & $\begin{array}{l}\text { No. } \\
\text { chrs. }\end{array}$ & Description \\
\hline TAG & 1 & Used for Internal Operation \\
\hline EXP ID & 6 & Experiment Identification \\
\hline HEAT__ID & 10 & Identification Code for Given Material \\
\hline PROD_ID & 3 & Material Type: $P_{\text {_late, }} \mathrm{F}_{-}$orging, W_eld, HAZ, or SRM \\
\hline SUPPLIER & 15 & Supplier of Material \\
\hline HEAT_TREAT & 15 & Facility Performing Heat Treatment \\
\hline HEAT_NO & 10 & Heat Number of Material Used by Supplier \\
\hline SUPPL ID & 10 & Identifier Used by Supplier \\
\hline MINTEMPP 1 & 4 & Heat Treatment Minimum Temperature, Run 1 \\
\hline MAXTEMP 1 & 4 & Heat Treatment Maximum Temperature, Run 1 \\
\hline NOMTEMP_1 & 4 & Heat Treatment Nominal Temperature, Run 1 \\
\hline RANGE 1 & 3 & Heat Treatment Temperature Range, Run 1 \\
\hline HOURS 1 & 6 & Heat Treatment Duration, Run 1 [ hours ] \\
\hline QCHM $\overline{1}$ & 2 & Quench Method, Run 1 \\
\hline ID_1 & 1 & N_ormalizing, A_ustenizing, T_empering, Stress R_elief, Run 1 \\
\hline MINTEMMP_2 & 4 & Heat Treatment Minimum Temperature, Run 2 \\
\hline MAXTEMP 2 & 4 & Heat Treatment Maximum Temperature, Run 2 \\
\hline NOMTEMP_2 & 4 & Heat Treatment Nominal Temperature, Run 2 \\
\hline RANGE 2 & 3 & Heat Treatment Temperature Range, Run 2 \\
\hline HOURS_2 & 6 & Heat Treatment Duration, Run 2 [ hours ] \\
\hline $\mathrm{QCHM} \overline{2}$ & 2 & Quench Method, Run 2 \\
\hline ID 2 & 1 & N_ormalizing, A_ustenizing, T_empering, Stress R_elief, Run 2 \\
\hline MINTEMP 3 & 4 & Heat Treatment Minimum Temperature, Run 3 \\
\hline MAXTEMP 3 & 4 & Heat Treatment Maximum Temperature, Run 3 \\
\hline NOMTEMP 3 & 4 & Heat Treatment Nominal Temperature, Run 3 \\
\hline RANGE_3 & 3 & Heat Treatment Temperature Range, Run 3 \\
\hline
\end{tabular}


Table 13 (continued)

\begin{tabular}{|c|c|c|}
\hline $\begin{array}{l}\text { Field } \\
\text { name }\end{array}$ & $\begin{array}{l}\text { No. } \\
\text { chrs. }\end{array}$ & Description \\
\hline HOURS_3 & 6 & Heat Treatment Duration, Run 3 [ hours ] \\
\hline QCHM_ $\overline{3}$ & 2 & Quench Method, Run 3 \\
\hline ID_3 & 1 & N_ormalizing, A_ustenizing, T_empering, Stress R_elief, Run 3 \\
\hline MINNTEMP 4 & 4 & Hēat Treatment Minimum Temperature, Run 4 \\
\hline MAXTEMP̄_ 4 & 4 & Heat Treatment Maximum Temperature, Run 4 \\
\hline NOMTEMP_4 & 4 & Heat Treatment Nominal Temperature, Run 4 \\
\hline RANGE_4 - & 3 & Heat Treatment Temperature Range, Run 4 \\
\hline HOURS_4 & 6 & Heat Treatment Duration, Run 4 [ hours ] \\
\hline QCHM_ 4 & 2 & Quench Method, Run 4 \\
\hline ID_4 & 1 & N_ormalizing, A_ustenizing, T_empering, Stress R_elief, Run 4 \\
\hline MINNTEMP_5 & 4 & Hēat Treatment Minimum Temperature, Run 5 \\
\hline MAXTEMP̄_5 & 4 & Heat Treatment Maximum Temperature, Run 5 \\
\hline NOMTEMP 5 & 4 & Heat Treatment Nominal Temperature, Run 5 \\
\hline RANGE_5 & 3 & Heat Treatment Temperature Range, Run 5 \\
\hline HOURS_5 & 6 & Heat Treatment Duration, Run 5 [ hours ] \\
\hline QCHM_ $\overline{5}$ & 2 & Quench Method, Run 5 \\
\hline ID_5 & 1 & N_ormalizing, A_ustenizing, T_empering, Stress R_elief, Run 5 \\
\hline MINTTEMP_6 & 4 & Heat Treatment Minimum Temperaturc, Run 6 \\
\hline MAXTEMP̄_ 6 & 4 & Heat Treatment Maximum Temperature, Run 6 \\
\hline NOMTEMP_6 & 4 & Heat Treatment Nominal Temperature, Run 6 \\
\hline RANGE_6 & 3 & Heat Treatment Temperature Range, Run 6 \\
\hline HOURS_6 & 6 & Heat Treatment Duration, Run 6 [ hours ] \\
\hline QCHM_6 & 2 & Quench Method, Run 6 \\
\hline ID_6 & 1 & N_ormalizing, A_ustenizing, T_empering, Stress R_elief, Run 6 \\
\hline MINNTEMP_7 & 4 & Heat Treatment Minimum Temperature, Run 7 \\
\hline MAXTEMP 7 & 4 & Heat Treatment Maximum Temperature, Run 7 \\
\hline NOMTEMP_7 & 4 & Heat Treatment Nominal Temperature, Run 7 \\
\hline RANGE_7 & 3 & Heat Treatment Temperature Range, Run 7 \\
\hline HOURS_7 & 6 & Heat Treatment Duration, Run 7 [ hours ] \\
\hline QCHM_ $\overline{7}$ & 2 & Quench Method, Run 7 \\
\hline ID_ 7 & 1 & N_ormalizing, $A$ ustenizing, $T$ empering, Stress $\mathrm{R}$ elief, Run 7 \\
\hline MINNTEMP 8 & 4 & Heat Treatment Minimum Temperature, Run 8 \\
\hline MAXTEMP_ 8 & 4 & Heat Treatment Maximum Temperature, Run 8 \\
\hline NOMTEMP 8 & 4 & Heat Treatment Nominal Temperature, Run 8 \\
\hline RANGE_8 & 3 & Heat Treatment Temperature Range, Run 8 \\
\hline HOURS_8 & 6 & Heat Treatment Duration, Run 8 [ hours ] \\
\hline QCHM_ $\overline{8}$ & 2 & Quench Method, Run 8 \\
\hline ID_8 & 1 & $\mathrm{~N}$ ormalizing, $\mathrm{A}$ ustenizing, $\mathrm{T}$ empering, Stress $\mathrm{R}$ elief, Run 8 \\
\hline TEMP_U & 1 & Unit used for Temperature Data \\
\hline REF ID & 20 & Reference Identifier \\
\hline PAGES & 20 & Page Number(s) \\
\hline NOTES & 30 & Pertinent Information Related to Data Entries, If Needed \\
\hline
\end{tabular}




\section{File WELD_TR.dbf}

The file WELD_TR.dbf (Table 14) gives additional information for weldments such as weld method, type and heat number of the filler material, and type and lot number of the flux used. The weld code plus the supplier of the weld is also listed. (A partial listing is given on p. 57 at the end of the section.)

Table 14 Structure file for WELD_TR.dbf

\begin{tabular}{|c|c|c|}
\hline $\begin{array}{l}\text { Field } \\
\text { name }\end{array}$ & $\begin{array}{l}\text { No. } \\
\text { chrs. }\end{array}$ & Description \\
\hline TAG & 1 & Used for Internal Operation \\
\hline EXP_ID & 6 & Experiment Identification \\
\hline HEAT ID & 10 & Identification Code for Given Material \\
\hline WLD_TYPE & 3 & Weld Type \\
\hline WLD_CODE & 10 & Identification Code used by Weld Manufacturer \\
\hline HEAT̄_1 & 10 & HEAT ID of the Plate on one side of the Weld \\
\hline HEAT_2 & 10 & HEAT_ID of the Plate on the other side of the Weld \\
\hline WELD_SUPLY & 15 & Supplier of Weld Material \\
\hline WIRE TTYPE & 10 & Type of Weld Wire Used in the Weld \\
\hline WIRE-HEAT & 10 & Weld Wire Heat Identifier \\
\hline FLUX_TYPE & 10 & Type of Flux Used in the Weld \\
\hline FLUX LOT & 10 & Weld Flux Lot Identifier \\
\hline REF_ID & 20 & Reference Identifier \\
\hline PAGES & 20 & Page Number(s) \\
\hline NOTES & 30 & Pertinent Information Related to Data Entries, If Needed \\
\hline
\end{tabular}

\section{File HAZ_TR.dbf}

The file HAZ_TR.dbf (Table 15) identifies the base material and weldments used to prepare the heat-affected-zone specimens. (A partial listing is given on p. 58 at the end of the section.) 
Table 15 Structure file for HAZ_TR.dbf

\begin{tabular}{|c|c|c|}
\hline $\begin{array}{l}\text { Field } \\
\text { name }\end{array}$ & $\begin{array}{l}\text { No. } \\
\text { chrs. }\end{array}$ & Description \\
\hline TAG & 1 & Used for Internal Operation \\
\hline EXP ID & 6 & Experiment Identification \\
\hline HEAT ID & 10 & Identification Code for Given Material \\
\hline HEAT B & 10 & HEAT ID of the Base Material Used in the HAZ \\
\hline HEATW & 10 & HEAT_ID of the Weld Material Connected with the HAZ \\
\hline REF_ID & 20 & Reference Identifier \\
\hline PAGES & 20 & Page Number(s) \\
\hline NOTES & 30 & Pertinent Information Related to Data Entries, If Needed \\
\hline
\end{tabular}

\section{File TITL_TR.dbf}

Most TR-EDB files contain a reference in the field REF_ID plus page numbers for each record. The complete bibliographic listing, including author, title, report number, and date of publication, $i$ located in the file TITL_TR.dbf (Table 16). Each listing may extend over more than one record because of the limited length the title field REF_TITL may occupy in the current version of dBASE. A set of linked records is characterized by the same REF_ID, and a sequence of numbers in the CONT field (i.e., 1,2 ,.. etc.). The list of authors and experiments described in the reference may also extend over more than one record. A complete listing of this file is given on p. 59 at the end of the section.

Table 16 Structure file for TITL_TR.dbf

\begin{tabular}{|c|c|c|}
\hline $\begin{array}{l}\text { Field } \\
\text { name }\end{array}$ & $\begin{array}{l}\text { No. } \\
\text { chrs. }\end{array}$ & Description \\
\hline EXP ID & 6 & Experiment Identification \\
\hline REF_ID & 20 & Reference Identifier \\
\hline ALT_REF & 20 & Alternative Reference (not used as REF_ID) \\
\hline $\mathrm{CONT}$ & 2 & Continuation Tag for References Occupying More than One Record \\
\hline AUTHOR_1 & 25 & $\begin{array}{l}\text { First Author } \\
\text { (or continuation from preceding record, same ref.) }\end{array}$ \\
\hline AUTHOR_2 & 25 & $\begin{array}{l}\text { Next Author } \\
\text { (may be continued in the next record for same ref.) }\end{array}$ \\
\hline REF_TITLE & 80 & Bibliographic Reference \\
\hline PUB_DATE & 10 & Date of Publication \\
\hline $\mathrm{TAG}^{-}$ & 1 & Used for Internal Operation \\
\hline
\end{tabular}




\section{File REF_TR.dbf}

This file links the key identifier EXP_ID with REF_ID (i.e., it lists all references associated with a particular experiment and vice versa). The linkage is not one-to-one since many experiments are reported in more than one reference and some publications cover more than one experiment. The field MPC_ID identifies the reports and data that were included in the MPC data base.

Table 17 Structure file for TITL_TR.dbf

\begin{tabular}{lll}
\hline $\begin{array}{l}\text { Field } \\
\text { name }\end{array}$ & $\begin{array}{l}\text { No. } \\
\text { chrs. }\end{array}$ Description \\
\hline
\end{tabular}

TAG 1 Used for Internal Operation

EXP ID 6 Experiment Identification

REF_ID 20 Reference Identifier

MPC_ID 3 Reference Number Assigned by Combustion Engineering (MPC) 
Tables 18 through 34 give partial or complete listings of the TR-EDB files discussed earlier. 
Table 18 Listing of E_LST

ELST_TR: Page 1

EXP_ID EXP_OESCR

ABORATORY

BET-AN Ameoling Experiments Performed by Westinghouse of the Bettis Loboratory

BUREXP Irrediation Experiments Performed by GE with D Verlety of BUR-PV Materials
CEA Experiments in French Reactors Sponsored by Comissariat I'Energy Atomique

CEA Experiments in French Reactors Sponsored by Commisear iot I'Energy Atomique

FKS-G Irr. Progra ot Geesthecht to Verify Safety Margin for German Licensing Rules

fKS-K Irr. progrem by KWU to verify sefety morgins for Germen licensing rules

MaY-AM Compiletion of Resulte from Ameoling Experinents by J.R. Howthorne

HFIR HFIR Surveillence Prooren and Releted Experiments at ORML

USST-0 Mean Section steal Technoloay (HSST) Progren, Initial Characterizatior.

USST-1 Heav Section steel Irrediation (HSSI) Experiments, Series 1, at ORW

MSST-2 Heavy Section Steel Irrediation (HSSI) Experfments, Serles 2, ot ORHL

MSST.3 Heev Section steel Irredietion (HSS1) Experinents, Series 3, ot ORHL

HSST-4 Heary Section steel Irrediation (HSSI) Experiments, Series 4, at ORNL

IAEA IAEA Co-ordinated Research Progran for Irradiation of Advanced RPV Steels

IAEAB IAEA CO-ordinuted Research Progran: AERE Contribution

IAEAC IAEA Co-ordinated Reseorch Program: Skodo Contribution

IAEAD IAEA Co-ordinated Research Progran: RISO Contribution

IAEAF IAEA CO-ordinated Research Prooran: CEM Contribution

IAEAG IAEA Co-ordinated Research Progran: GXSS Contribution

IAEAI IAEA Co-ordinoted Research Program: Bhabho Contribution

IAEAS IAEA Co-ordinated Research Progran: Japan At. Res. Inst.

IAEAM IAEA Co-ordinated Research Prooram: Steel manufocturer

IAEAN IAEA Co-ordinated Research Program: MRL Contribution

JPOR Jepan Power Oenonstration Resctor (JPOR) SUrvelll ance Progra

KFA Misc. Irrediation Experiment Performed ot the Kernforschungsenstalt (KFA), FRC

KRB Experiments Concerning the Decomisioned Reactor KRB-A, Gundremingen, Germeny

KWU-PR Compilation of German Irrodiated RPV Dota for Iransfer to NRC

LAC Test Reactor Irradiation in Support of the LaCrosse Reactor

NCD-AN Compilation of Results from Amealing Experinents by B. McDonald

MEA-AA POst-irrediation Ameal ing Experiments ot Materisls Engineerino Ass.. Inc. (MEA)

MEA-RT Study of the Influence of Fluence Rates on Irradiation Embrititement at MEA

MolBR3 Irrediation Experiments in Support of the BR3 Reactor ot Mol, Belgiven

MRI-1 Test of Kydrogen influence in steels performed at Materials Research, Idaho

WRL-1 Exploratory Irrediation Studles of A533, A543, and 1302 Steels ot MRL

MRL-2 Irrediation Experimente with MSST Material at the Naval Research Laboratory

WRL-3 Test of Irradietion Sensitivity for Commercial and Improved Steels at MRL

WRL-4 Wotch Ouctillity Degredation of Low Alloy Steels with Low-to internediste fluence

MRL-A Imvestigation of Crelic Irrediation and Ameal in Effect in A533-B Held

WRL-EP MRL-EPRI Reseurch Progran (RPBs6-2)

ORRPSF SUrveillence Dosimetry Improvement Progran, ORR-PSF Metallurgical Irrediation

PR-ED8 Experiments in Support of U.S. Power Reactor Survelll ance

RRA Series of Experiments Performed at Rolls Royce Assoclates, Ux.

SN-1 Experiments with Denonatrotion Mele 1533 Plates

SW-2 Exp. W. Split-Melts to Study the Influence of Residuat Elements in A302-8 steels

SN-3 Exp. W. Split-Melts to study the influence of Residual Elements in 1543 steels

SH.6 Experiments with Split-Melts to Study MIckel-Copper Interaction

sw-5 Experiments with Split-Malts to Study Copper-Phosphoru Interaction

SRH Irrodiation of Stenderd Reference Materlals In Power and Teat Reactors

VDE Steel Irrediation Prosran Sponsored by Verein Deutscher Eisentuttenl eute

Bettis Loboretory

General Electric co.

Gxs5-Forschungszentrum

Kroftwerkunion $A G$

Ouk Ridge Mational Laboratory

Dak Ridge Mational Laboratory

Oak Ridge National Leboratory

Ook Rlobe National Leboratory

Oak Ridoe National Laboratory

Oak Ridge National Laboratory

Int. Atomic Eneroy Agency

Ux Atomic Energy Authority

Skode Mational Corporation

Rlso Metionsl Leboretories

Centre d'Etudes Mucléaires

Gxss

Dhobhe Atomic Research Centre

Jepen Atconic Eneroy Res. Inst.

Kernfor schungsantele

Maval Research Laboratory

Jepen Atomic Energy Res. Jol

Kernforschungsanstalt

Materials Engineering Assoc.

Kraftwerk Union

Materials Engineering Assoc.

Materials Engineering Assoc.

Moterials Engineering AssoC.

Moval Research Leboratory

Maval Research Laboratory

Moval Research Laboratory

Maval Research Laboratory

Maval Research Laboratory

Naval Research Leboratory

Oak Ridge Nat fonal Laboratory

Metal Properties Councll

Rolls Rovee and Associates

Woval Research Laboratory

Noval Research Leboratory

Moval Research Leboratory

Materials Engineering Assoc.

Materlals Enoineering Assoc.

AsTM

Kernforechungsantalt

Meval Research Laboratory 


\section{TR.dbf}

Mons

LOCATION

-REACTORS

A

- Mall, D.J. Sernan

Pitesburgh, PA
San Jose, CA

cuionnet, P. Petrequin, P. Soulat, et al.

M

- Mager

ilf, O. Bell lmann, et al.

San Jose, CA

UNAR

Geesthecht, Germomy PRG-2

Eriengen

VAX

Foni, Ch. Leitz, 0 . Anders

- Mawthorne

Mansted, et ol.

- Childress. M.d. Stelzman

- Stelzman, G.R. Bergoren, et al

- Menstad, G.R. Berggren, et al.

- Mensted, G.R. Bergaren, et. Il.

- Mansted, G.R. Bergoren, et al.

- Dovies, et $\bullet$ l.

Brumovsky

- Debel

Petrequin, et al.

spal thoff, et ol.

- Sivaramokrishnan

Mivazono

Pechur

Ook Ridoe, $T$ II

Oak Ridoe, TN

Oak Ridoe, IH

Oak Ridoe, TII

Oak Ridge, $T M$

Oak Ricoe, TM

Vienna, Austrio

Harweli, Oxfordahire, U.K. MERALO

Plzen, Czechoslovaki: WR

Roskilde, Dermark

Saclay, France

Geesthacht, Germamy BRG-2, axs, vax

Bombay, India

Tokyo, Jepan

Jül ich, Germary

JHTR

Jeshington, DC

Tokyo, Jepen

Julich, Germenty

Kawasaki, et al

Pochur

Lentien, in

MFIR, CRR

1. Mawthorne

JPOR

FRJ-1, FRJ-2, HFR

UBR

Serpan, dr

Mcoonald

1. Nawthorn

1. Mawthorne

fobry, et al

- Brinkmon, J.M. Meeston

1. Mawthorne

. Hawthorne

. Mawthorne

1. Hawthorne

. Mawthorne, M.E. Watson, F.J. Loss

1. Hawthorne, H.E. Watson

l. Mawthorne, et al.

C. Steele, C.2. Serpen, Jr.

l. Willians, et al

i. Hawthorne

i. Hawthorne

l. Nowthorne

1. Hawthorne

l. Mawthorne

l. Hawthorne

Pechur

1. Serpan, Jr., J.R. Mawthorne

Lenhem, no

Lerhen, id

Lentean, is

Machington, $D C$ Washington, $O C$ Washington, OC Uashimgton, $D C$

Uashimgton, DC

Ueshington, $D C$

Oak Ridge, II

Derby, Englend

Ueshimgton, $D C$

Washimoron, DC

Ueshington, DC

Lerhem, in

Larhan, 10

Jülich, Germem

Uashington, $D C$
IITR, UCRR

Use

UBR

Var

ETR, MTR

LITR, MTR, UCRK

MTR, UCRR

UCRR

UBR

8SR

DIDO, MERALO, PLUTO

ATR, ER, ETR, UCRR

LITR, var

UITR

UBR

LesR

FRJ-2 
Table 19 Partial listing of S_LST_TR.dbf

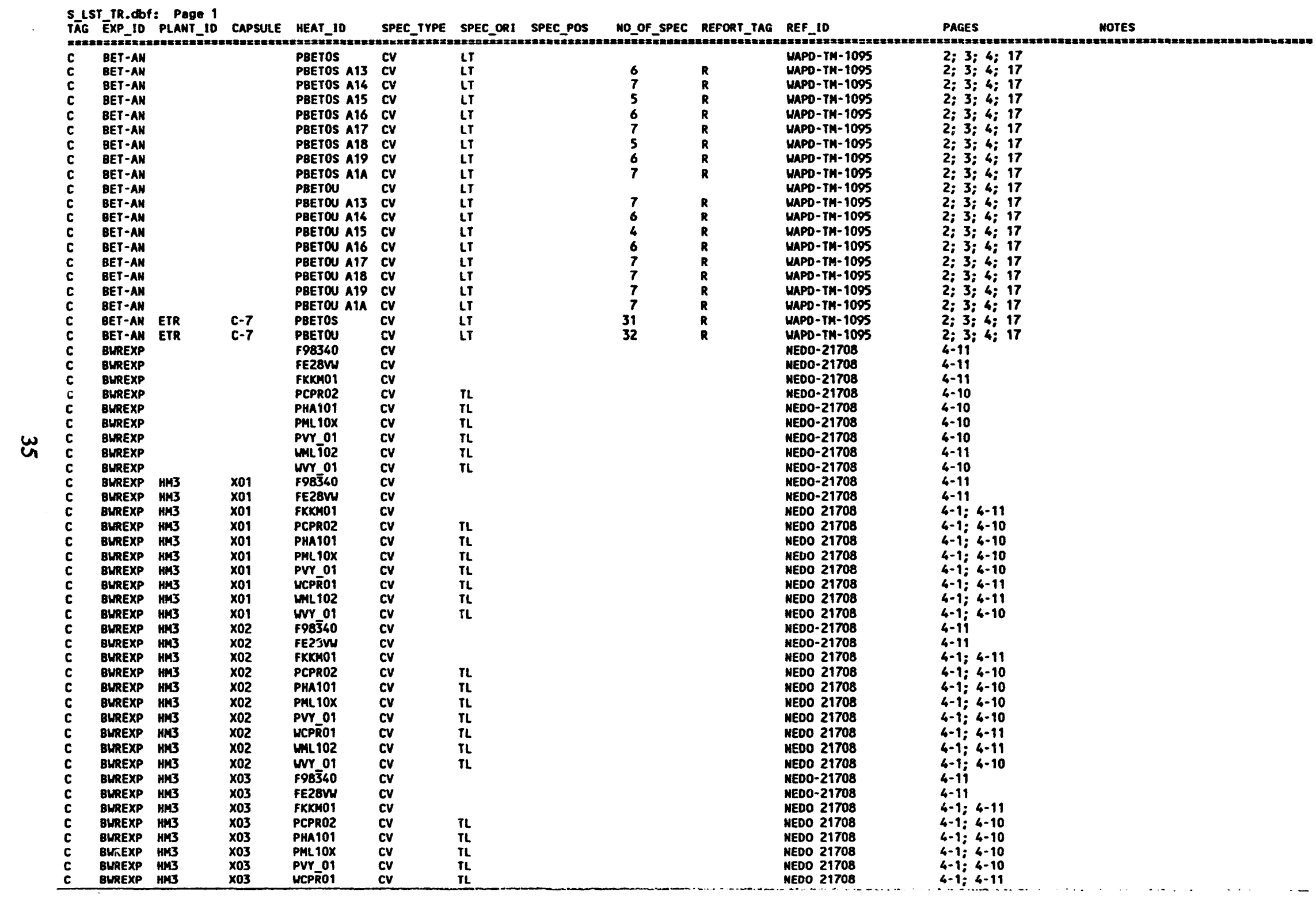


Table $20 \mathrm{~Pa}$

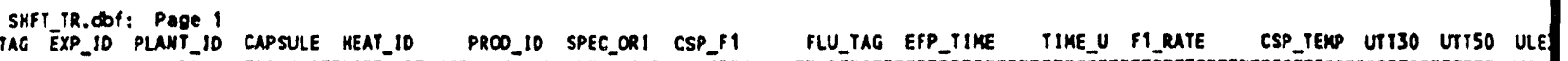

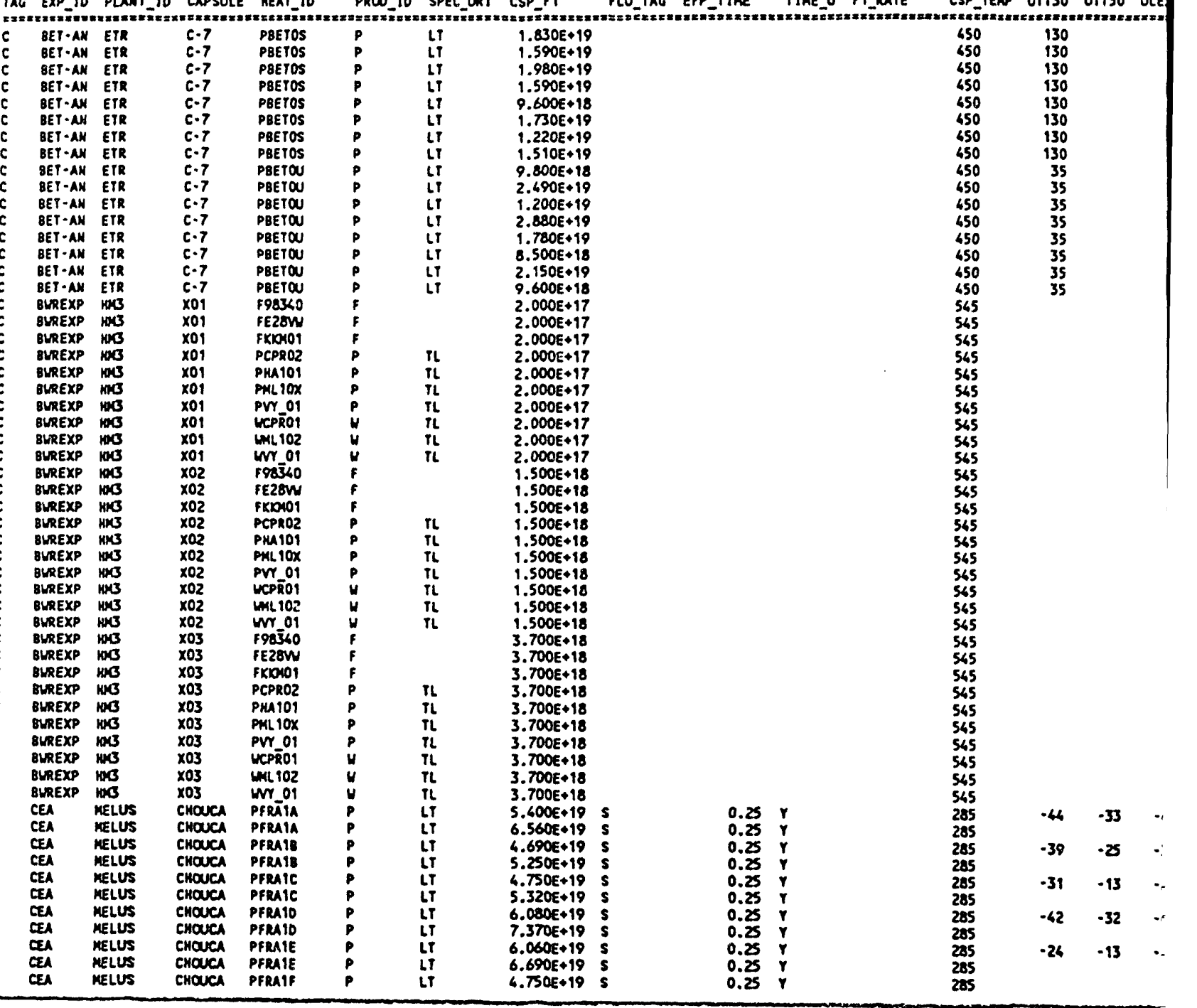




\section{tial listing of SHFT_TR.dbf}

SHFT TR.COF: POge 1

5 WSE U_FIT ITT3O IITSO ILE35 IUSE I_fIT DIT3O OITSO DLESS OUSE_AES OUSE_REL TEKP_U USE_U REF_10

$\begin{array}{ll}465 & 300 \\ 465 & 3 \\ 460 & 3 \\ 460 & 3 \\ 450 & 310 \\ 440 & 3 \\ 450 & 3 \\ 315 & 320 \\ 365 & 280 \\ 315 & 330 \\ 365 & 280 \\ 365 & 330 \\ 340 & 330 \\ 365 & 305 \\ 340 & 330 \\ & 305\end{array}$

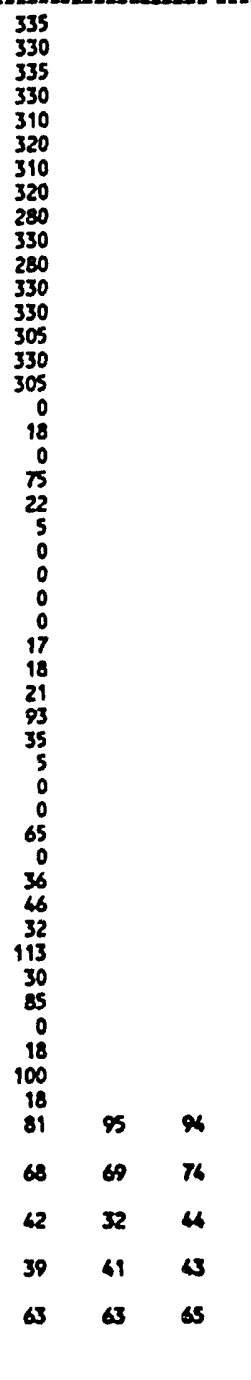

tR-1S WAPO-TH-1095

It- Ib WAPO-TM-1095

TE-lb WAPO-TH-10OS

PT-lb HAPD-TM-1095

ft-lb WNPD-TK-1095

ft.lo UNPO-TH-1095

tt-lb WAPD-TK-1095

ft-lb WAPD-TK-1095

ft- lb UAPD-TM-100S

ft- ib WAPO-TK-1005

tc. Ib UAPO-TK-1005

ti- ID UMPO-TM-1005

Ti-ID WAPO-IN-TOOS

It.lo WAPD-IK-1095

It-lb WAPO-TH-1095

ft-Ib WAPD-TM-1095

ft- Lb WAPO-TK-1095

$f t \cdot$ lb NEDO-21708

ft-lb NEDO-21708

$f t-1 b$ NEDO-2i70s

$f t .10$ MEDO-2170s

ft. Ib MEDO-2170s

$\mathrm{ft} \cdot 1 \mathrm{~b}$ MEDO-21708

ft-lb MEDO-2170s

ft. Ib MEDO-2170s

it.lb MEDO-2170

ft- Ib MEDO-21708

ft-lb NEDO-21708

ft-lb NEDO-21708

fi-lo NEDO-2170S

ft-16 NEDO-2170s

ft-lo NEDO-21708

Tt-1b KEDO-21708

tt-1b NEDO-21708

ft-lb MEDO-2170s

Ft-1b NEDO-2170:

$f t-1 b$ NEDO-21708

$f t-1 b$ NEDO-21708

ft-Ib NEDO-2170s

ft-1b MEDO-21708

ft.lb MEDO-21708

$+t-16$ NEDO-21708

ft-lb WEDO-2170s

ft- Ib

A

Ft-lb NEDO-21708

ft-lb MEDO-21708

ft-lb MEDO-21708

ft-lb NEDO-21700

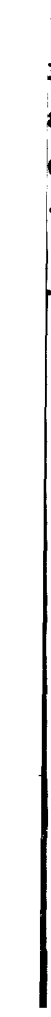

$\begin{array}{rrrr}37 & 62 & 53 & 139 \\ 29 & 46 & 41 & 162 \\ 11 & 20 & 16 & 169 \\ -3 & 8 & 2 & 189 \\ 39 & 50 & 46 & 153 \\ & & & 186\end{array}$

ASTM STP T2S/20

ASTK STP T25/20

ASTM STP T25/20

ASTM STP $725 / 20$

ASTM STP 725/20

ASTM STP $725 / 20$

ASTM STP $725 / 20$

ASTM STP T25/20

ASTM STP 72S/20

ASTM STP T2S/20

2; $3 ; 4 ; 17$

2; $3 ; 4 ; 17$

2; 3; $4: 17$

2; $3 ; 4 ; 17$

2; 3; 6; 17

2; 3; $4 ; 17$

2. 3: $4: 17$

2; 3; $6 ; 17$

2: 3: 4: 17

2: 3: $4: 17$

2; 3; $4: 17$

2; 3; 4; 4 : 17

; $3 ; 4 ; 17$

2; $3 ; 4 ; 17$

$6 \cdot 11$

$4-11$

$4-11$
6.10

$6 \cdot 10$
$6 \cdot 10$

$6-10$
$4-10$

$4-10$
$6-11$

$6-11$

$6 \cdot 11$

$4 \cdot 10$

$4-11$

$4 \cdot 11$

$6-11$
$4-10$

$4-10$

$4 \cdot 10$

$4 \cdot 10$

$6+11$

$6-11$
$4-10$

$6-10$
$6-11$

$6-11$
$4 \cdot 11$

$4-11$

6. 10

$4-10$

$6-10$

$4 \cdot 10$

$4-11$

$6-11$

6-10 28

22; 28

22: 28

22; 32

22; 20

22; 32

22; 28

22; 32

192

153
186

ASTM STP T2S/20

22; 32 
Table 21 Partial listing $\mathrm{C}$

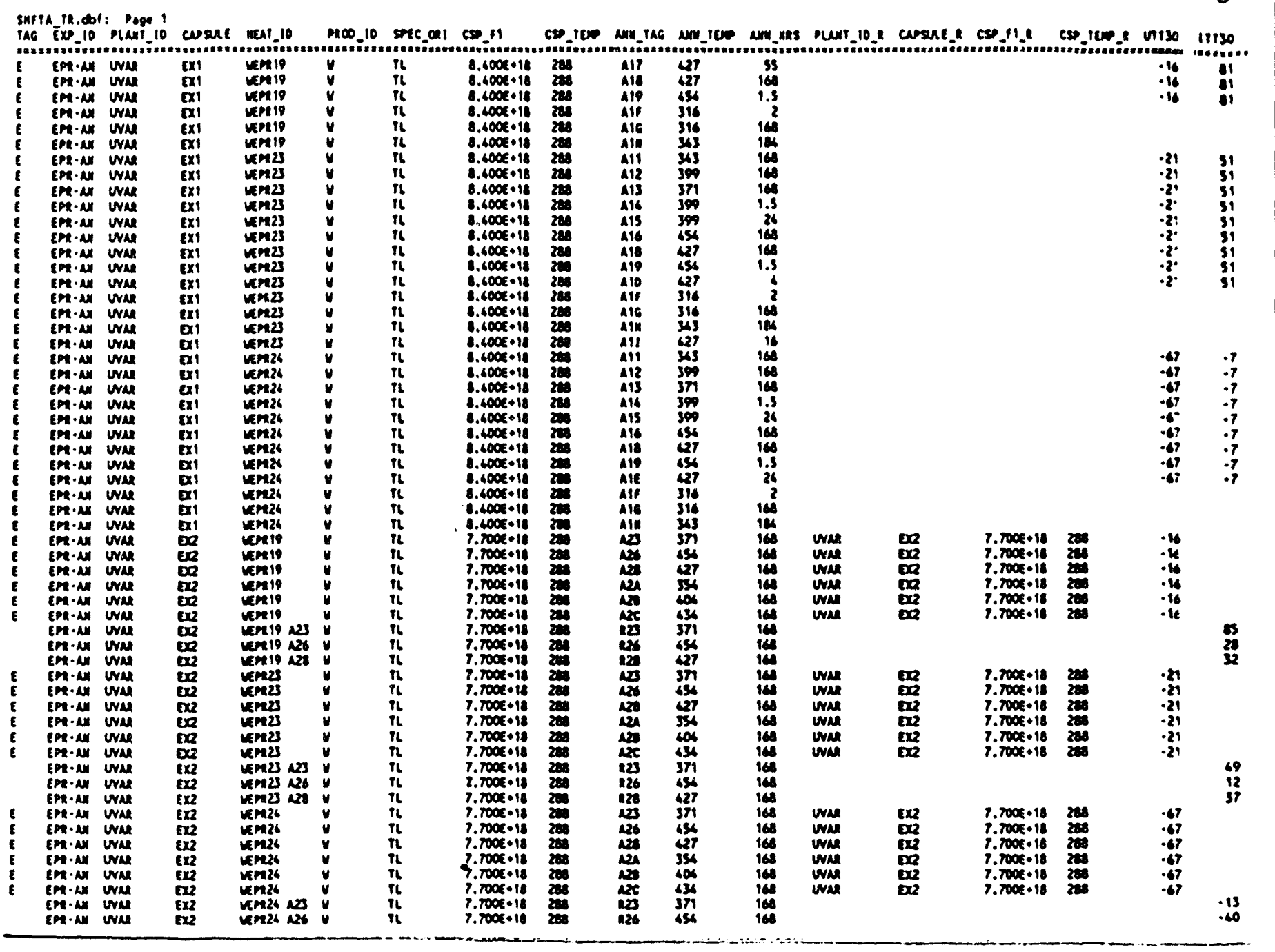


tial listing of SHFTA_TR.dbf

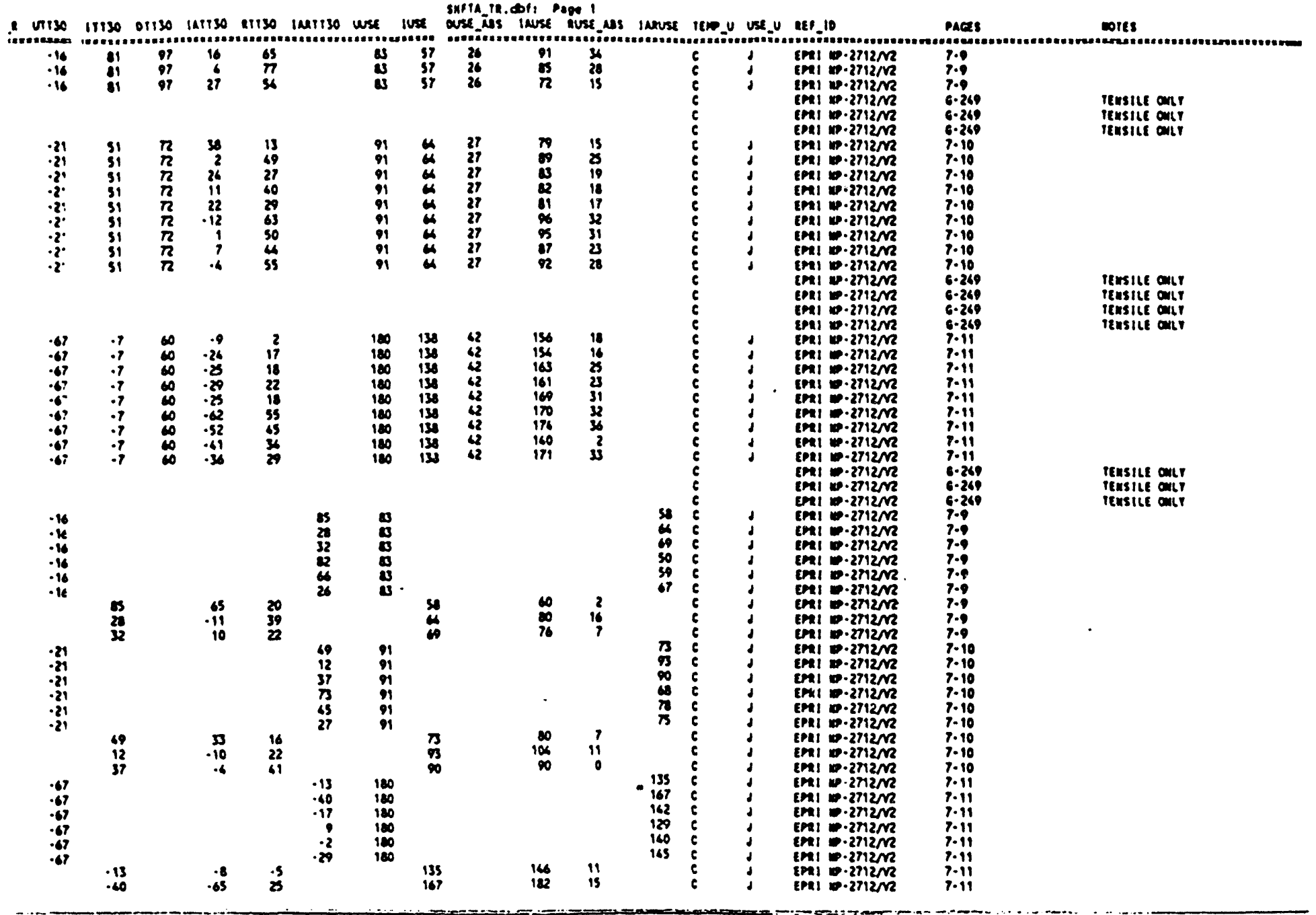


Table 22 Partial listing

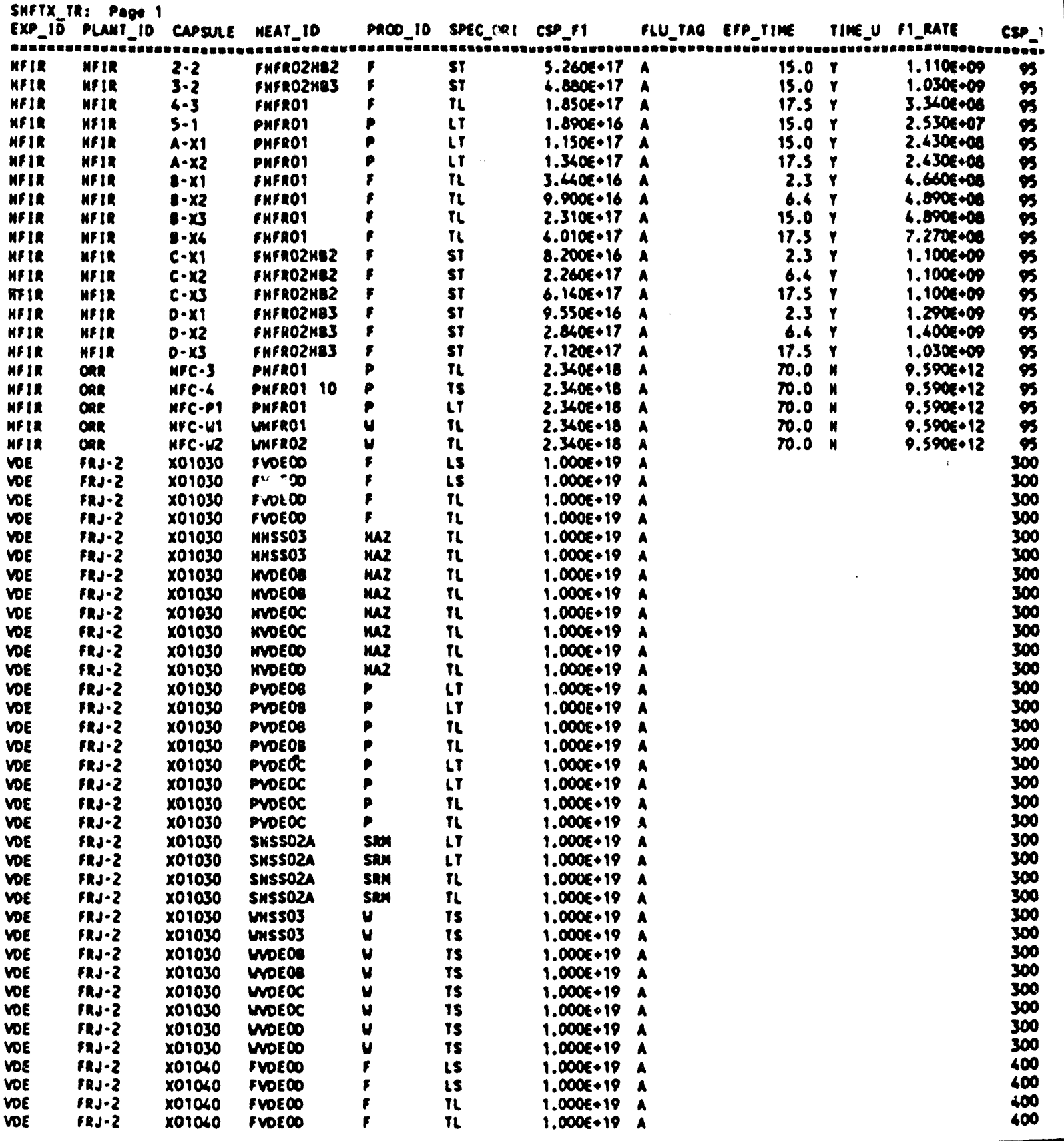


al listing of SHFTX_TR.dbf

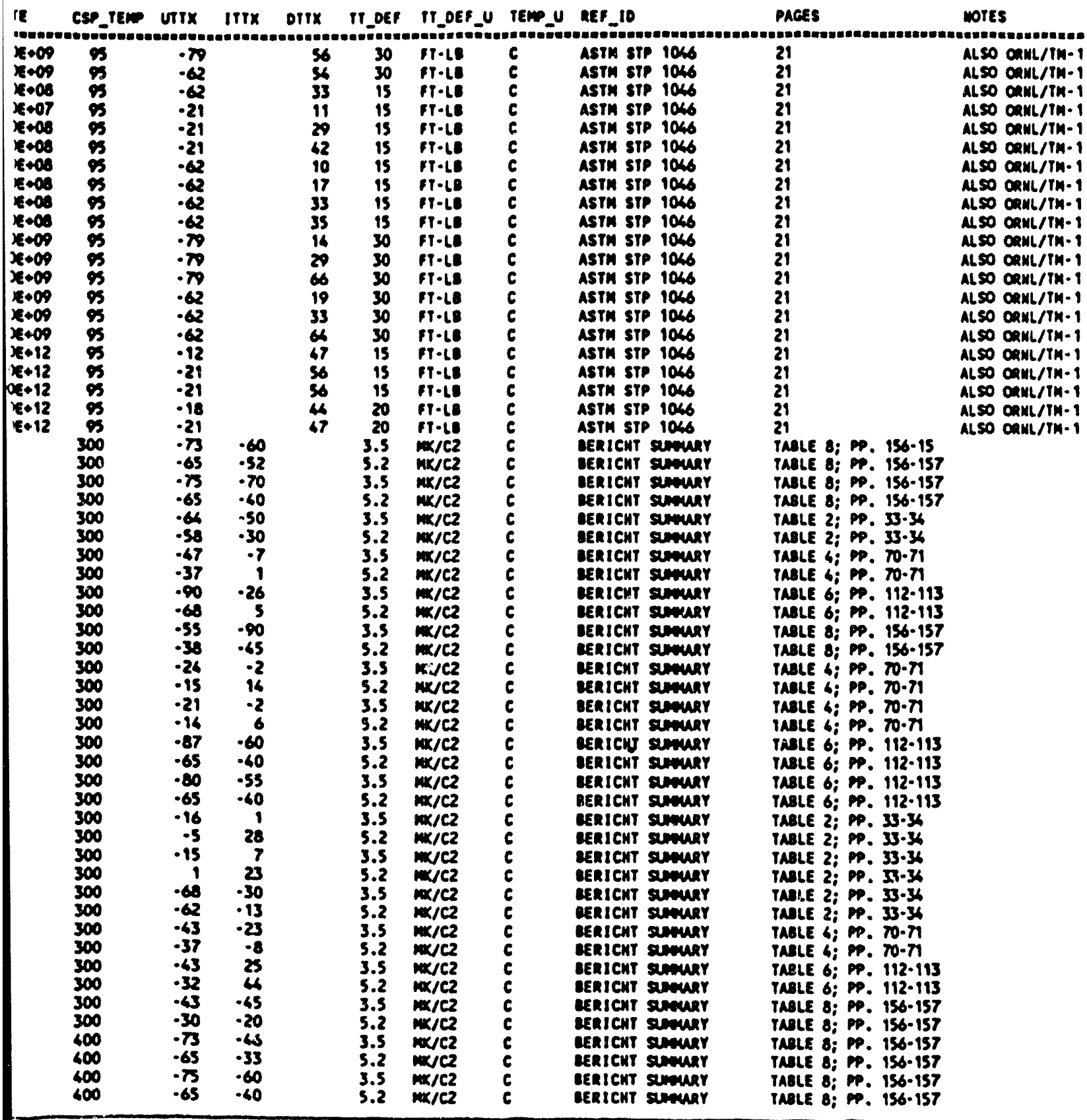


Table 23 Partial listing of RAW_C

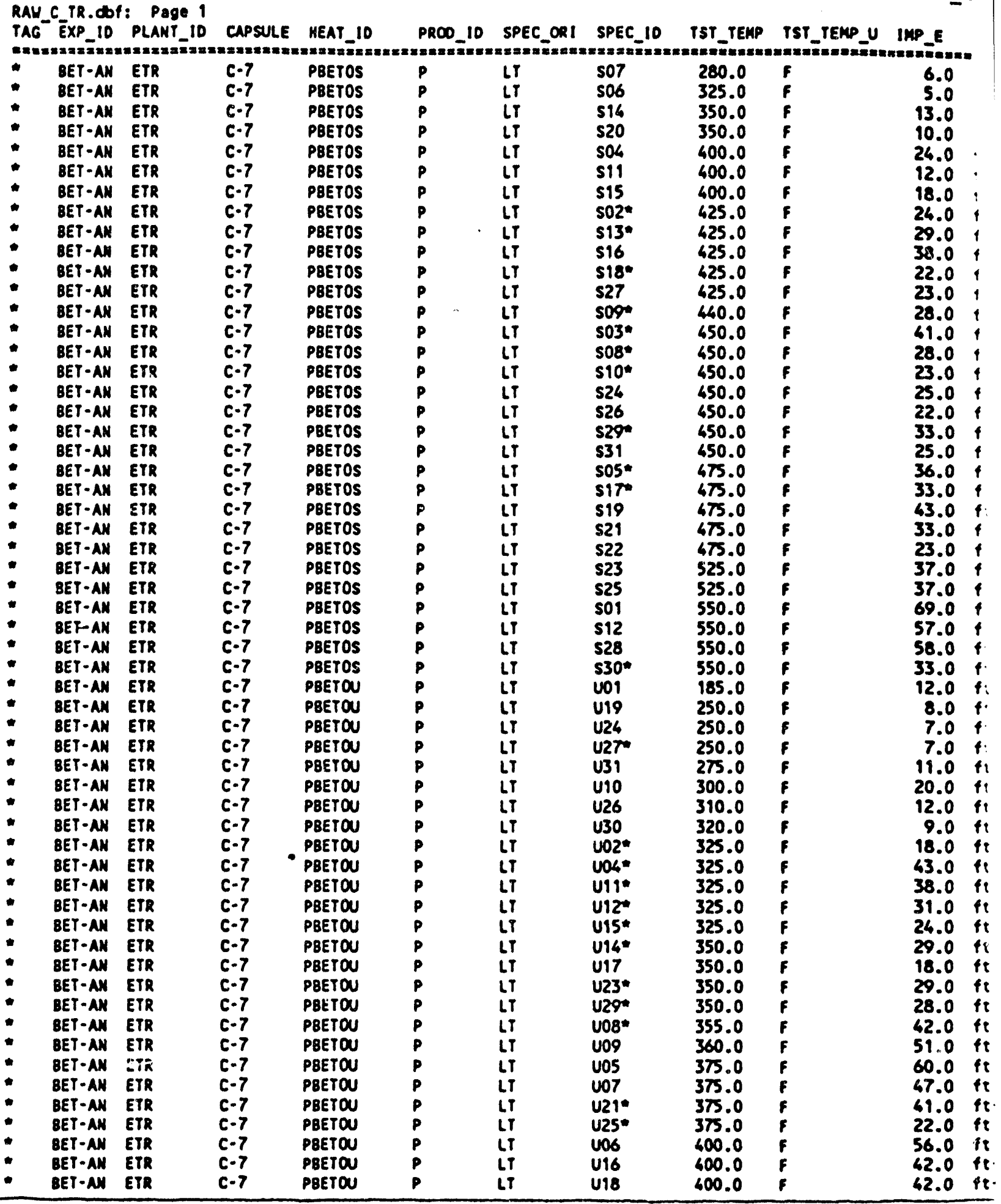


sle 23 Partial listing of RAW_C_TR.dbf ) TST_TEMP TST_TEMP_U IMP_E IMP_E_U FRACT_APP LAT_EXP LAT_EXP_U CSP_FI CSP_TEMP CSP_TEMP_U

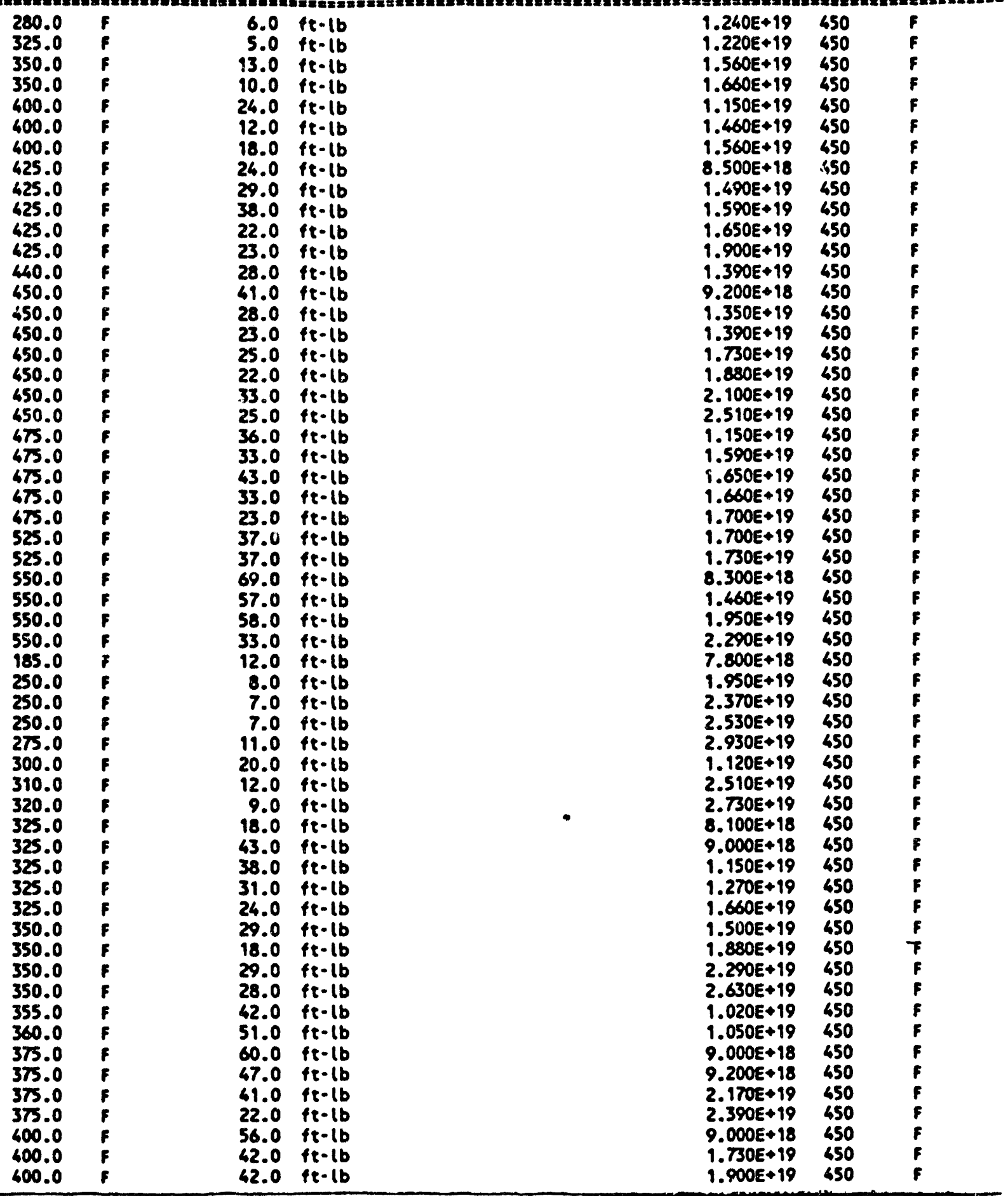


Table 24 Partial listing of CV_RF_TR.dbf

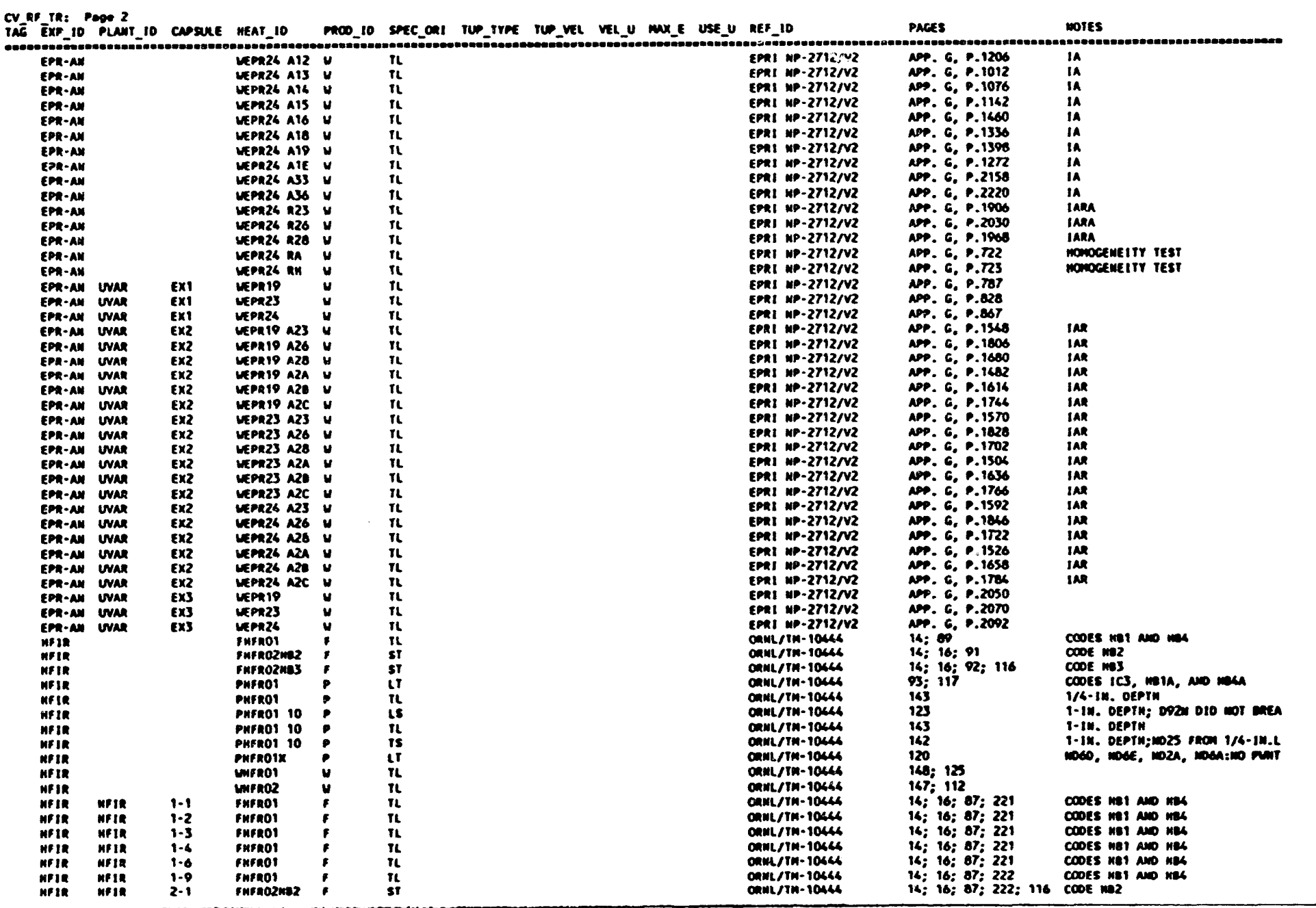


Table 25 Partial listing of TEN_TR.d

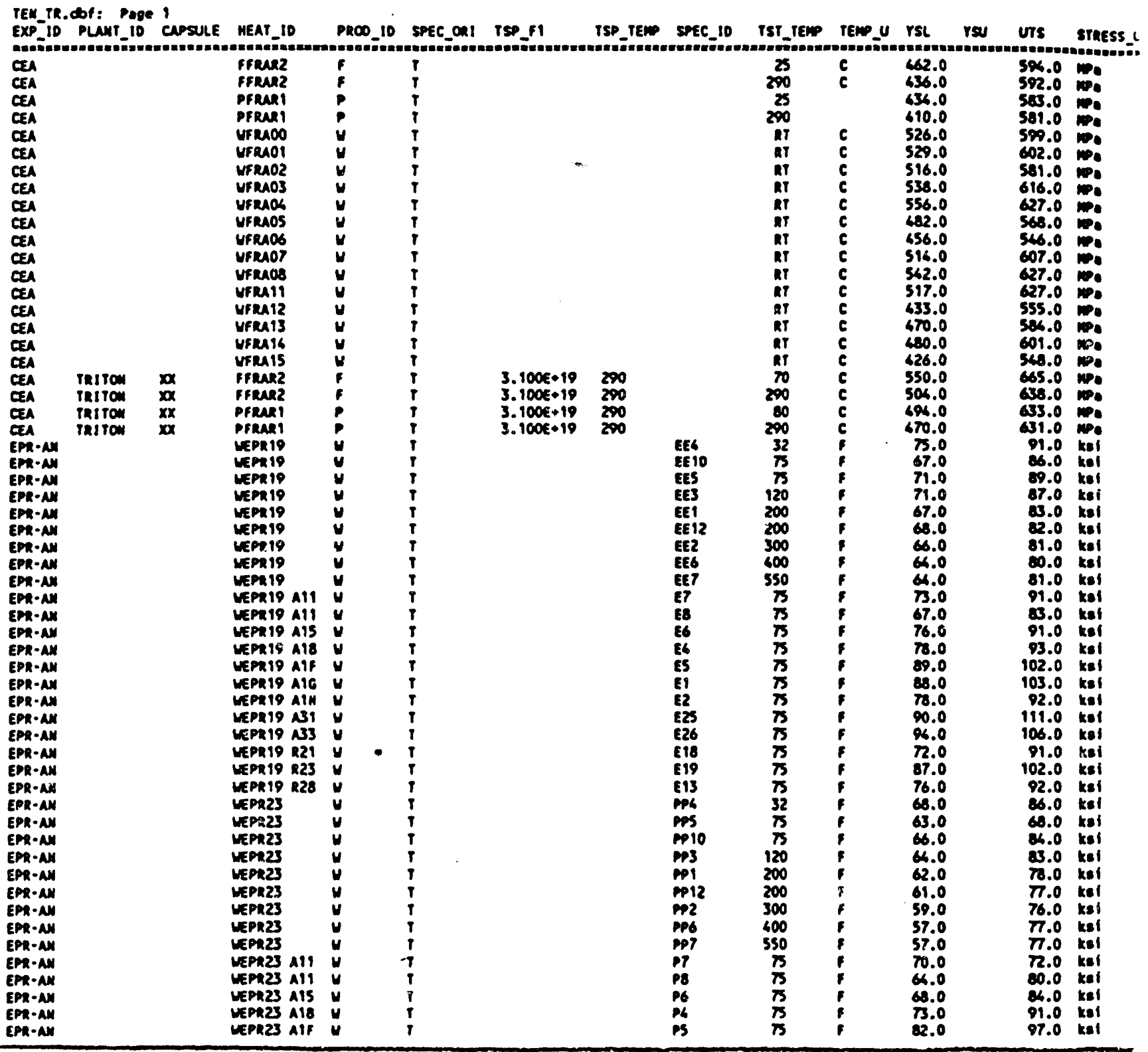


Partial listing of TEN_TR.dbf

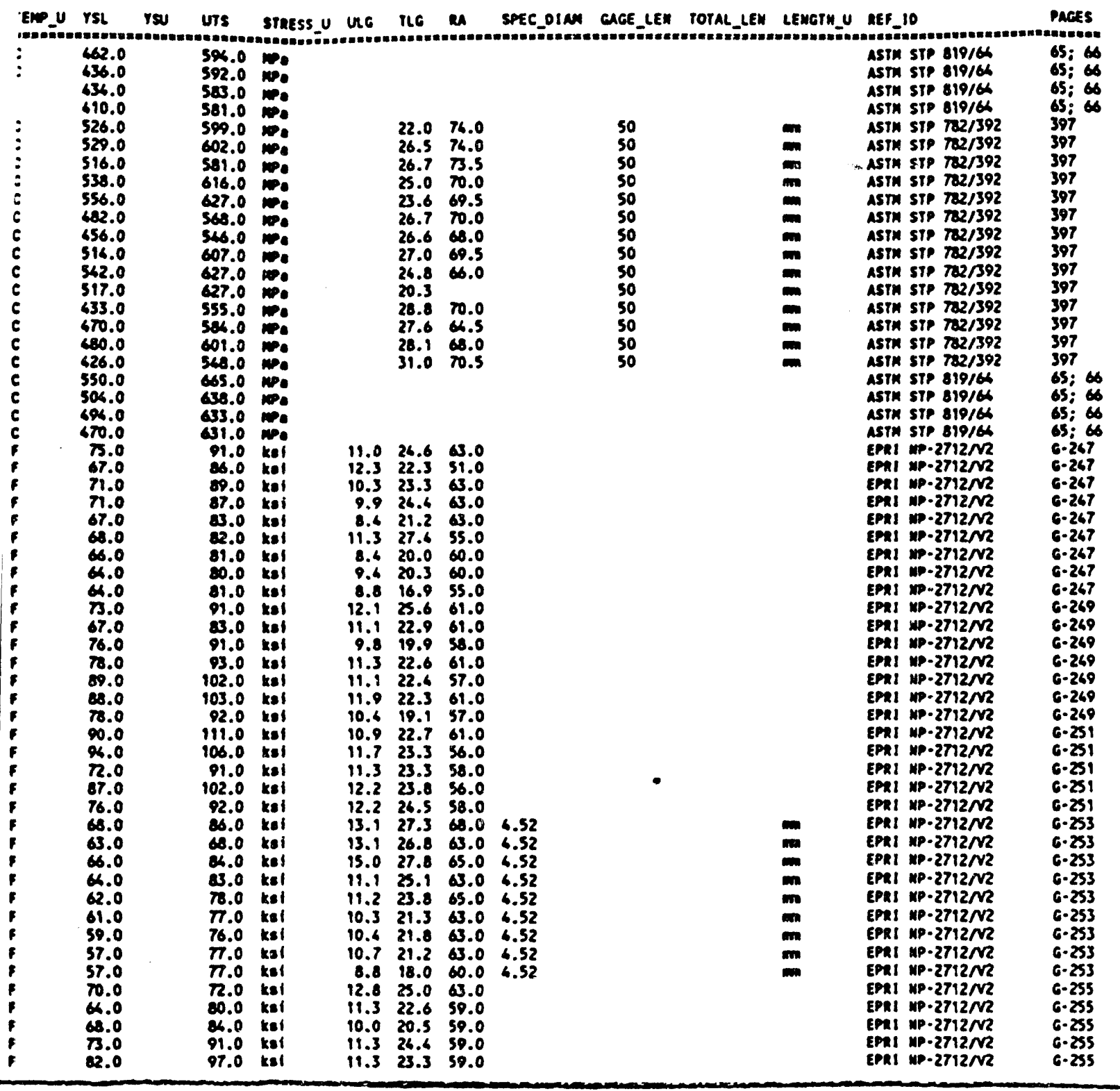


Table 26 Listing of R_LST_TR.dbf

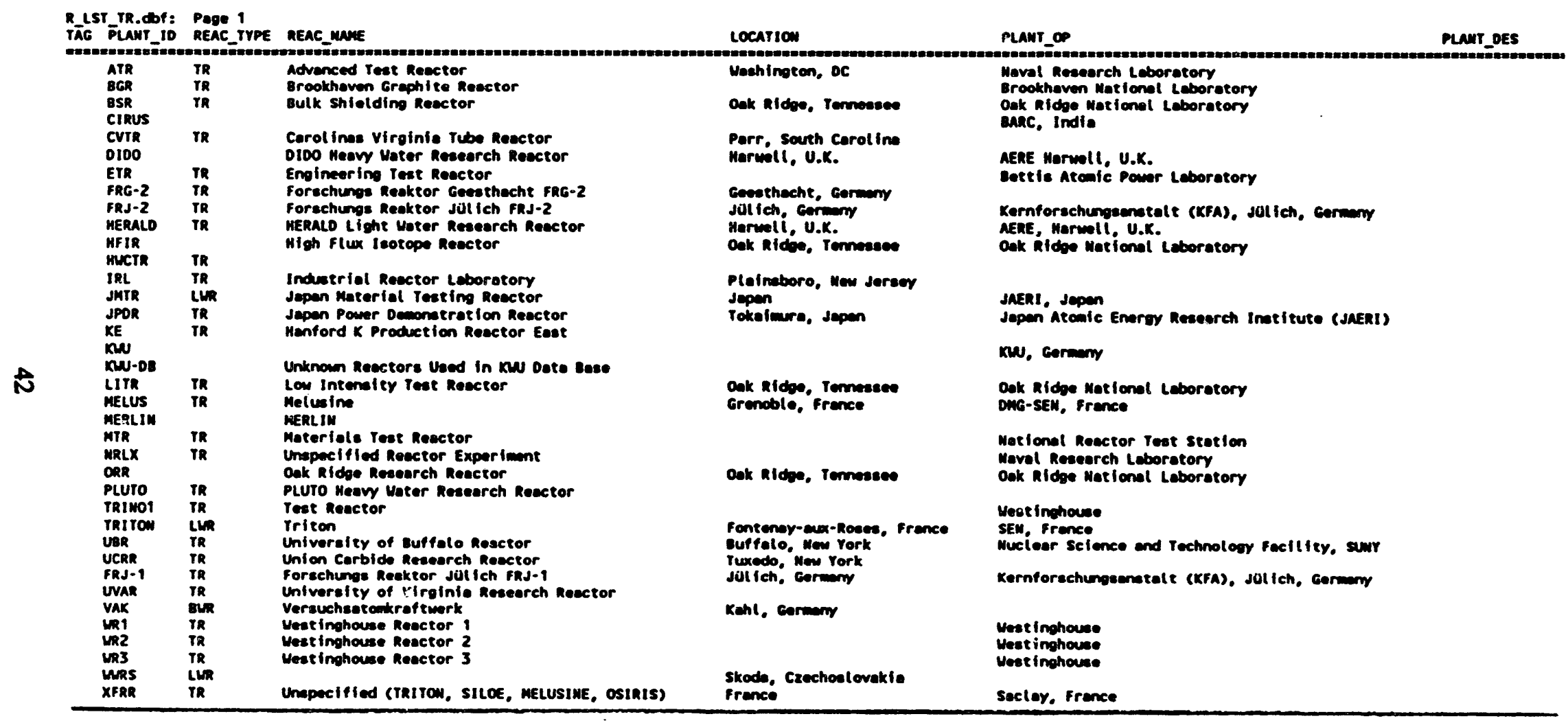


Table 27 Partial listir

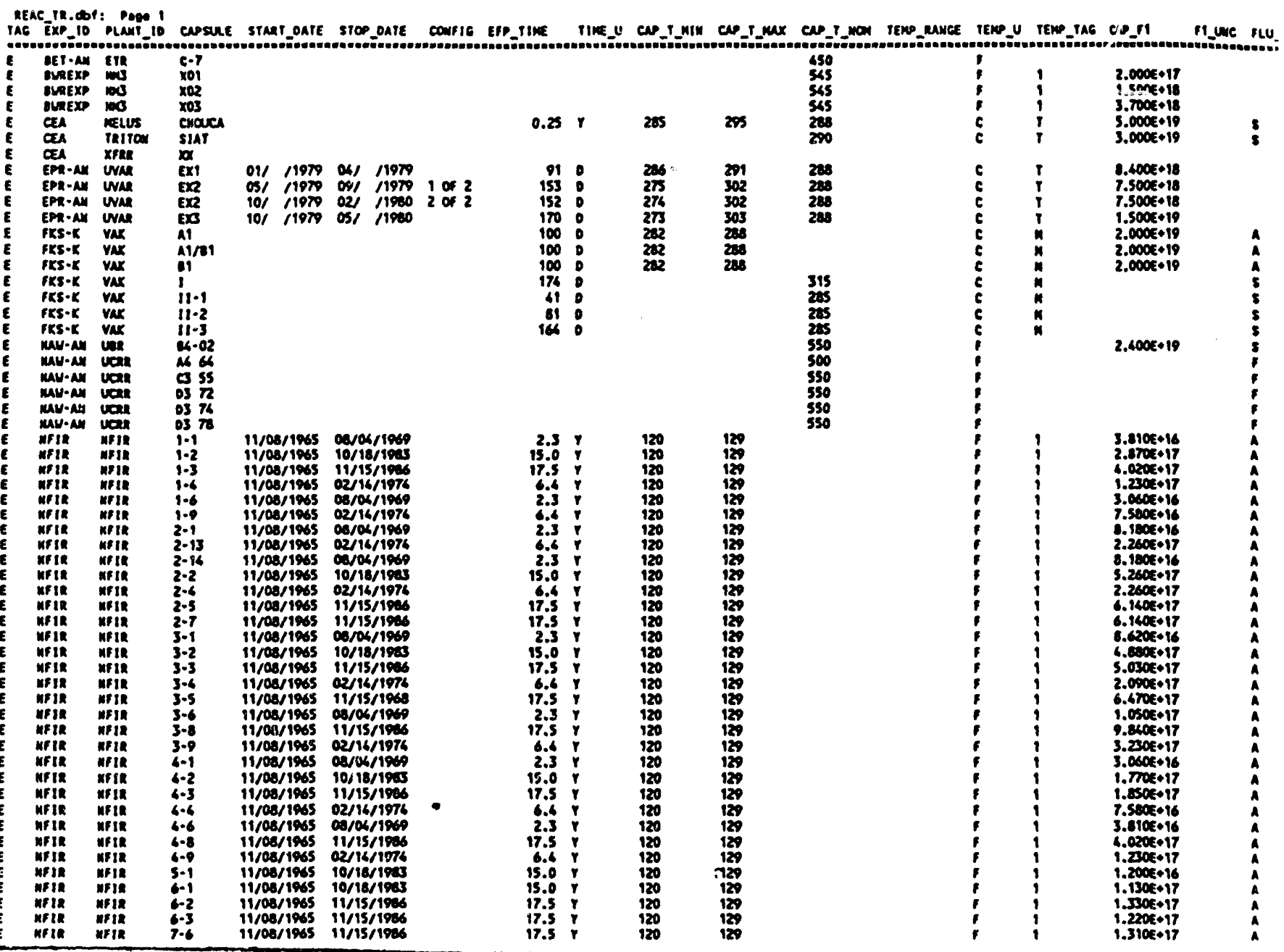


iting of REAC_TR.dbf

\begin{tabular}{|c|c|c|c|c|}
\hline MU_IAc & nere & CN_EDI & 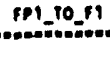 & 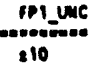 \\
\hline : & $7.000 E+12$ & & 2.03 & \\
\hline
\end{tabular}

nenc_ll.cor: page 1

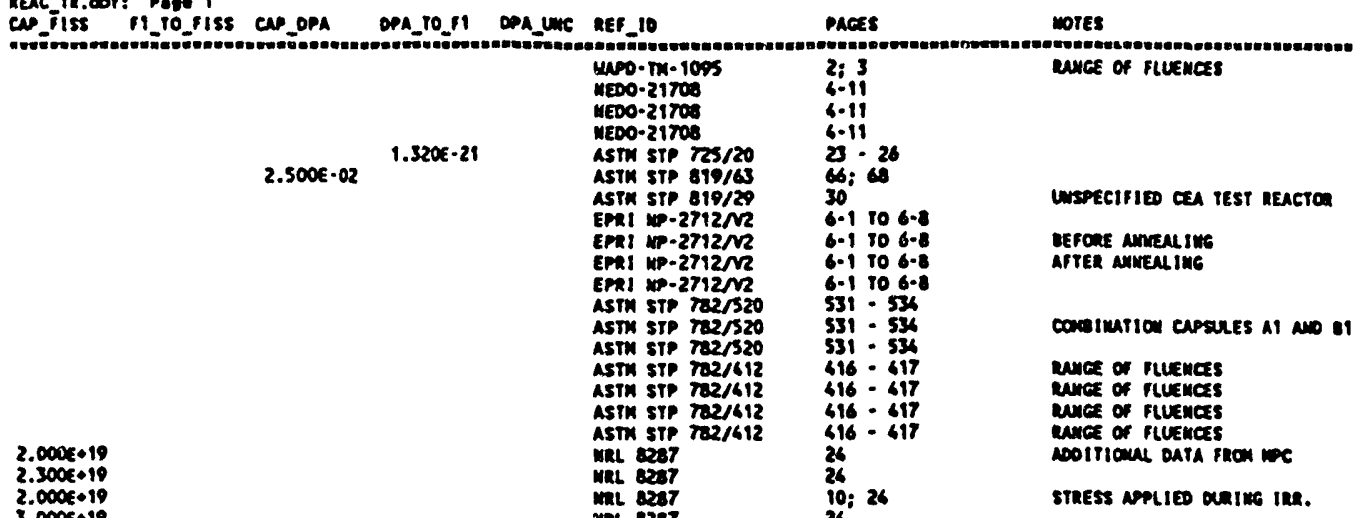

$2.200 E+12$
$2.200 E+12$

$7.100 \times \cdot 19$

2. $700 \mathrm{0}+19$

10; 26

mint 2287

mat 2087

MiRt 6257

Oant/rn-1064s

cant/rk- 1044

cant/7m-10ses

crit/min- ickes

comenu-10ess

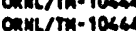

conthrn-1064

contrin-10ses

CRIVIM- Tow

comintion-104

cantm- ioses

cantrm- roes

convrm-1044

canc/m- 10ess

canc/Tw- 10est

onw/rn-1044

conchrm- ions

comitru-100es

CanL/TK-1064

onntmin- 1064

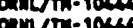

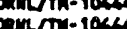

cann-rin-1006s

onutrm-tows

cher Th- 1064

anic $\pi x-1004$

ORWLTN-1004

26

15; 15: 09; 201

14; 15; 90; 221

14; 15;

16; 15; :; 221

16; 15; $99 ;$

14: 15: $91: 22$

16: 15: 91; 222

14; 15; 91; 22

14: 15; 91; 22

14; 15: 91; 202

16; 15; $91 ;$ :22

16; 15: 91; 222

14; 15; 92; 223

14; 15; 92; 220

16: 15; 02: 223

14; 15; 92; 226

16: 15: v2; 226

14: 15; 92; 226

16: 15; 92; 226

14; 15: 0 ; 226

16: 15; $10 ; 226$

16: 15;

16: 15; $89 ; 25$

16; 15; $90 ; 235$

14: 15; 93; 226

16; 15; 95; 226

16: 15; 95; 227

16; 15; 93; 227
Opa finch astm sip 1066, P.21 Dep from AST STP lase: ? opa From ASTM STP 1046. OPA FRON ASTI STP 1066. P. OPA FIEN ASTM STP 1046. P.2 DPA FINOA ASTM STP 1066, P.21

opa rnon astm stp lous, P.21

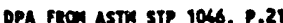

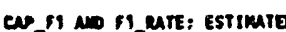


Table 28 Listing of H_LST_TR.dbf

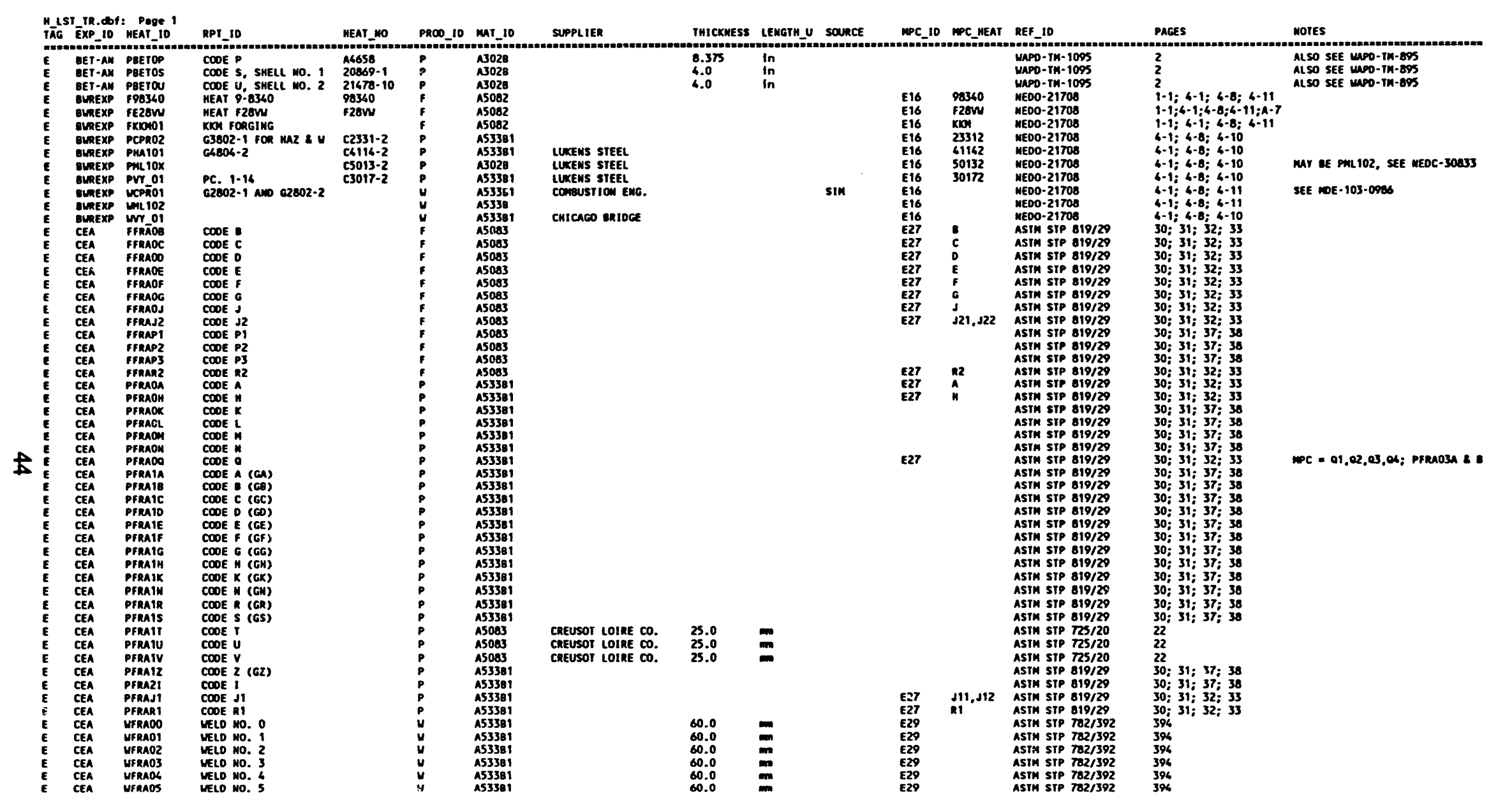


Table 28 (continued)

\begin{tabular}{|c|c|c|c|c|c|c|c|c|c|c|c|c|c|}
\hline 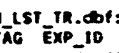 & 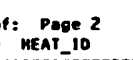 & APP_10 & MEAT_mo & PROD_10 & $M I_{-} 10$ & SUPpLIEn & inickntess & Lenerm_u & sounce & mPC_10 mPC_MEAT & REF 10 & PACES & mores \\
\hline 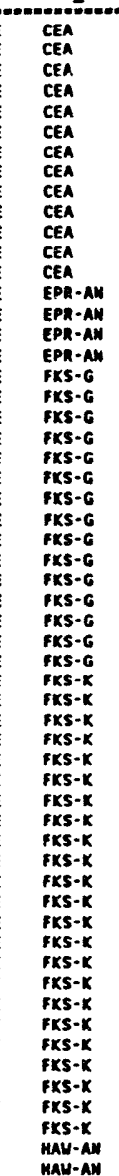 & 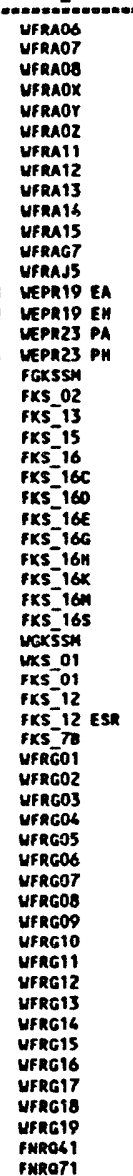 & 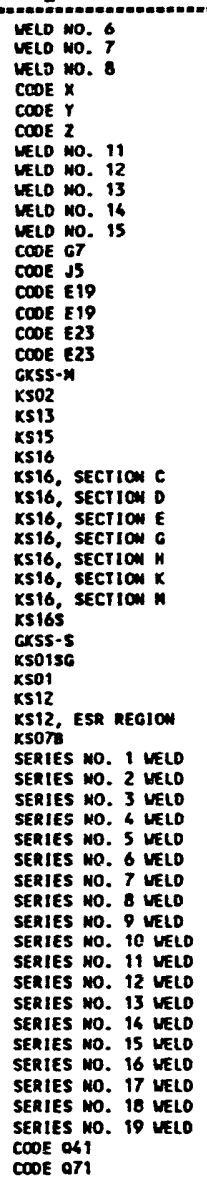 & & & 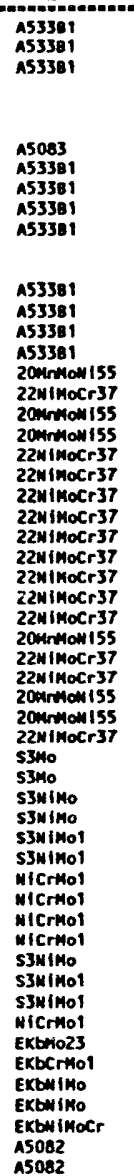 & 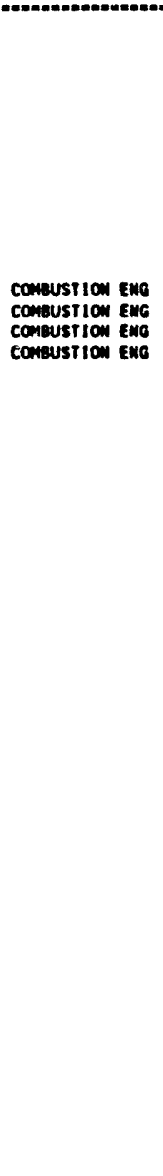 & $\begin{array}{l}60.0 \\
60.0 \\
60.0 \\
60.0 \\
\\
220.0 \\
55.0 \\
85.0 \\
85.0 \\
85.0 \\
85.0 \\
\\
8.75 \\
0.75 \\
9.75 \\
9.75\end{array}$ & $\begin{array}{l}= \\
= \\
= \\
= \\
\text { in } \\
\text { in } \\
\text { in }\end{array}$ & 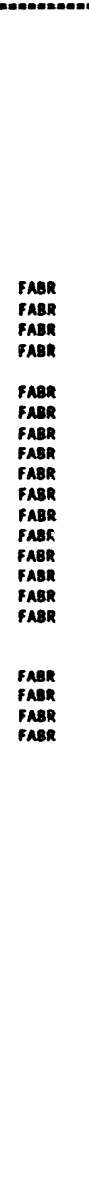 & 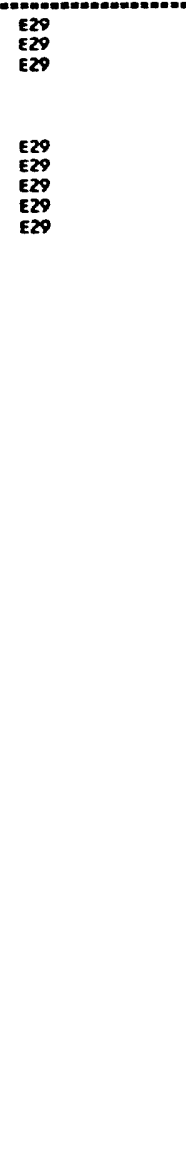 & 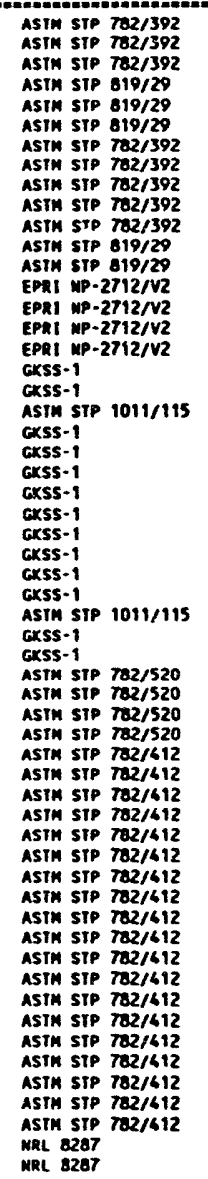 & 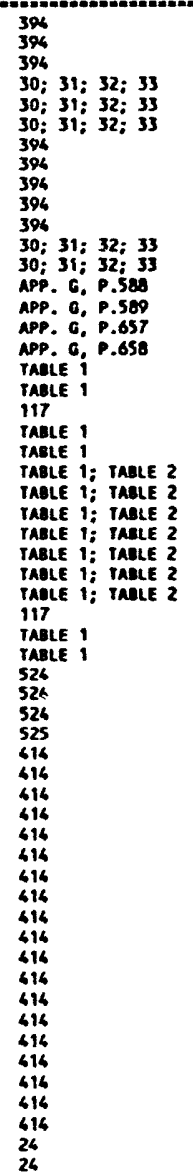 & 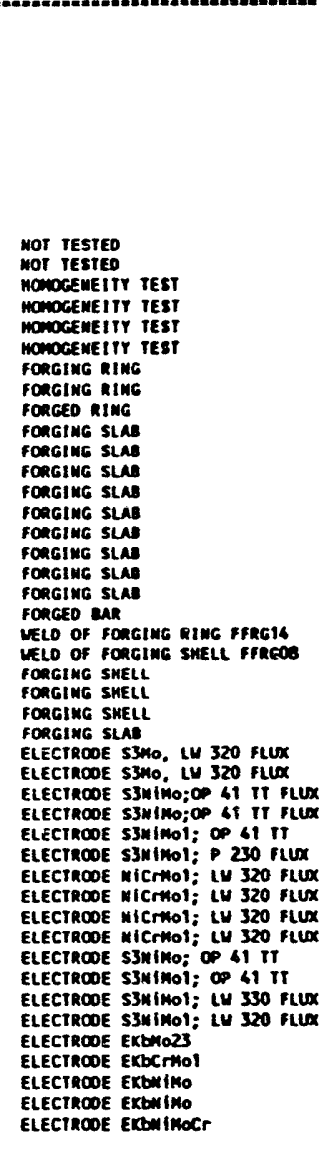 \\
\hline
\end{tabular}


Table 28 (continued)

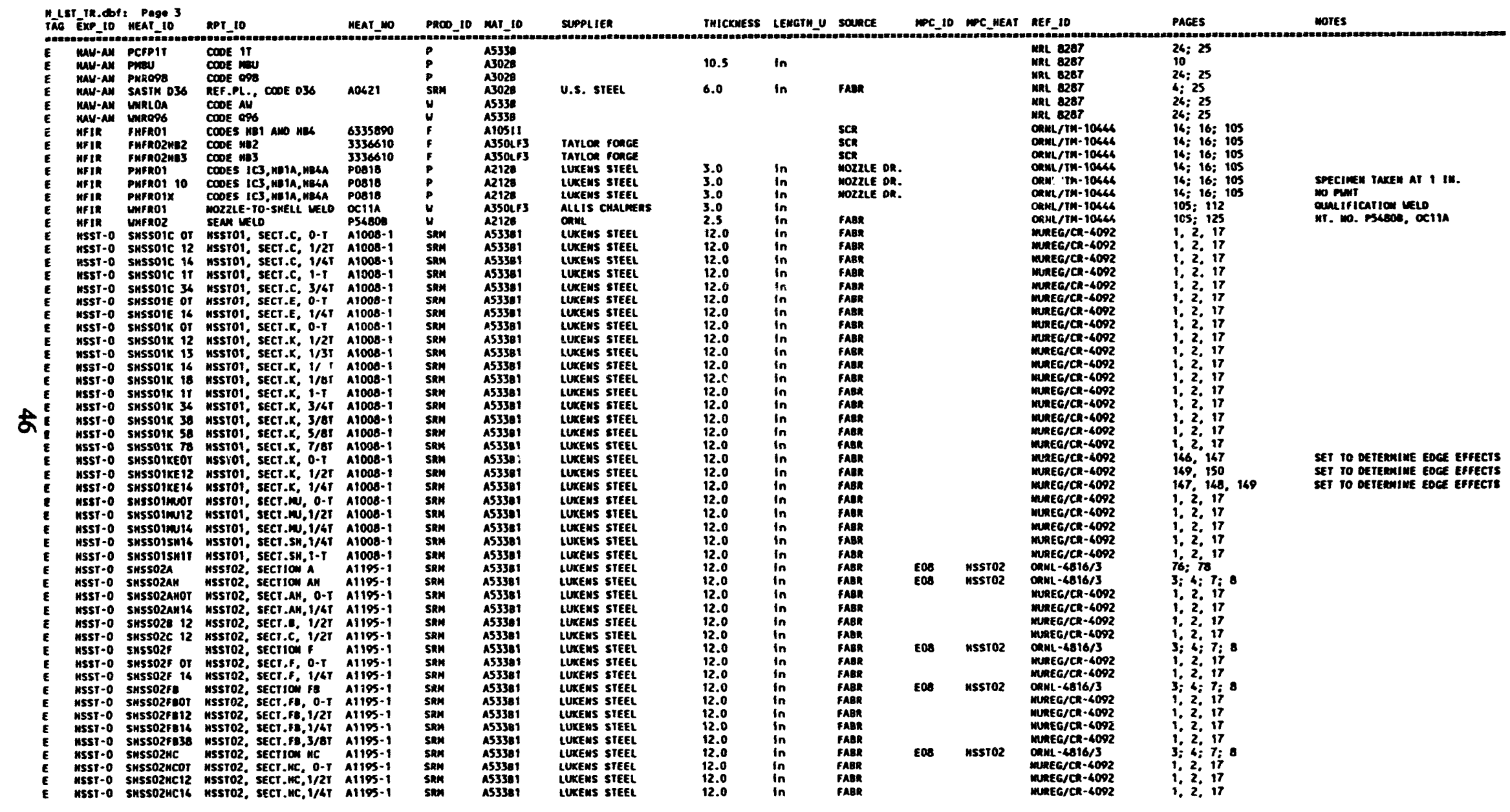


Table 28 (continued)

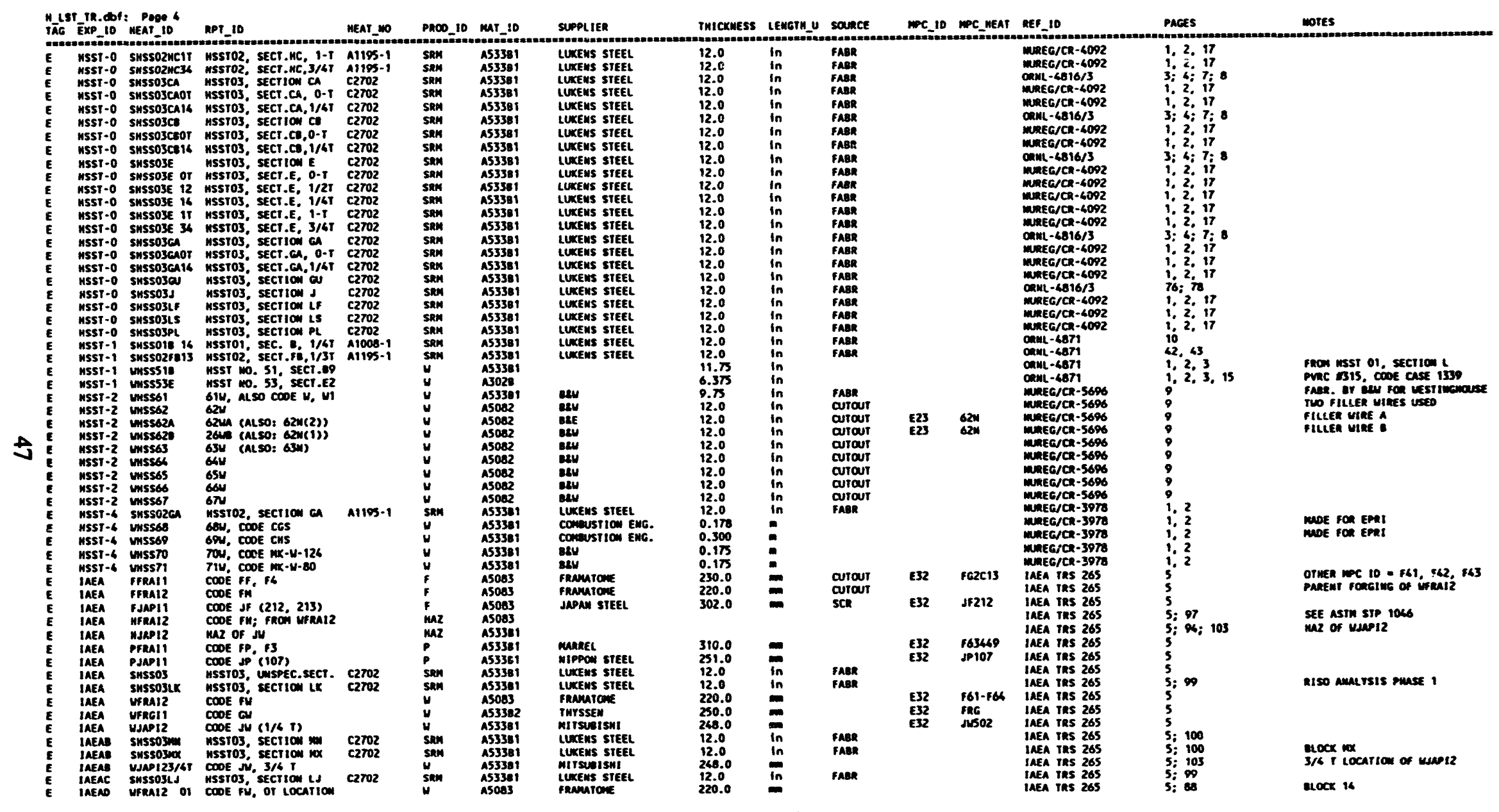


Table 28 (continued)

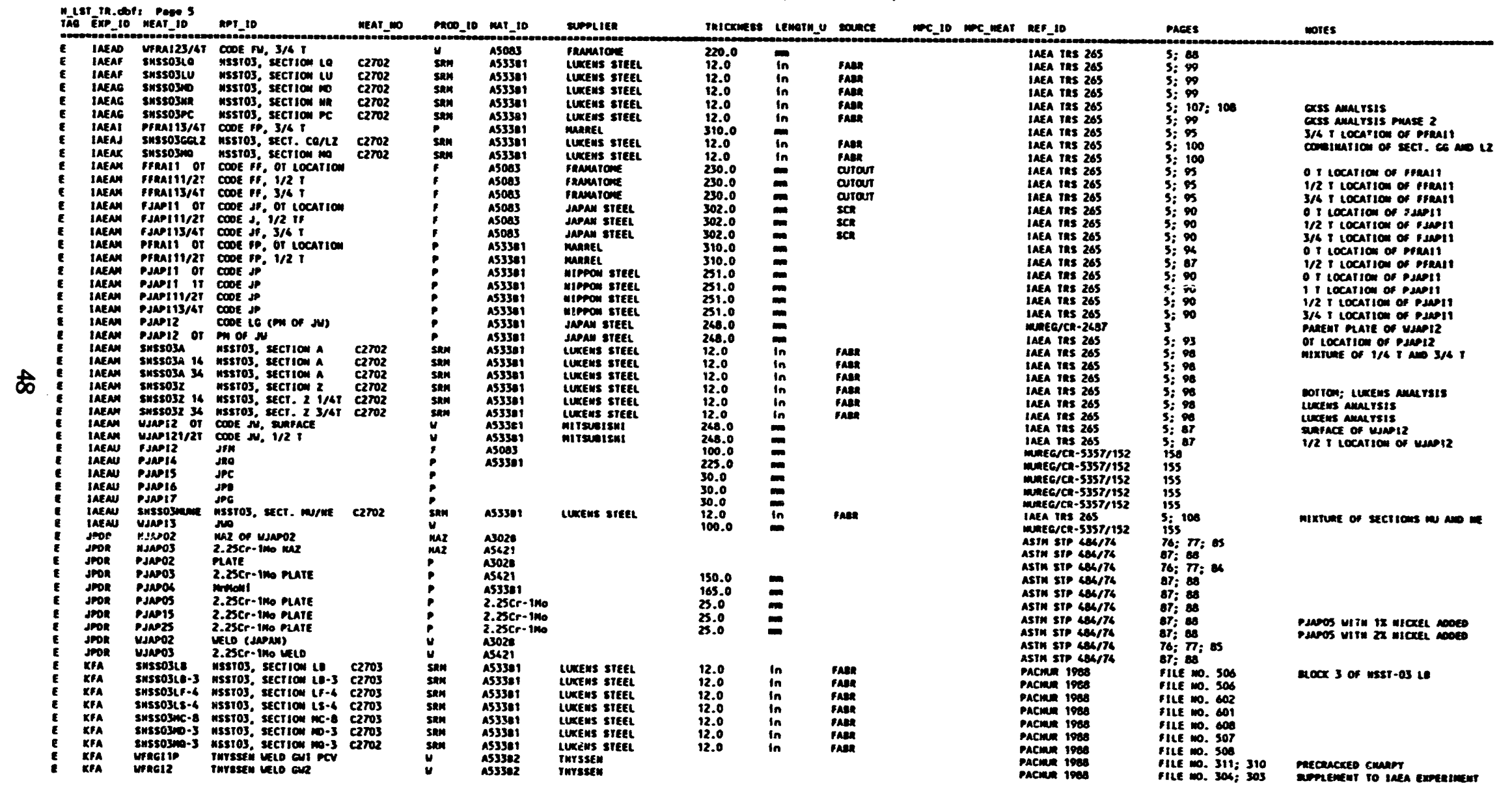


Table 28 (continued)

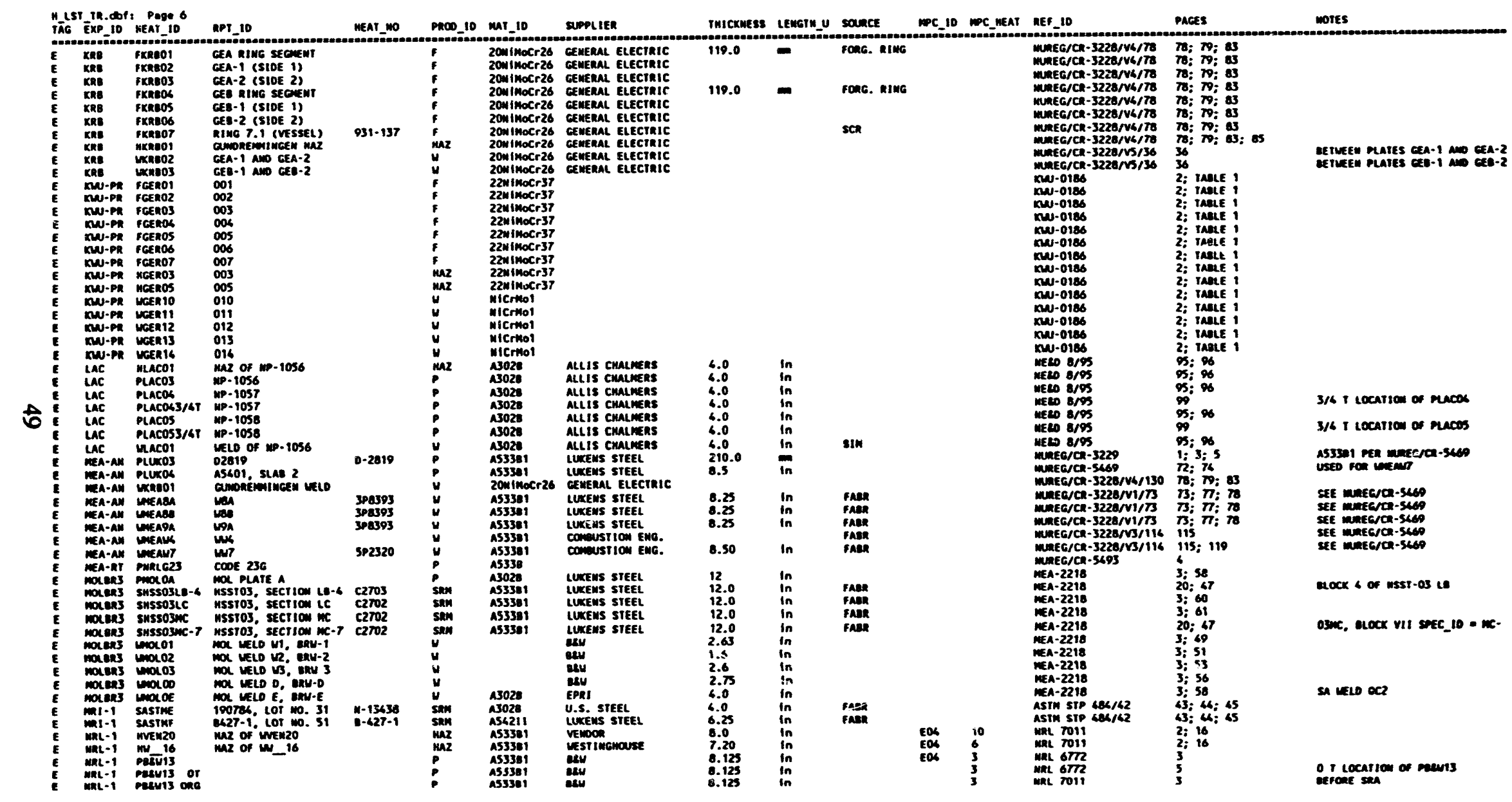


Table 28 (continued)

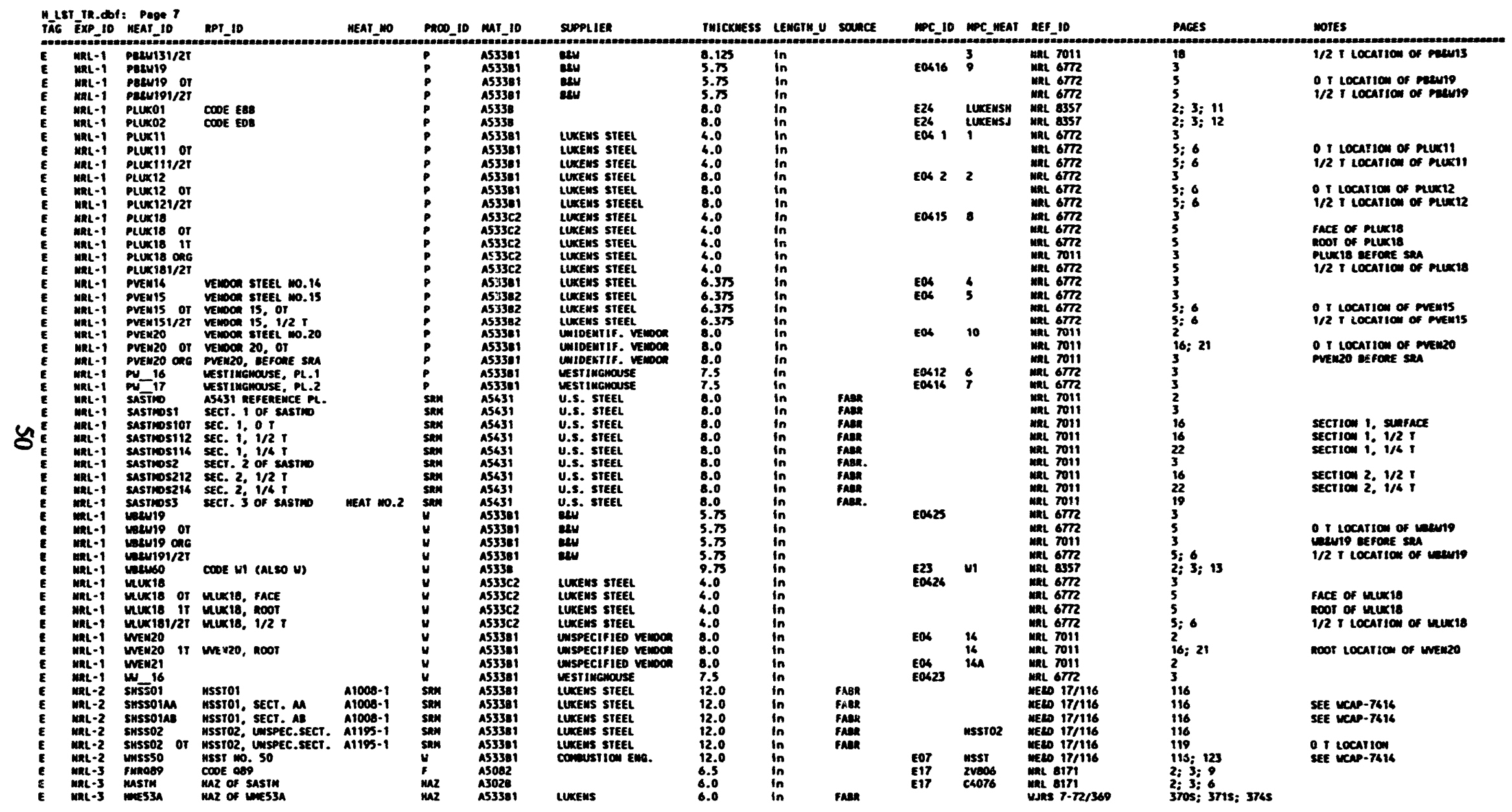


Table 28 (continued)

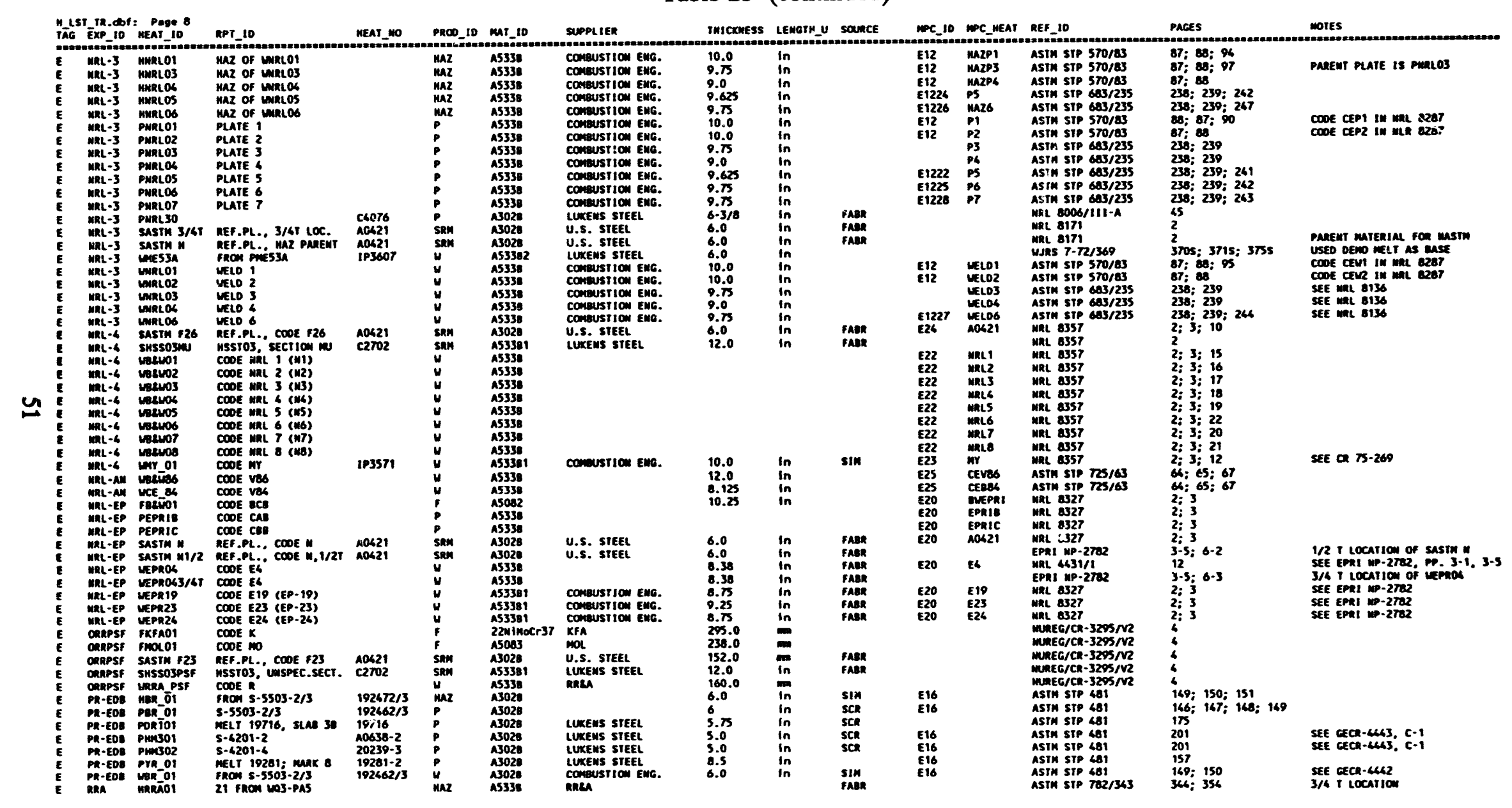


Table 28 (continued)

\begin{tabular}{|c|c|c|c|c|c|c|c|c|c|c|c|c|c|c|}
\hline 27. & A: Peape? & MPT_10 & HEAT_WO & $P R 00$ _10 & Mur_lo & SPPPLLER & ruickness & Lencru_u & sounce & mp_10 & MPC \#EAT & REE_10 & Paces & mores \\
\hline 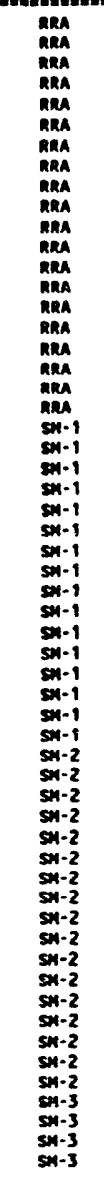 & 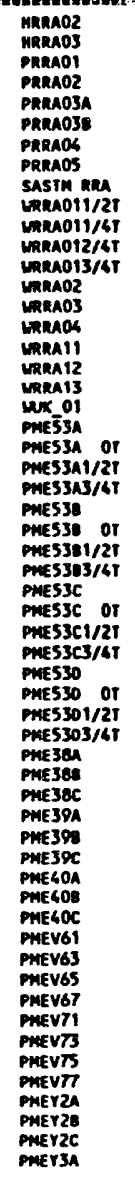 & 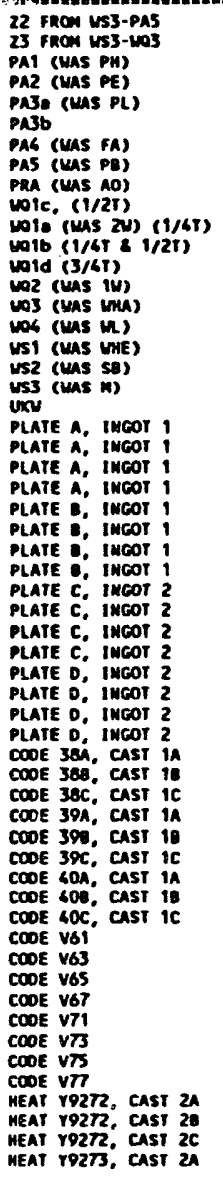 & 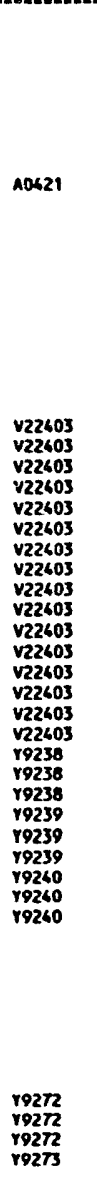 & & 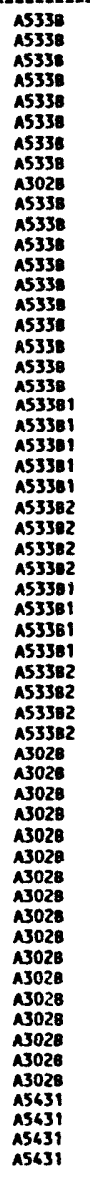 & 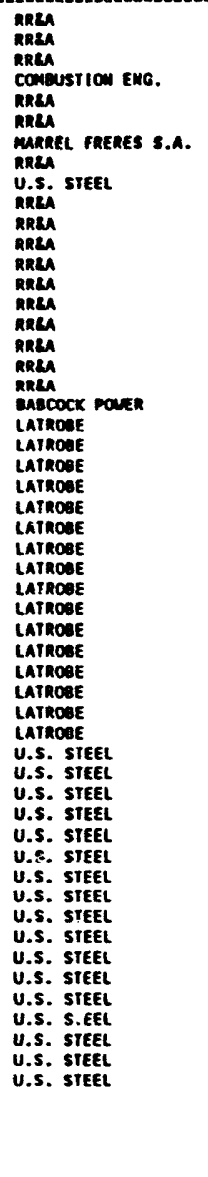 & $\begin{array}{l}150.0 \\
150.0 \\
150.0 \\
150.0 \\
150.0 \\
150.0 \\
150.0 \\
150.0 \\
150.0 \\
150.0 \\
150.0 \\
150.0 \\
150.0 \\
150.0 \\
150.0 \\
150.0 \\
150.0 \\
150.0 \\
6.0 \\
6.0 \\
6.0 \\
6.0 \\
6.0 \\
6.0 \\
6.0 \\
6.0 \\
6.0 \\
6.0 \\
6.0 \\
6.0 \\
6.0 \\
6.0 \\
6.0 \\
6.0 \\
0.5 \\
0.5 \\
0.5 \\
0.5 \\
0.5 \\
0.5 \\
0.5 \\
0.5 \\
0.5 \\
0.5 \\
0.5 \\
12.0 \\
12.0 \\
12.0 \\
12.0 \\
12.0 \\
12.0 \\
12.0 \\
12.0 \\
0.5 \\
0.5 \\
0.5 \\
0.5\end{array}$ & 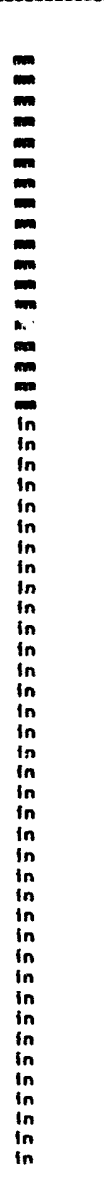 & 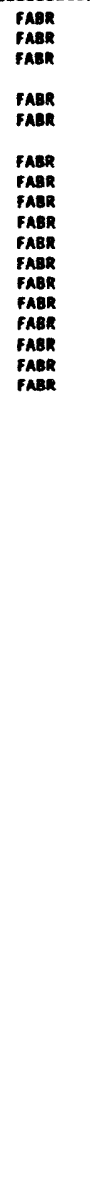 & 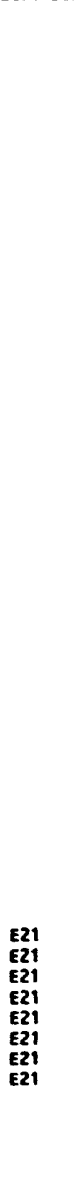 & 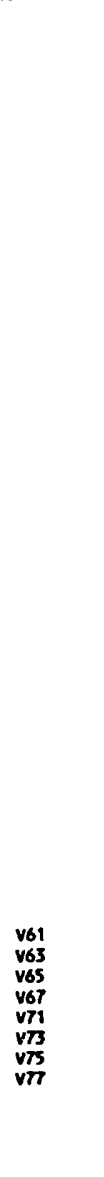 & 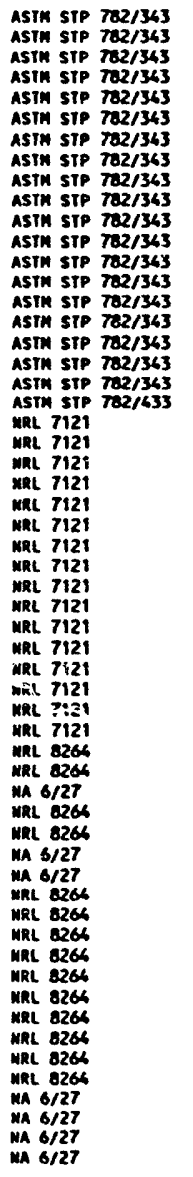 & 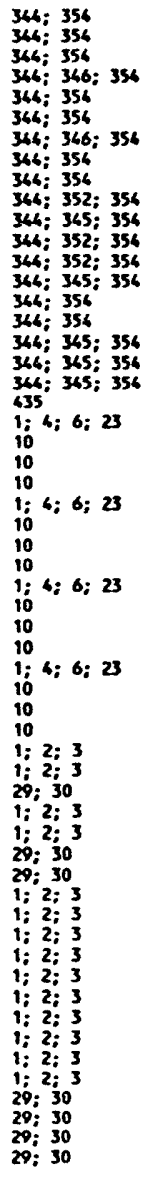 & 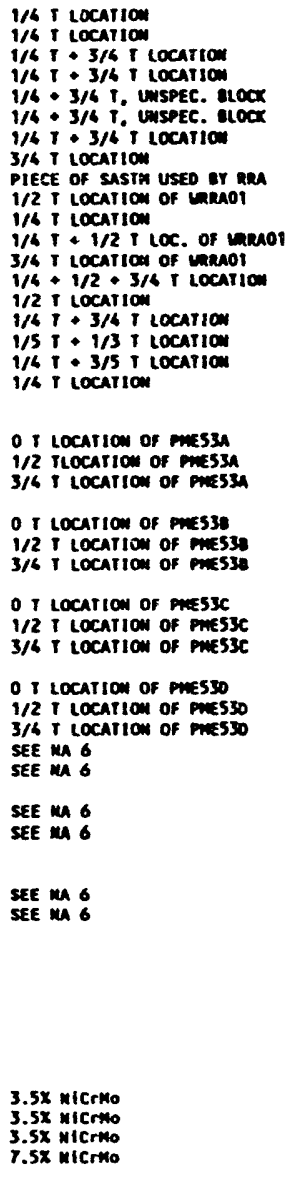 \\
\hline
\end{tabular}


Table 28 (continued)

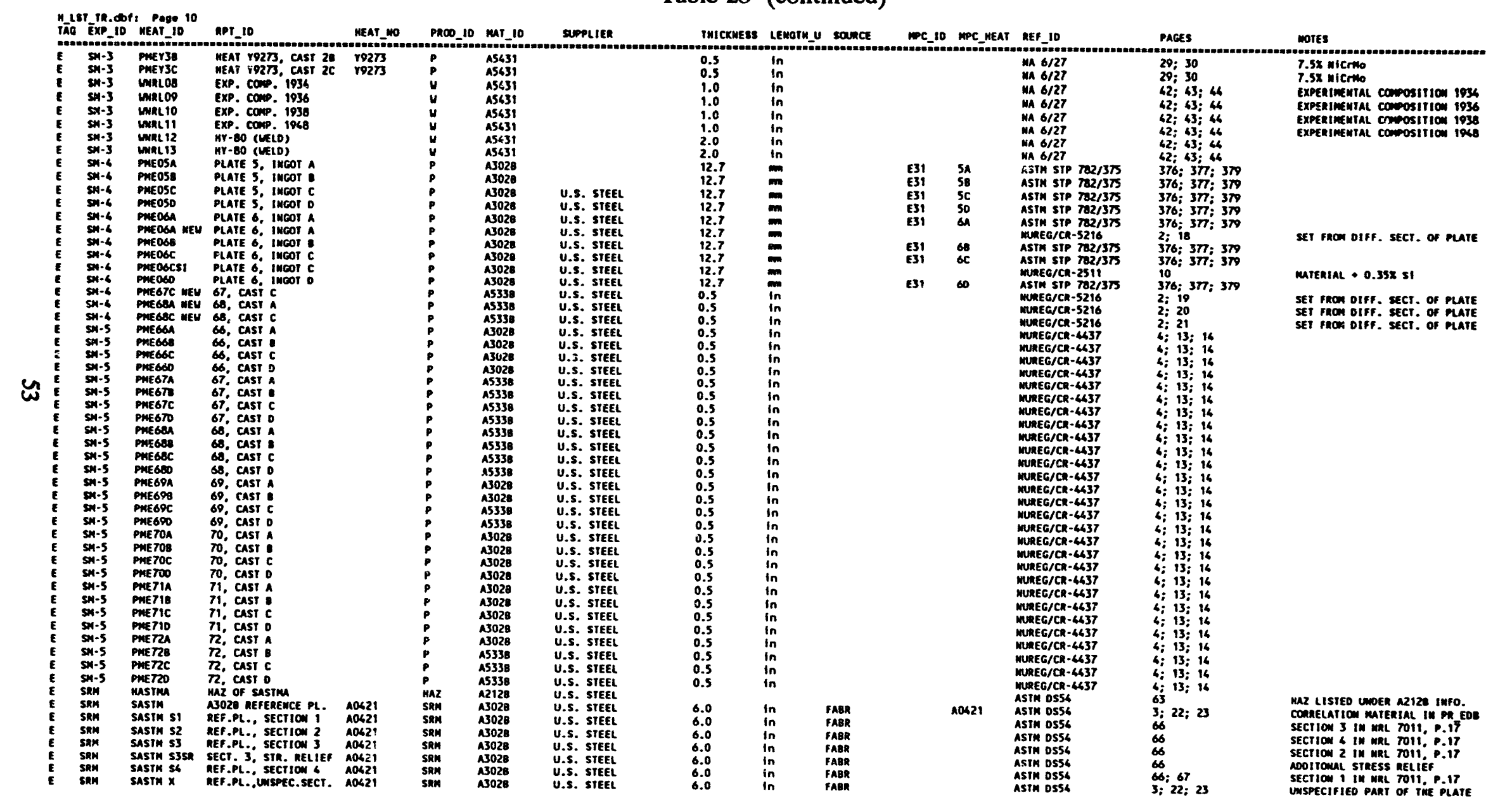


Table 28 (continued)

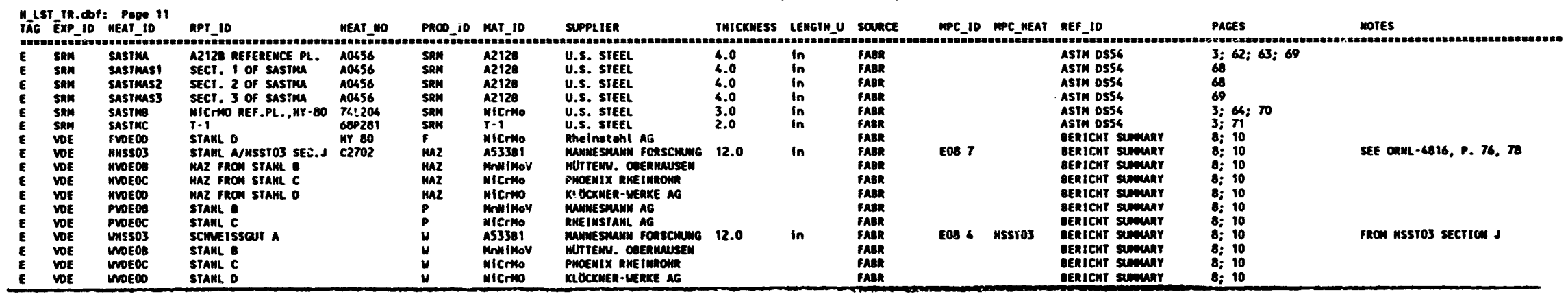




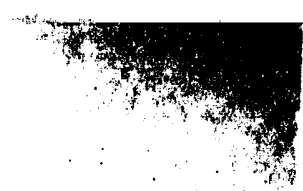

Table 29 Partial listin

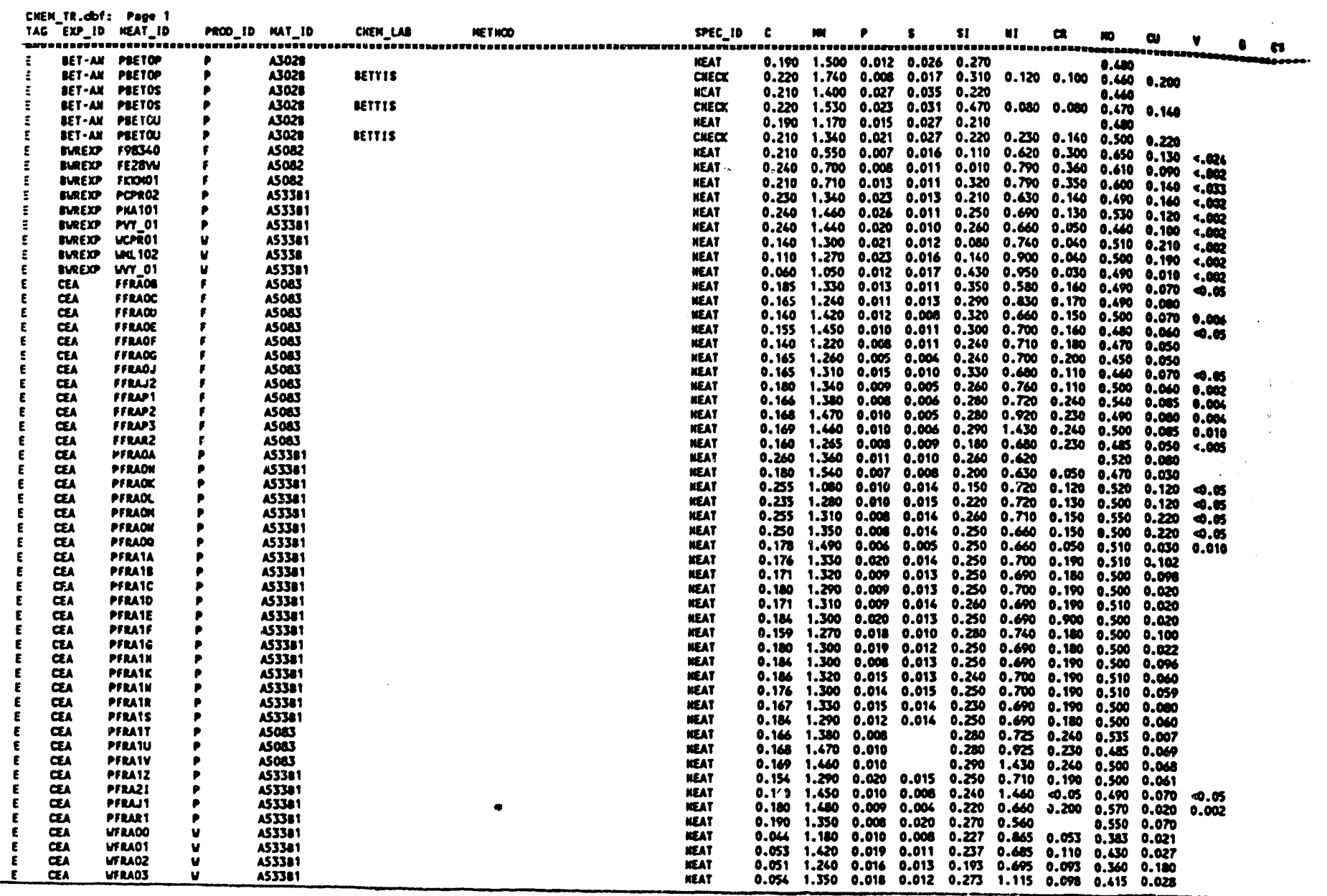


ial listing of CHEM_TR.dbf

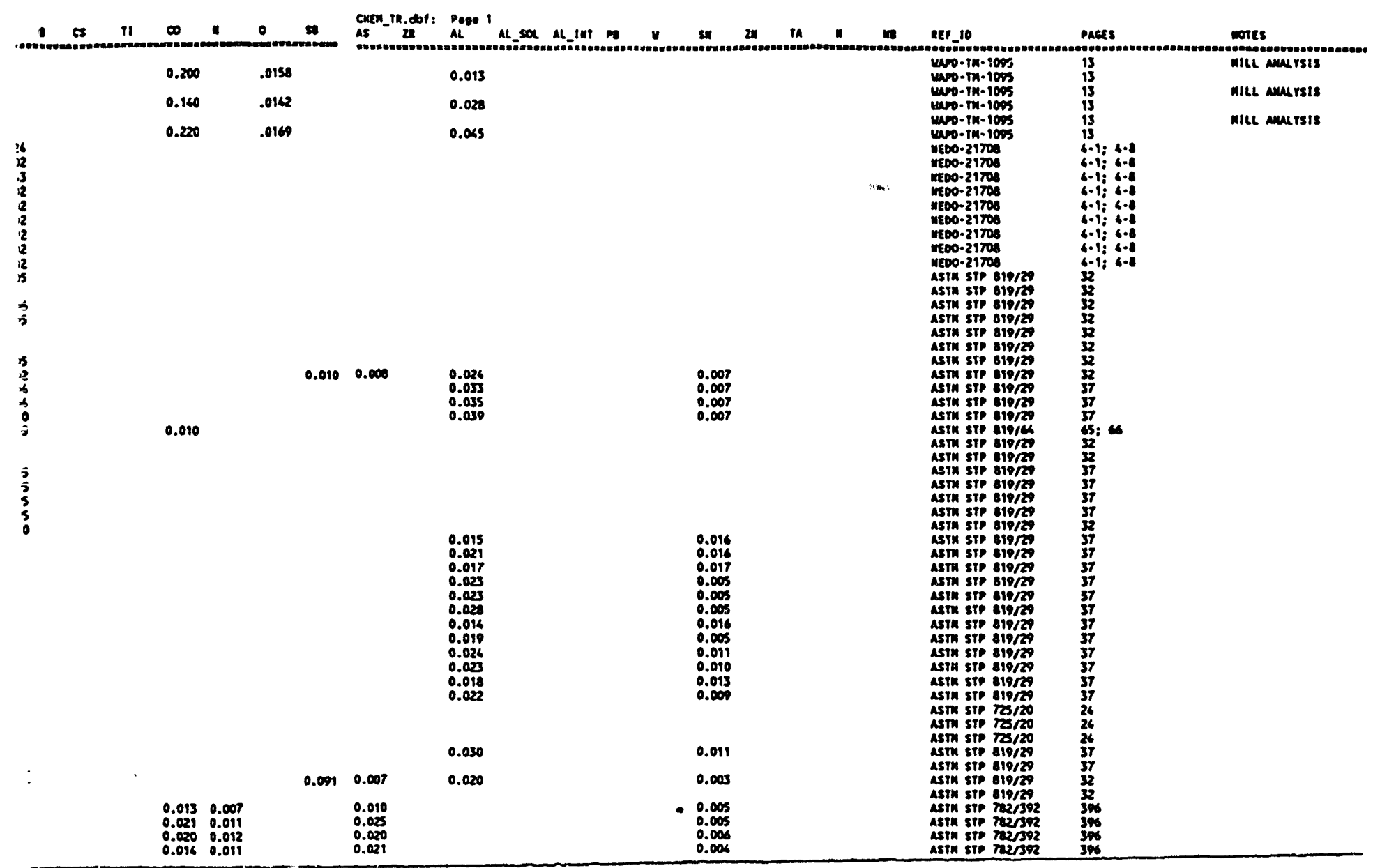




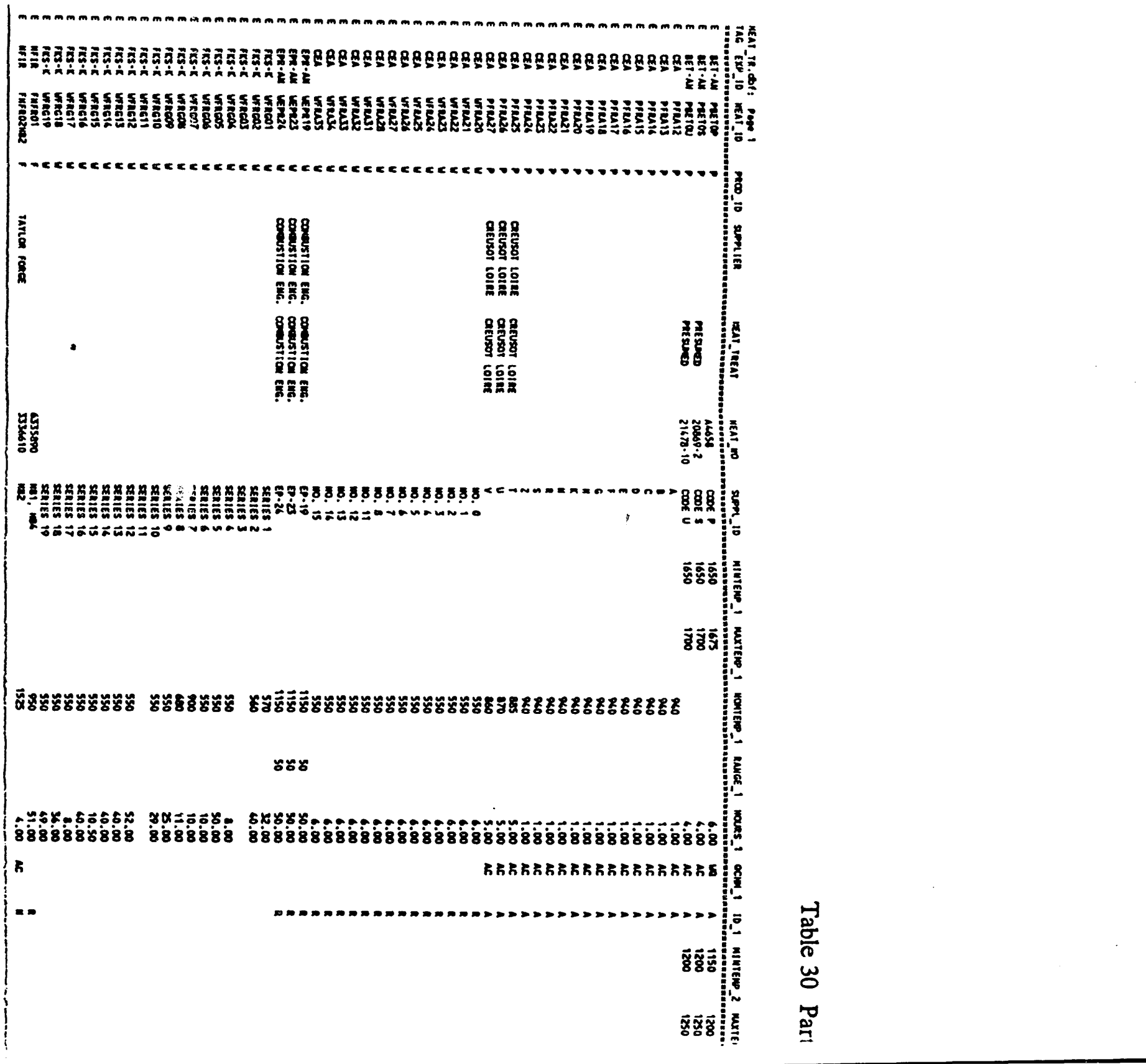


listing of HEAT_TR.dbf

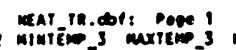

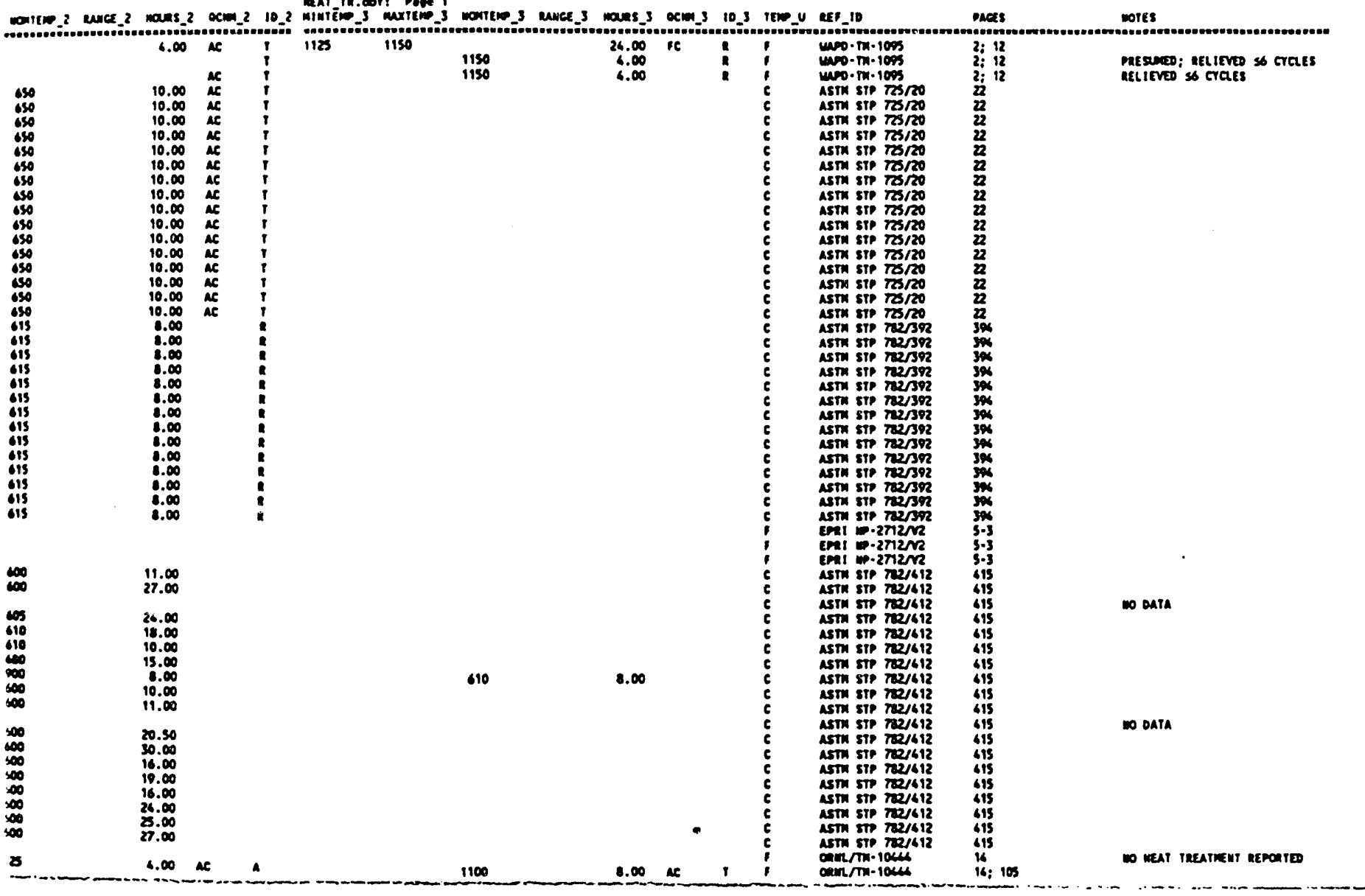


Table 31 Partial listing of WELD_TR.dbf

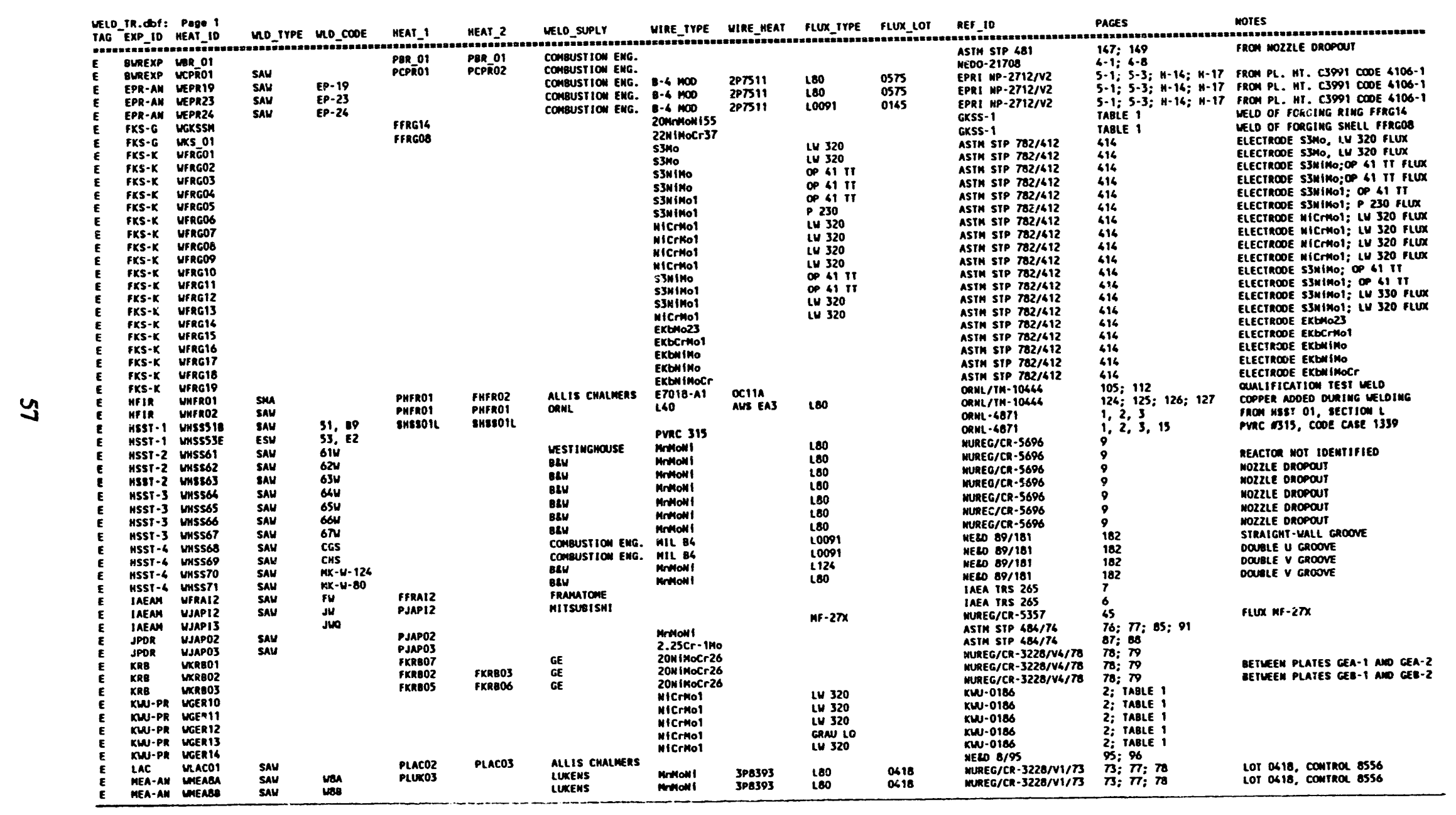


Table 32 Listing of HAZ_TR.dbf

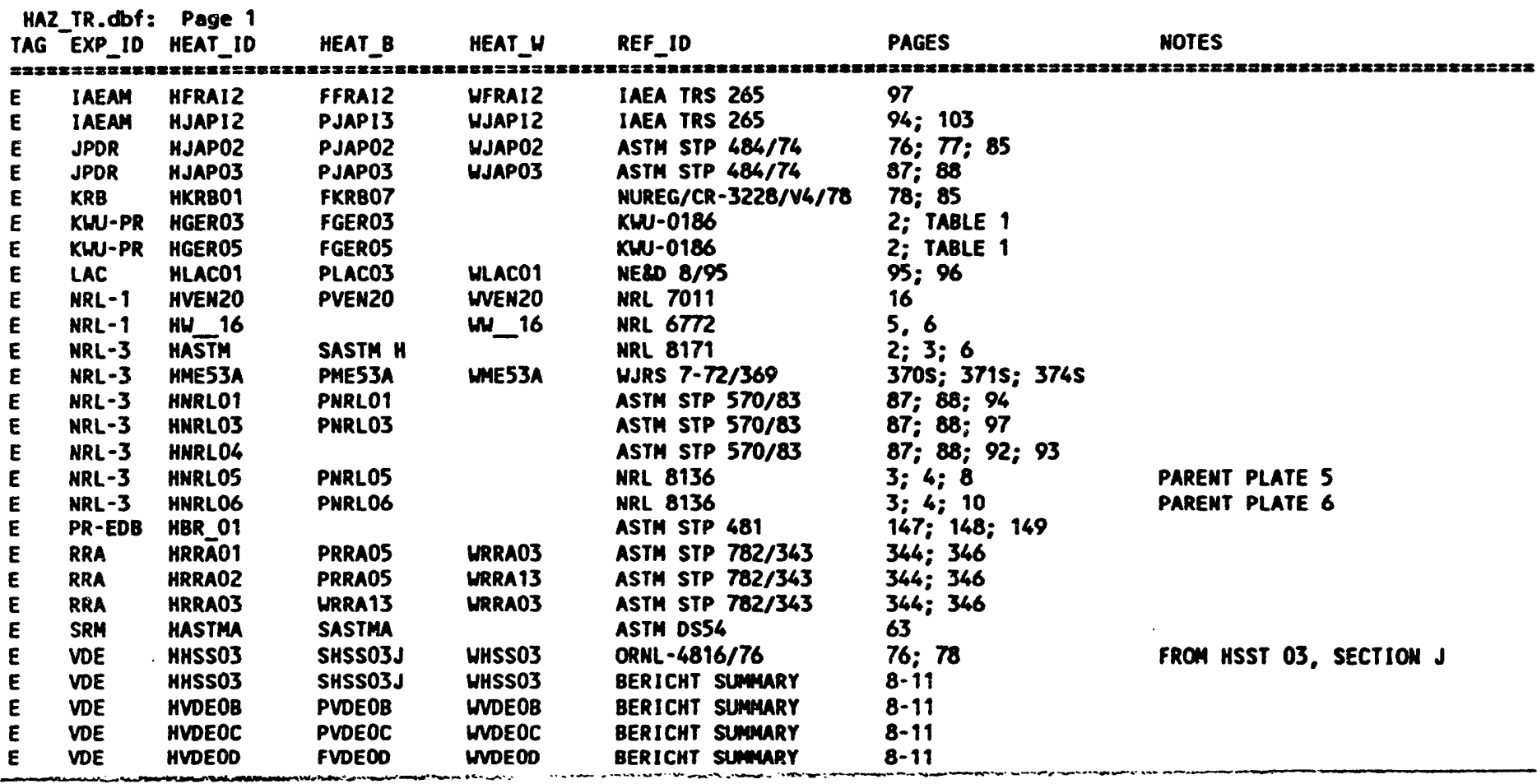




\section{○}

Table 33 Listing of TITL_TR.dbf

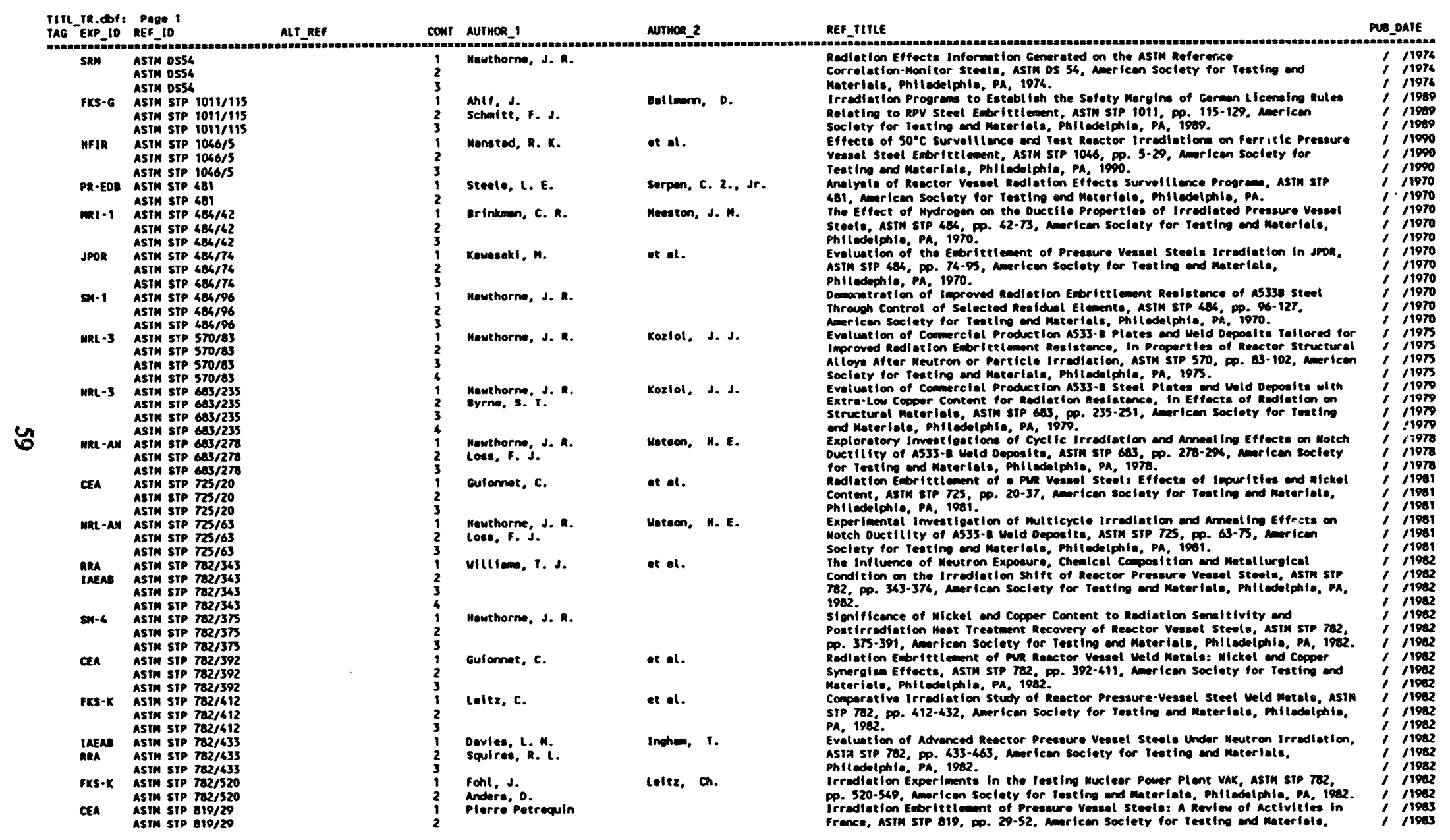


Table 33 (continued)

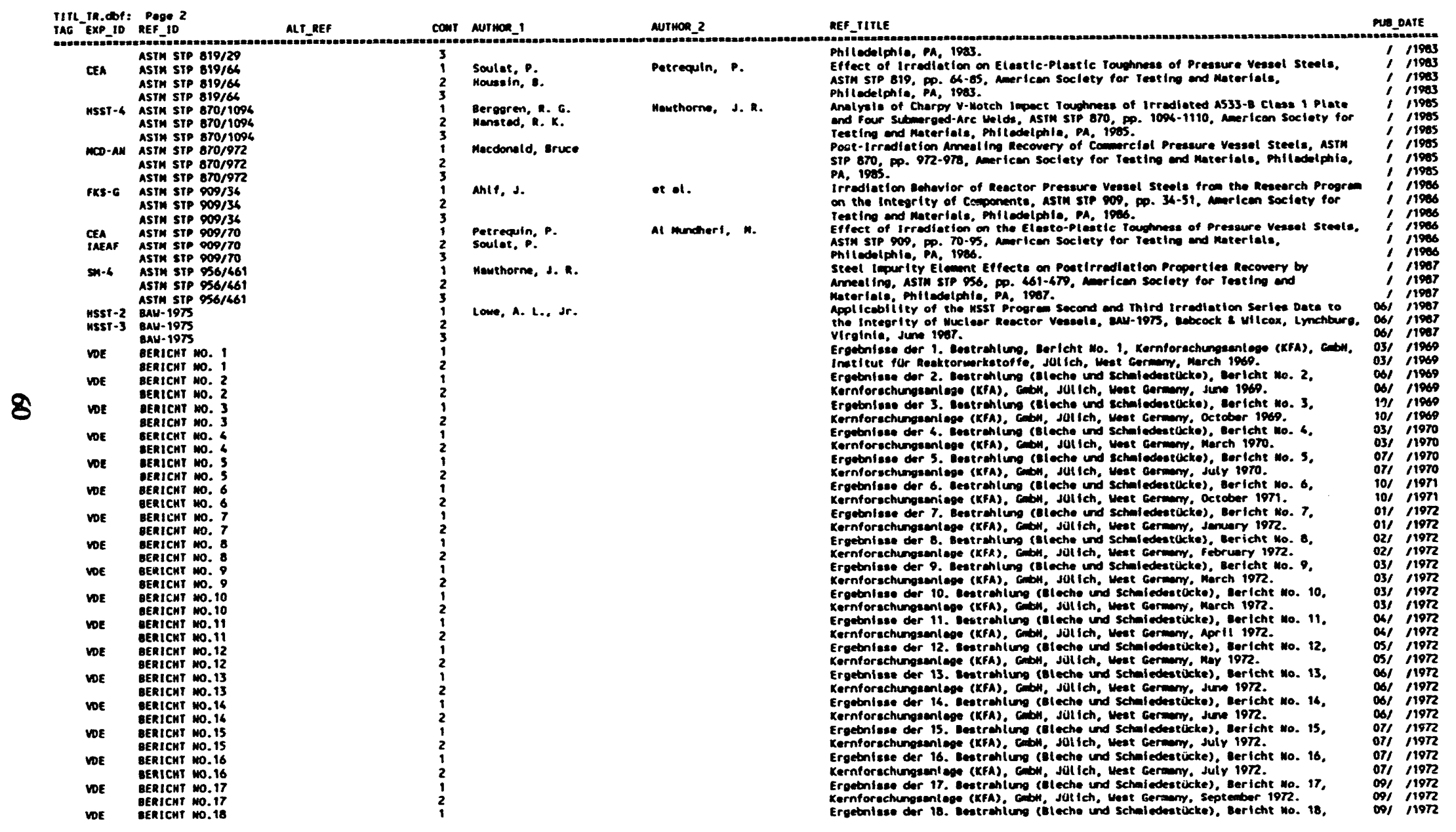




\section{○}

Table 33 (continued)

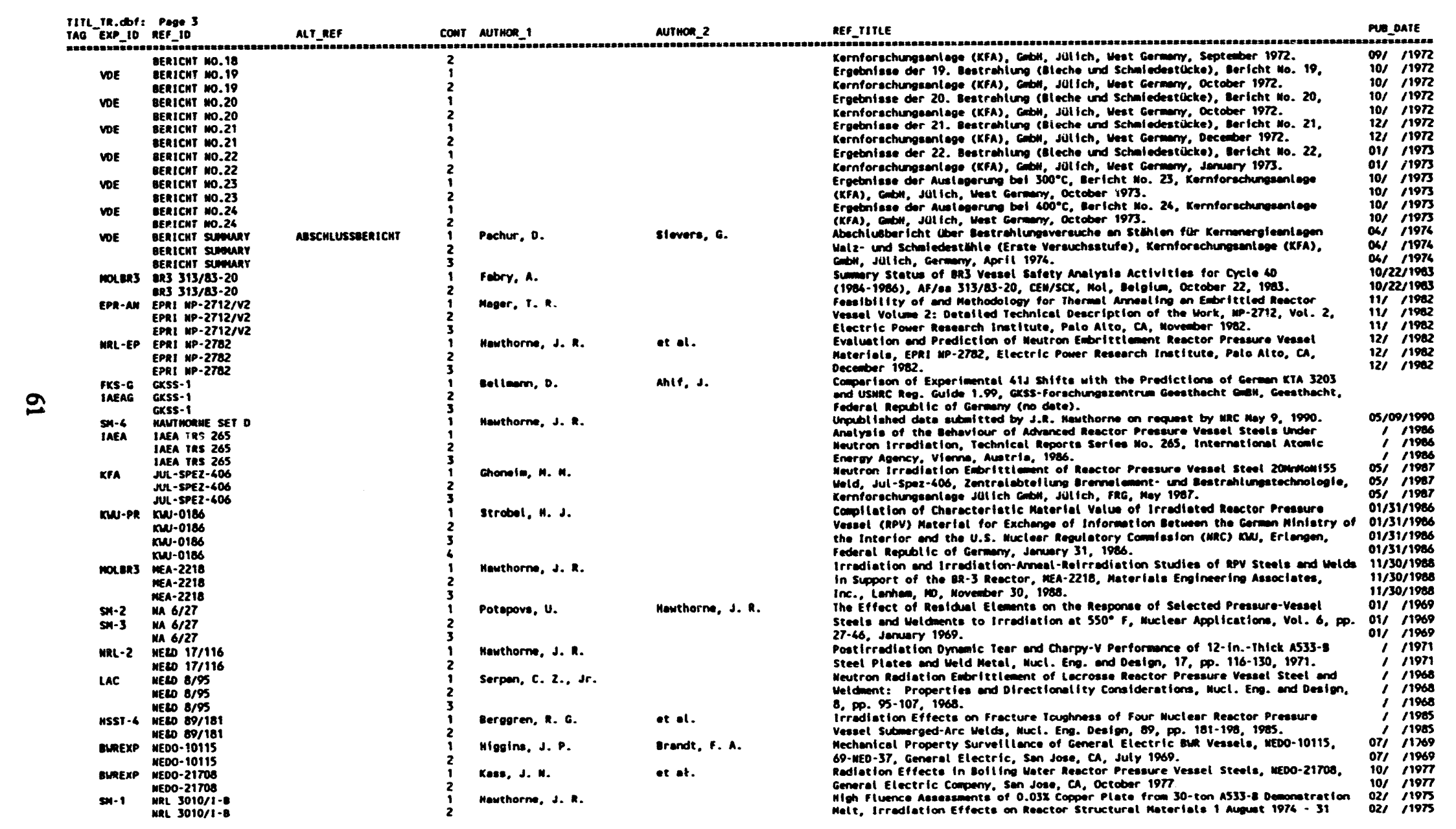


Table $\mathbf{3 3}$ (continued)

\begin{tabular}{|c|c|c|c|c|c|c|c|}
\hline 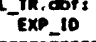 & PEF_10 & ALI_REF & cour & NUTHOR_I & aurmon 2 & REF_HTLE & Du_oATE \\
\hline $\begin{array}{l}\text { Mat-1 } \\
\text { mat-1 } \\
\text { sn-1 } \\
\text { sN-1 } \\
\text { mat-3 }\end{array}$ & 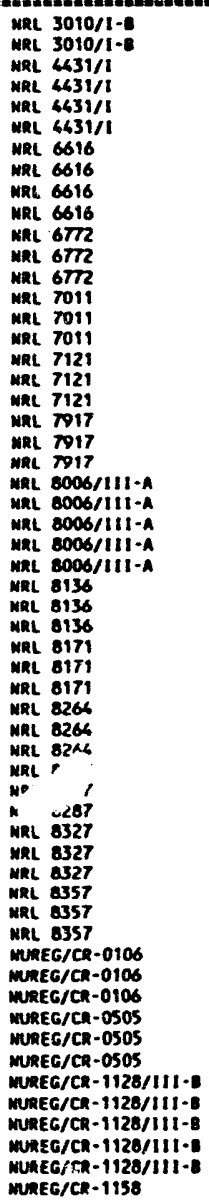 & MUREG/CR- $\cos 3$ & $\begin{array}{l}3 \\
3 \\
1 \\
2 \\
3 \\
4 \\
1 \\
2 \\
3 \\
4 \\
1 \\
2 \\
3 \\
1 \\
2 \\
3 \\
1 \\
2 \\
3 \\
1 \\
2 \\
3 \\
1 \\
2 \\
3 \\
4 \\
5 \\
1 \\
2 \\
3 \\
1 \\
2 \\
3 \\
1 \\
2 \\
3 \\
1 \\
2 \\
3 \\
1 \\
2 \\
3 \\
1 \\
2 \\
3 \\
1 \\
2 \\
3 \\
1 \\
2 \\
3 \\
1 \\
2 \\
3 \\
4 \\
5 \\
1\end{array}$ & 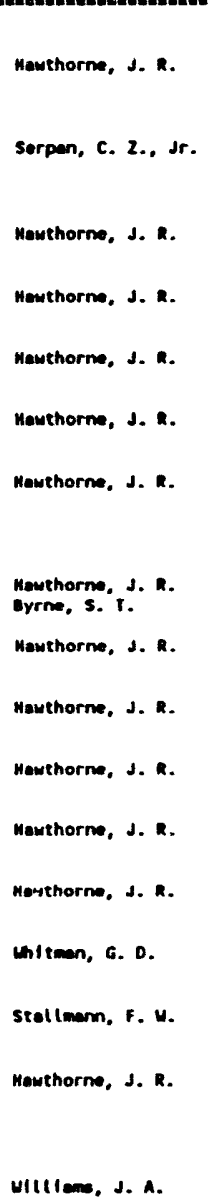 & Mauthorne, J. R. & 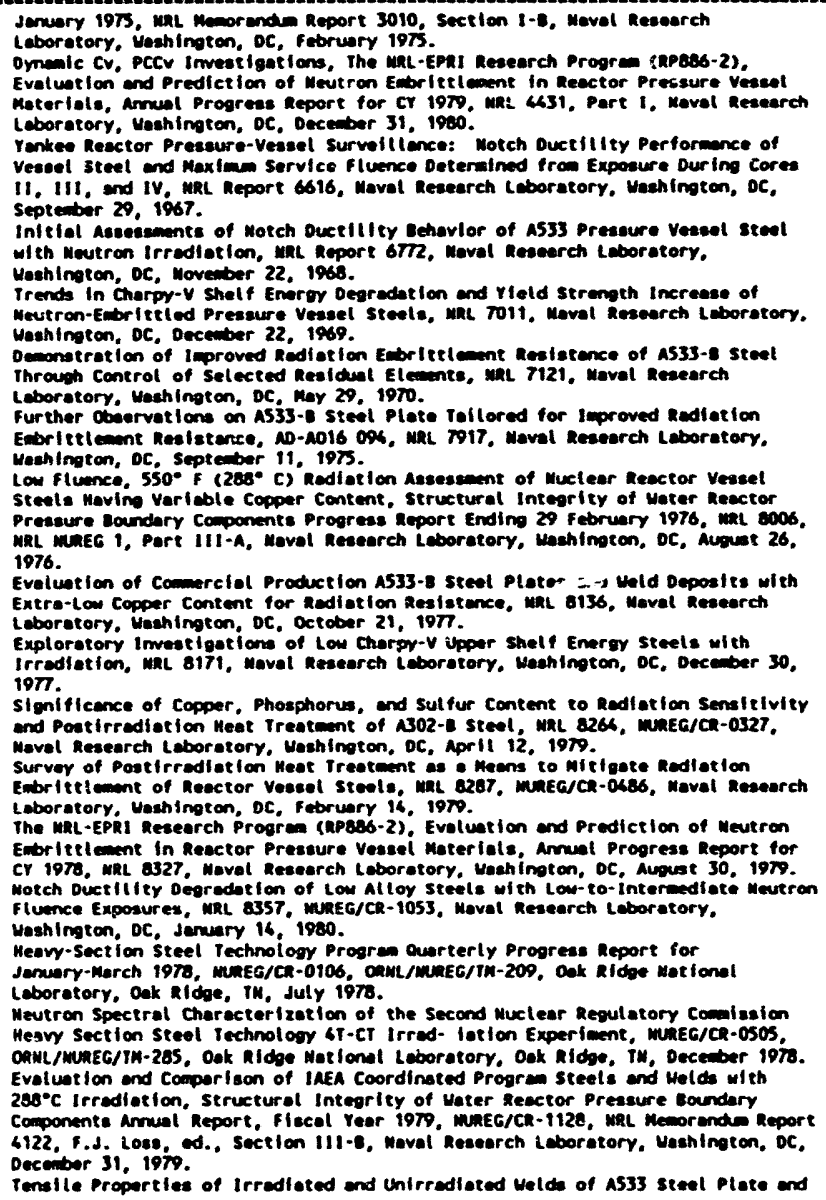 & 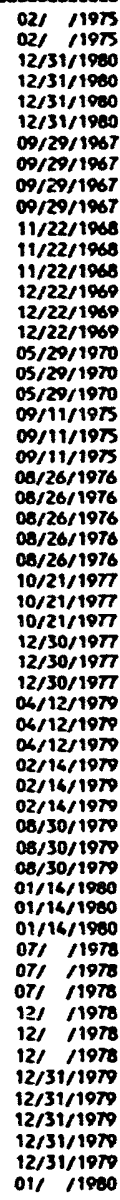 \\
\hline
\end{tabular}


Table 33 (continued)

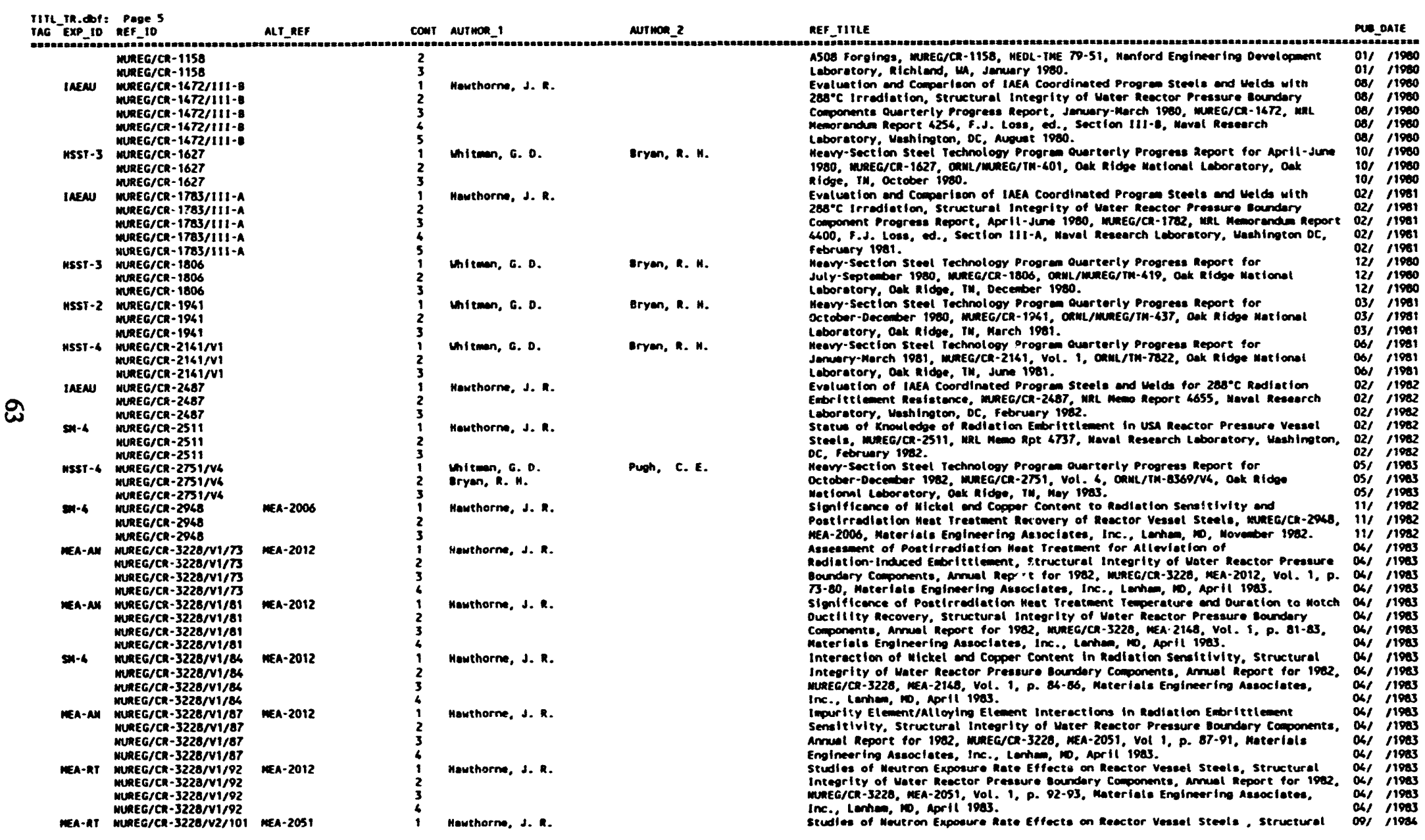


Table 33 (continued)

\begin{tabular}{|c|c|c|c|c|c|c|c|}
\hline$\prod_{M A G} \lim _{E X P_{-1}}$ & 806 & ALt_REF & cont & Aurroon_1 & aurmot_2 & REF_IITLE & PUSOARTE \\
\hline SonRss & 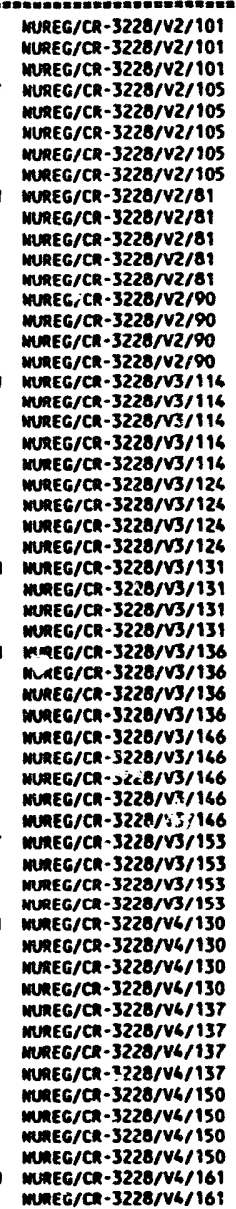 & $M \in A-2146$ & $\begin{array}{l}1 \\
2 \\
3 \\
4 \\
5 \\
2 \\
3 \\
3 \\
5 \\
1 \\
2 \\
3 \\
4 \\
2 \\
2 \\
4 \\
5 \\
2 \\
3 \\
4 \\
2 \\
3 \\
4 \\
2 \\
3 \\
4\end{array}$ & 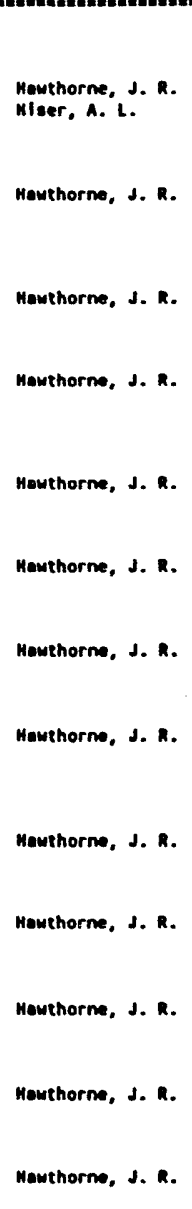 & Menke, I. ". & 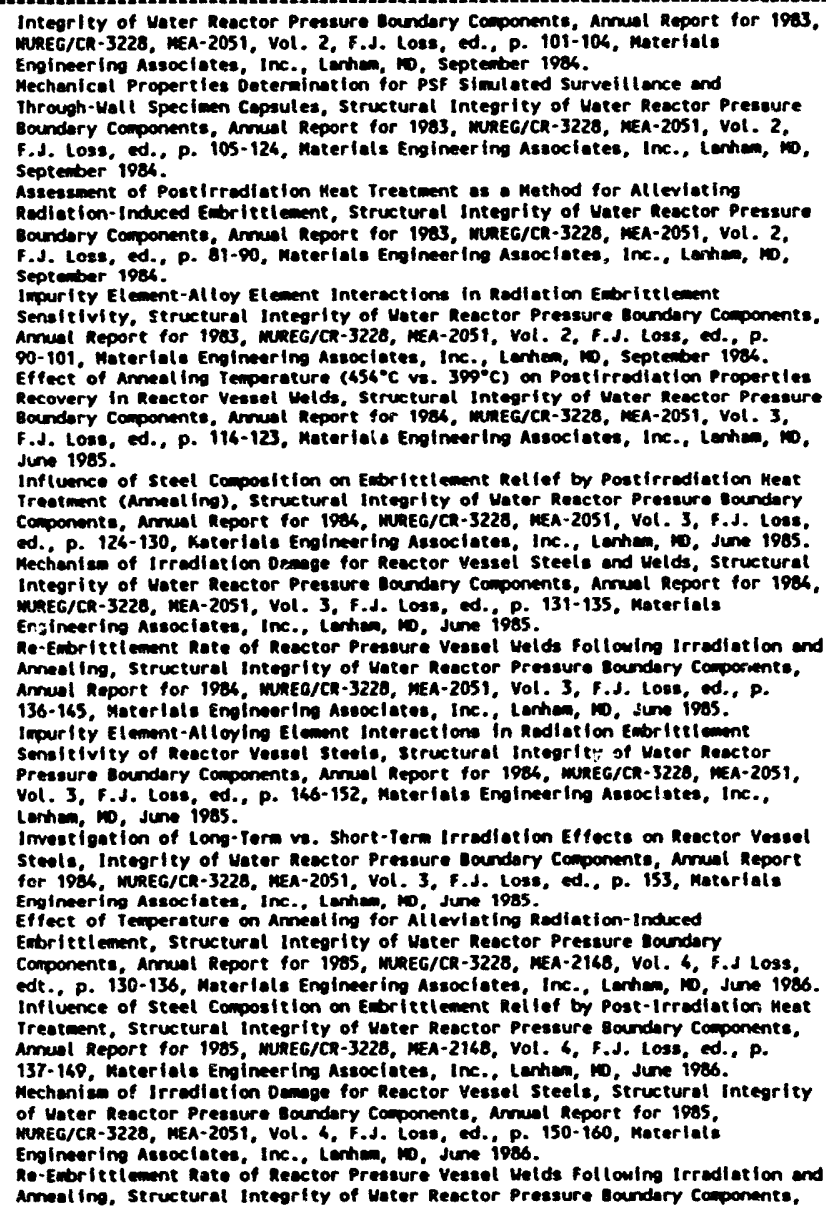 & 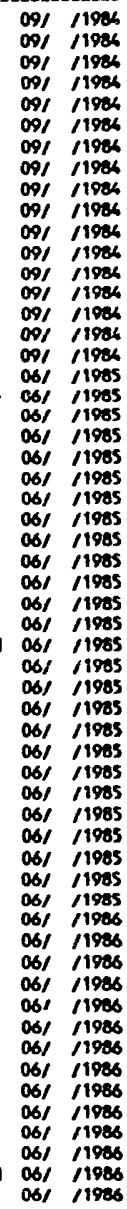 \\
\hline
\end{tabular}


Table 33 (continued)

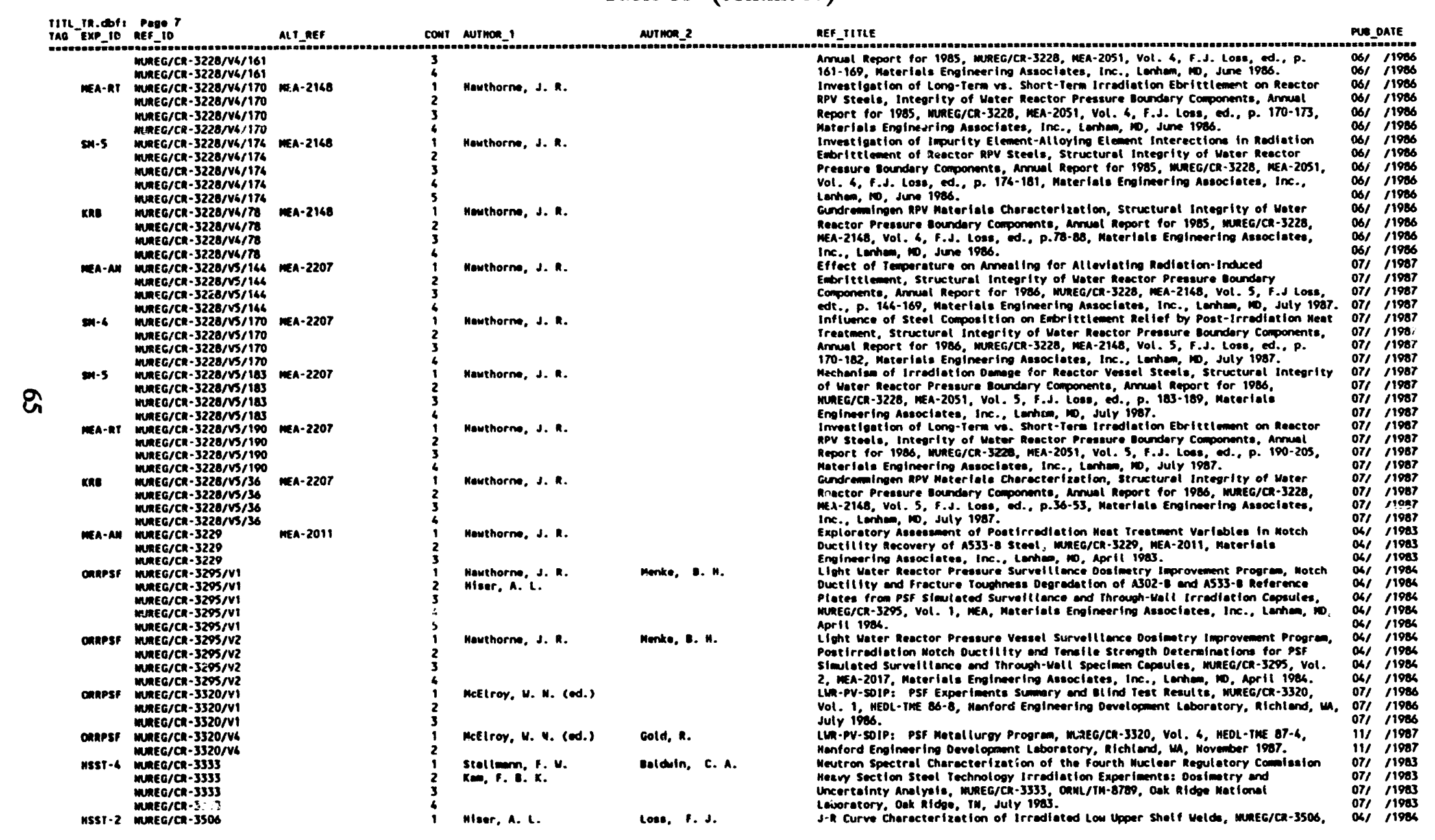


Table 33 (continued)

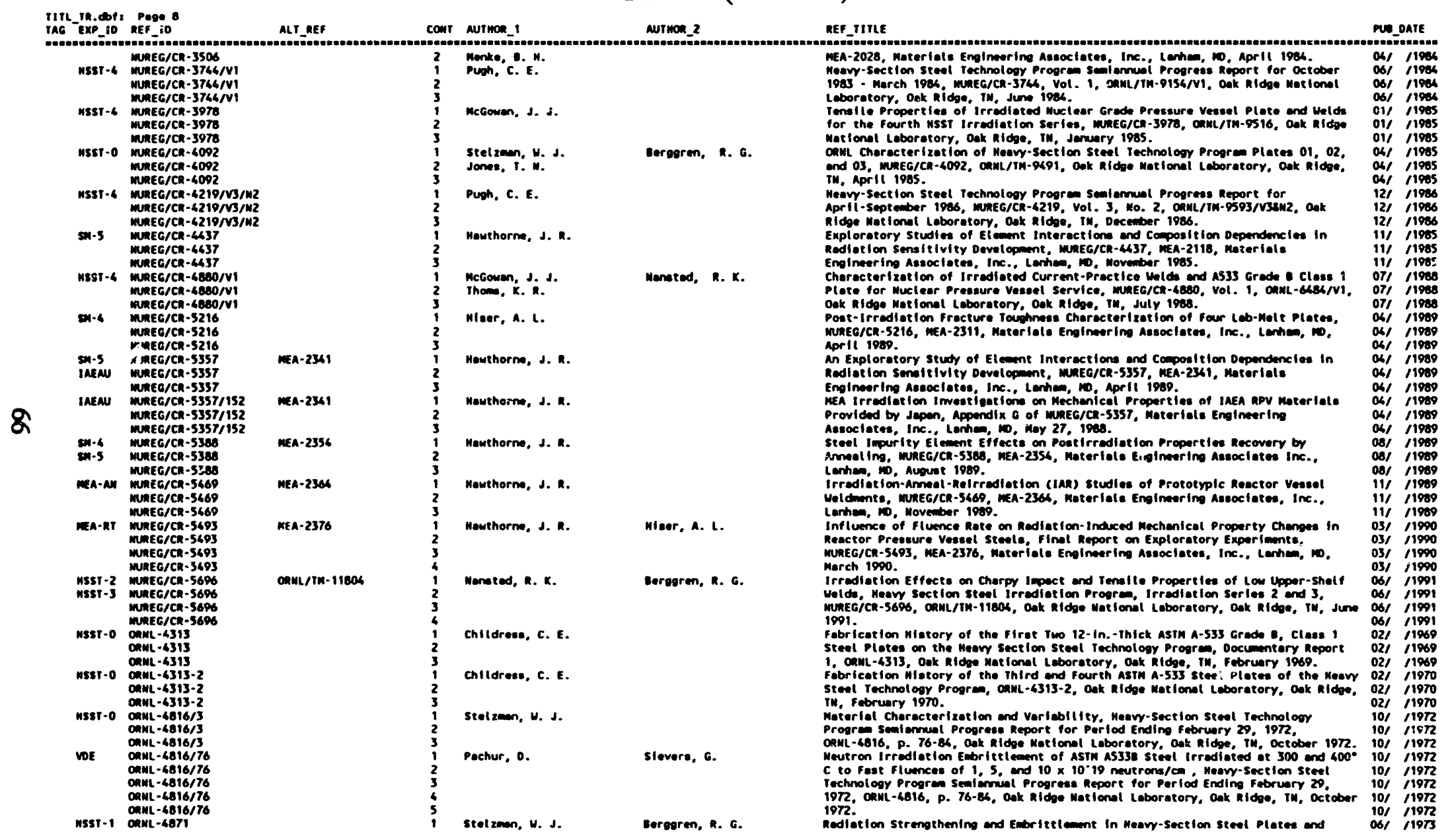


Table 33 (continued)

\begin{tabular}{|c|c|c|c|c|c|c|c|}
\hline $\begin{array}{l}\text { TITL_Th.dof: } \\
\text { YAO EXP_10 }\end{array}$ & Pege of & ALT_REF & CONT & aurHon 1 & Avition 2 & REE_TITE & Wo_DATE \\
\hline 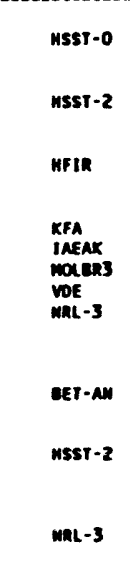 & 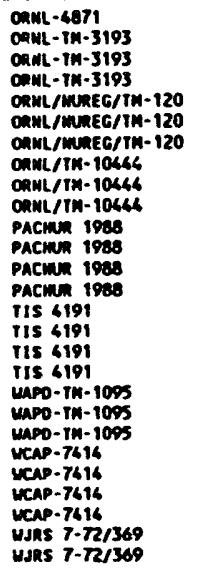 & & $\begin{array}{l}2 \\
1 \\
2 \\
3 \\
1 \\
2 \\
3 \\
1 \\
2 \\
2 \\
3 \\
1 \\
2 \\
3 \\
4 \\
1 \\
2 \\
3 \\
4 \\
1 \\
2 \\
3 \\
3 \\
2 \\
3 \\
4 \\
1 \\
2\end{array}$ & 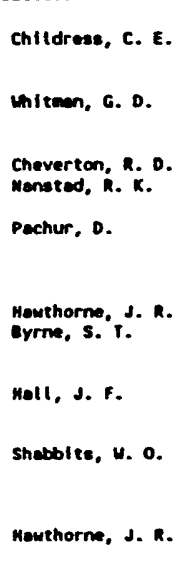 & $\begin{array}{l}\text { Merkle, J. G. } \\
\text { Kozlot, J. J. } \\
\text { semen, O. J. } \\
\text { ot ol. }\end{array}$ & 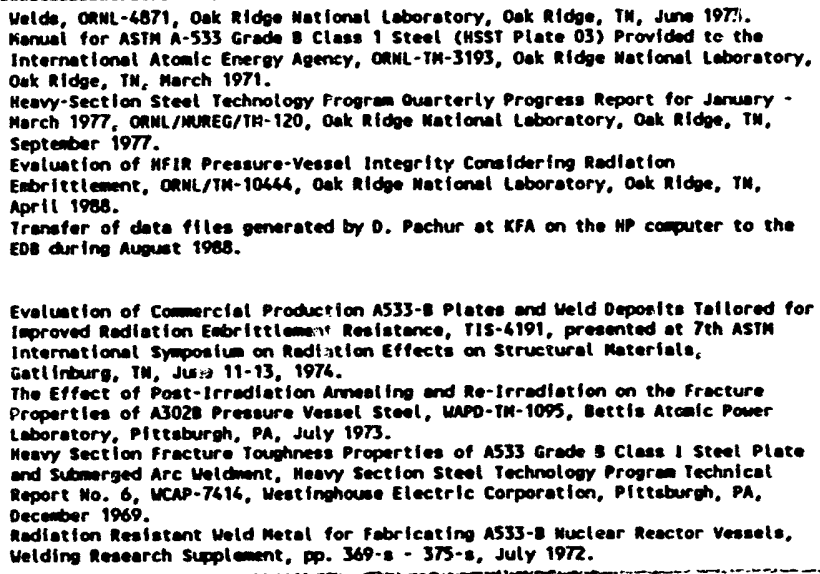 & 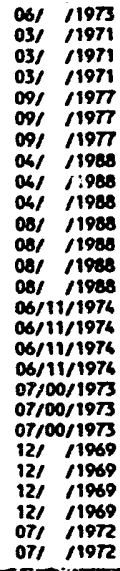 \\
\hline
\end{tabular}


Table 34 Listing of REF_TR.dbf

\begin{tabular}{|c|c|c|c|c|c|c|c|c|}
\hline 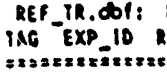 & 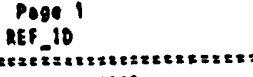 & $\begin{array}{l}\operatorname{MPC} 10 \\
=2 \sin =\end{array}$ & 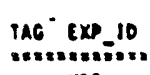 & 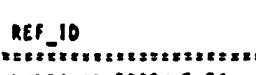 & $=2 \operatorname{xac} 10$ & $\begin{array}{l}\text { IAG EXP } 10 \\
\text { izexzost:ax }\end{array}$ & 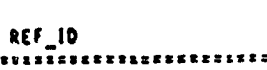 & \\
\hline 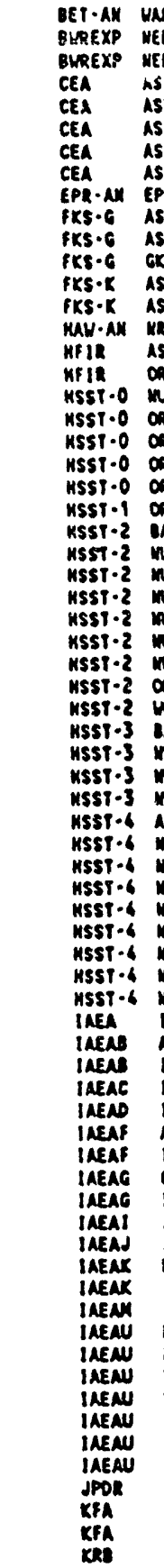 & 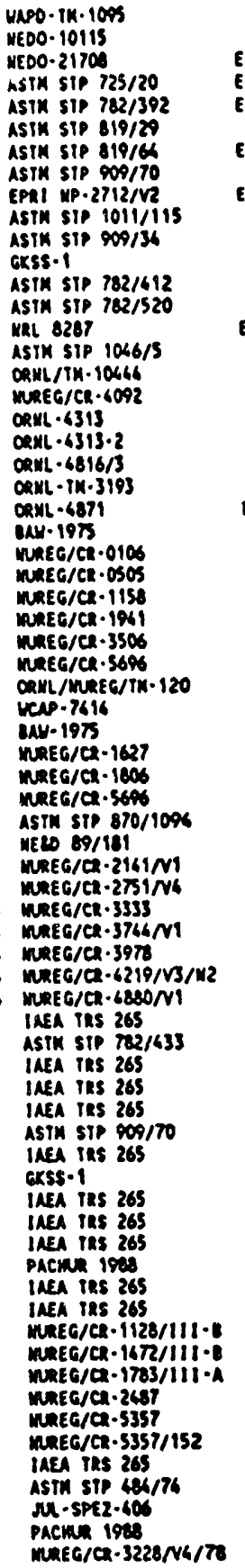 & $\begin{array}{l}E 16 \\
E 20 \\
E 20 \\
E 27 \\
E 30\end{array}$ & 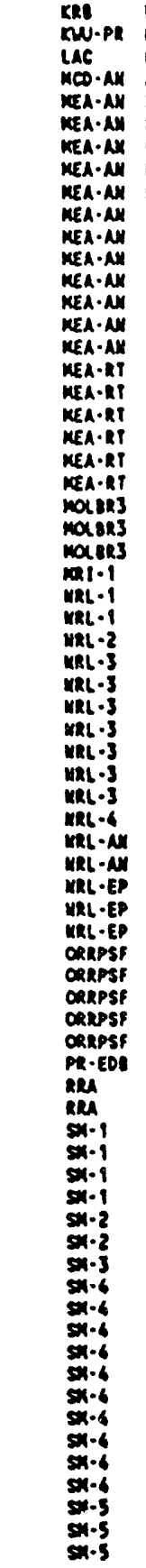 & 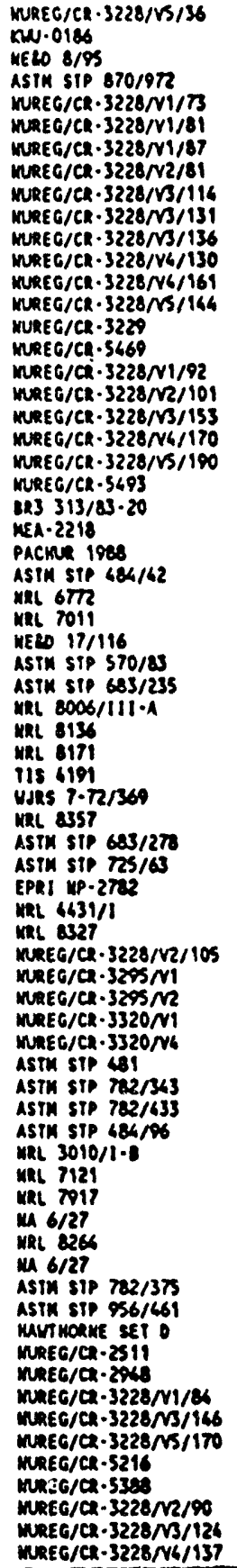 & $\begin{array}{l}E O 4 \\
E \alpha \\
E 07 \\
E 12 \\
E 12 \\
E 15 \\
E 19 \\
E 17 \\
E 12 \\
E 09 \\
E 22 \\
E 25 \\
E 33 \\
E 20 \\
E 35 \\
E 35 \\
E 16\end{array}$ & 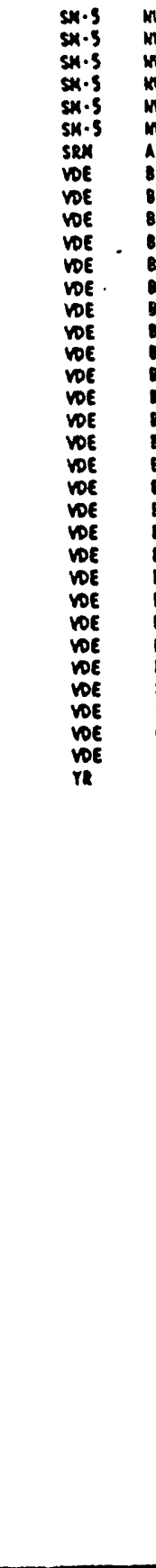 & 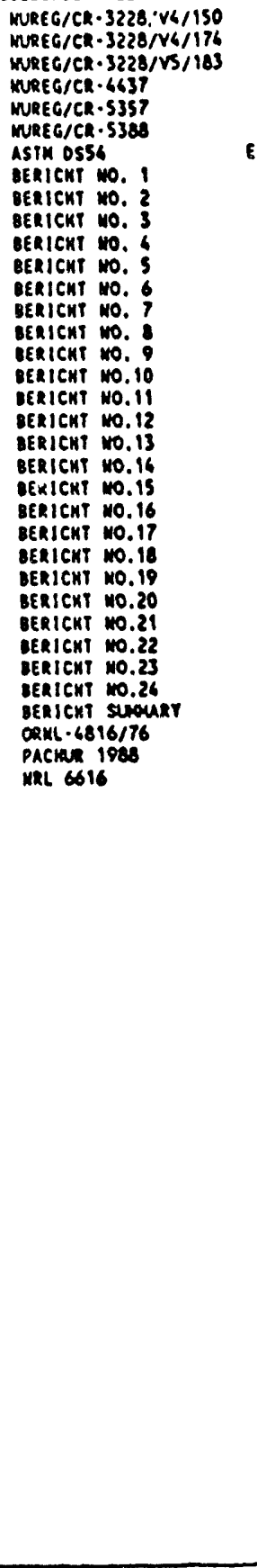 & E11 \\
\hline
\end{tabular}




\section{BET-AN}

Annealing Experiments Performed by Westinghouse at the Bettis Laboratory

Specimen from two steel plates coded S and U (EDB codes PBETOS and PBETOU) were irradiated to fluences in the range of 1 to $3 \times 10^{19} \mathrm{n} / \mathrm{cm}^{2}(>1.0 \mathrm{MeV})$ at the Engineering Test Reactor (ETR). The fluences received were determined by dosimetry for some of the specimen (identified by an ${ }^{*}$ at the SPEC_ID), the reported fluences for others are just estimates. The irradiated Charpy specimen were tested, and the broken halves at both ends were reconstituted and annealed for different lengths of time at different temperatures. The arbitrarily assigned SPEC_IDS were given to the irradiated Charpy set; additional extensions _A and _B were added to the SPEC_ID of irradiated Cnarpy set for the reconstituted Charpy specimens, which were made from the broken halves of the irradiated Charpy set. (The identifications are not given in the original report - WAPD-TM-1095 - but can be inferred from the fluence data.)

\section{BWREXP}

Irradiation Experiments Performed by GE with a Variety of BWR-PV Materials

The irradiation experiments were done at three different fluences--2.0E17, 1.5E18, and $3.7 \mathrm{E} 18 \mathrm{n} / \mathrm{cm}^{2}$ (E > 1.0 MeV)--in the Humbold Bay reactor (HM3). All materials were from or similar to materials used in existing BWRs.

CEA

Experiments in French Reactors Sponsored by Commissariat à l'Energy Atomique Experiments performed in support of French power reactors sponsored by the Commisariat a l'Energy Atomique (CEA) with the participation of different companies, mainly Framatome and EDF. Some of the experiments were run as research programs coordinated with the IAEA (see EXP_ID = IAEAF). All experiments were performed at the CEA test reactors Triton, Siloe, Melusine, and Osiris. A large variety of steels of the type used in French PWRs were investigated.

\section{EPR-AN}

Annealing Experiments Sponsored by the Electric Power Research Institute (EPRI) EPR-AN is a large-scale annealing experiment sponsored by the Electric Power Institute (EPRI). Three welds, coded WEPR19, WEPR23, and WEPR24, were irradiated in the University of Virginia Reactor (UVAR) and subsequently annealed. Some of the material was re-irradiated and re-annealed. Specifically, in CAPSULE EXP1 material was irradiated to a fluence of about $7.5 \mathrm{E} 18 \mathrm{n} / \mathrm{cm}^{2}(\mathrm{E}>1.0 \mathrm{MeV})$ and annealed at a variety of temperatures and durations. The contents of CAPSULE EXP2 were also irradiated in a first run to approximately the same fluence, followed by a variety of anneal procedures repeated again by a second irradiation and anneal run. The contents of CAPSULE EXP3 were irradiated to twice the fluence without intermediate anneal for comparison with EXP2. 
FKS-G

Irr. Program at Geesthacht to Verify Safety Margins for German Licensing Rules

The German nuclear safety standard KTA (Kerntechnischer Ausschuss) 3203 predicts radiation embrittlement of PV material similar to the NRC Reg. Guide 1.99. To verify and validate these rules, selected forgings, plates, and welds were irradiated in the Geesthacht reactor FRG-2 and the results compared with the KTA predictions. This investigation is part of research program "Integrity of Components" (FKS). Another participant is the Kraftwerkunion (KWU), see EXP_ID = FKS-K.

FKS-K

Irradiation Program by KWU to Verify Safety Margins for German Licensing Rules

The German nuclear safety standard KTA (Kerntechnischer Ausschuss) 3203 predicts radiation embrittlement of PV material similar to the NRC Reg. Guide 1.99. To verify and validate these rules, selected forgings, plates, and welds were irradiated in the Testing Nuclear Power Plant VAK, Kahl, Germany, and the results compared with the KTA predictions. This investigation is part of the research program "Integrity of Components" (FKS). Another participant is the GKSS, Geesthacht, Germany, see EXP_ID = FKS-G.

HAW-AN

Compilation of Results from Annealing Experiments by J. R. Hawthorne

This group of data is a compilation of results from annealing experiments performed at NRL by J. R. Hawthorne. Most of the data that are contained in the associated report (NRL 8287) could be traced to the original reports and are listed under the original reference. Additional information was obtained from data sheets for the MPC data base.

HrTR

HFIR Surveillance Program and Related Experiments at ORNL

This group of data was collected in connection with the surveillance program for the HFIR reactor at ORNL. The HFIR surveillance specimen showed an unexpectedly large shift in transition temperature for rather low fluences. (The shifts were determined at $15 \mathrm{ft}-\mathrm{lb}$ instead of the more common 30 or $50 \mathrm{ft}-\mathrm{lb}$ and are, therefore listed in the file SHFTX_TR.dbf; no test data at higher impact energies are: available.) This shift is still unexplained. For comparison purposes, additional specimens from the same or similar materials were irradiated in the ORR at ORNL to a higher fluence of $2.3 \mathrm{E} 18 \mathrm{n} / \mathrm{cm}^{2}(\mathrm{E}>1.0 \mathrm{MeV})$. The surveillance specimens were distributed in small batches over many different capsules; specimens that received similar fluences were combined to determine Charpy shifts. The same applies to some of the ORR irradiations. The raw data for separate and combined sets can be found in RAW_C_TR.dbf and RAW_C_FT.dbf, respectively. 
HSST-0

Heavy Section Steel Technology (HSST) Program, Initial Characterization

Three A533B1, 12-in.-thick steel plates were fabricated by Lukens for the HSST program at ORNL. Specimens from these plates are used as correlation monitor (standard reference) material in surveillance capsules of commercial power reactors whose pressure vessels were fabricated from A533B steel. Specimens from the first plate, SHSS01, were used in Combustion Engineering reactors, from the second plate, SHSS02, in other U.S. reactors. (The other correlation material, the 6-in. A302B plate SASTM was used in older power reactors.) The third plate, SHSS03, was used in the German VDE experiment, the IAEA Joint Programme, and the ORR PSF benchmark experiment. The purpose of the data collected under the EXP_ID HSST-0 was to determine the variability of the material properties at different locations and different thickness layers, for each plate, which is substantial. No irradiations were performed in this experiment.

\section{HSST-1}

Heavy Section Steel Irradiation (HSSI) Experiments, Series 1, at ORNL

This is the first of a series of experiments performed at ORNL as part of the HSST irradiation program. Specimens from the two HSST plates, SHSS01 and SHSS02, and two welds that were fabricated from these plates, WHSS51B and WHSS53E, were irradiated in the ORR. Fluences and irradiation temperatures differ widely between specimens and are reported for each individual specimen. Charpy transition temperature shifts and upper-shelf energies are determined for groups of specimen from the same material that are sufficiently similar in irradiation conditions. Raw data are provided for every test and can be used for independent evaluations.

\section{HSST-2}

\section{Heavy Section Steel Irradiation (HSS) Experiments, Series 2, at ORNL}

Three welds, WHSS61 to WHSS63, were investigated. The irradiation rig consisted of three identical capsules, each containing two 4T CT specimens and a variety of smaller CT, Charpy, and tensile specimen, plus dosimeters. The capsules were rotated during irradiation to obtain uniform exposure of the large CT specimens; the smaller specimen received widely varying fluences and irradiation temperatures, which are reported individually. Charpy transition temperatures and upper-shelf energies were determined by pooling together specimens that were exposed to similar irradiation conditions and by making corrections to account for differences in fluence and irradiation temperature. Raw data for individual Charpy tests are available for independent evaluations.

\section{HSST-3}

Heavy Section Steel Irradiation (HSSI) Experiments, Series 3, at ORNL

The third experiment in the HSSI series (see HSST-1 and HSST-2) investigates four welds, WHSS64 to WHSS67. It uses the same irradiation rig as HSST-2 with comparable results and problems. 


\section{HSST-4}

Heavy Section Steel Irradiation (HSSI) Experiments, Series 4, at ORNL

The fourth experiment in the HSSI series investigates specimens of the HSST-2 plate, Section A, SHSS02A, and four welds, WHSS68 to WHSS71. The irradiation is again performed in three capsules at the BSR facility at ORNL, but the rigs are different and more tightly controlled in fluence and irradiation temperature.

IAEA

IAEA Co-ordinated Research Program for Irradiation of Advanced RPV Steels

This is a program co-ordinated by the International Atomic Energy Agency (IAEA) for the investigation of reactor pressure vessel steels provided by vendors and laboratories of several countries. Each participating laboratory irradiated some or all of a set of forgings, plates, and welds provided and evaluated the results. A summary of the results is contained in IAEA TRS 265, but many participants published more detailed data in separate reports. Different EXP_ID have been assigned to the different laboratories as follows:

\begin{tabular}{llll} 
EXP_ID & \multicolumn{1}{c}{ Laboratory } & \multicolumn{1}{c}{ Country } \\
\cline { 2 - 2 } IAEAB & AERE & & United Kingdom \\
IAEAC & Skoda Nat. Corp. & & Czechoslovakia \\
IAEAD & Riso Nat. Laboratories & & Denmark \\
IAEAF & CEN & & France \\
IAEAG & GKSS & Germany \\
IAEAI & Babha At. Center & & India \\
IAEAJ & Japan At. Res. Inst. & & Japan \\
IAEAK & KFA & Germany \\
IAEAM & Manufacturer's data & Country of origin \\
IAEAU & NRL & U.S.A.
\end{tabular}

\section{IAEAB}

IAEA Co-ordinated Research Program: AERE Contribution

The investigation was conducted by the U.K. Atomic Energy Authority with participation of Rolls Royce and Associates. Detailed results are published in ASTM STP 782/433. Some of the data in IAEA TRS 265 differ slightly from the ASTM STP report.

IAEAC

IAEA Co-ordinated Research Program: Skoda Contribution

All data listed are from IAEA TRS 265.

IAEAD

IAEA Co-ordinated Research Program: RISO Contribution

The Riso contribution to IAEA TRS 265 contains only chemistry data. 


\section{IAEAF}

IAEA Co-ordinated Research Program: CEN Contribution

Detailed reports that contain other investigations with French test reactors are published in several ASTM STP reports (see EXP_ID = CEA).

\section{IAEAG}

IAEA Co-ordinated Research Program: GKSS Contribution

Additional data can be found in GKSS-1.

\section{IAEAI}

IAEA Co-ordinated Research Program: Bhabha Contribution

All listed data are from IAEA TRS 265.

\section{IAEAJ}

IAEA Co-ordinated Research Program: Japan At. Res. Inst. Contribution All data come from IAEA TRS 265.

\section{IAEAK}

IAEA Co-ordinated Research Program: KFA Contribution

These data are the contributions of D. Pachur from irradiations at the FRJ-1 and FRJ-2 reactors at the Kernforschungsanstalt in Jülich, Germany. D. Pachur has supplied additional data on diskettes beyond those published in IAEA TRS 265.

\section{IAEAM}

IAEA Co-ordinated Research Program: Steel Manufacturer's Contribution

These data are the baseline values for the pre-irradiation properties of the IAEA supplied materials as provided by the manufacturers and listed in IAEA TRS 265.

\section{IAEAU}

IAEA Co-ordinated Research Program: NRL Contribution

The U.S. contribution to the LAEA Co-ordinated Research Program consisted of irradiations in the UBR reactor with evaluations by J. R. Hawthorne in the Naval Research Laboratory. In addition to the material investigated in IAEA TRS 265, other IAEA-supplied Japanese steels were investigated in NUREG/CR-5357.

\section{JPDR}

Japan Power Demonstration Reactor (JPDR) Surveillance Program

The report in ASTM stp 484/74 contains the results of the surveillance program for the Japan Power Demonstration Reactor (JPDR), including supplemental experiments. 
KFA

Miscellaneous Irradiation Experiment Performed at the Kernforschungsanstalt (KFA) Most of the data are unpublished supplements to the VDE and IAEA experiments that were supplied by $D$. Pachur on diskettes. The transition temperatures were obtained from Pachur's two-stage impact-energy-versus-test tomperature model. These data are referenced as "Pachur 1988."

KRB

Experiments Concerning the Decommissioned Reactor KRB-A, Gundremmingen

Parts of the pressure vessel of the decommissioned reactor in Gundremmingen, Germany, are being tested at MEA and compared with archived material from the same PV after irradiation in the UBR to comparable fluences.

KWU-PR

Compilation of German Irradiated RPV Data for Transfer to NRC

This compilation contains surveillance data from pressure vessels of German power reactors from the Kraftwerkunion. The steel samples were obtained from ring forgings and associated weld and HAZ material. The data were collected per re uuest by the U.S. NRC and MEA.

LAC

Test Reactor Irradiations in Support of the LaCrosse Reactor

Several steel samples from the Lacrosse reactor were irradiated in the LITR and UCRR test reactors as supplement to the surveillance program. The principal investigator was C. Z. Serpan, Jr.

\section{MCD-AN}

Compilation of Results from Annealing Experiments by B. McDonald

This compilation was collected by B. McDonald in support of his annealing model. All data could be traced to the original reports and are referenced accordingly.

MEA-AN

Post-irradiation Annealing Experiments at Materials Engineering Associates, Inc.

Four welds, coded W8A (WMEA8A), W9A (WMEA9A), WW4 (WMEAW4), and WW7 (WMEAW7) were investigated at various states of irradiation, annealing, and re-irradiation.

MEA-RT

Study of the Influence of Fluence Rates on Irradiation Embrittlement at MEA

The influence of fluence rates was studied by exposing A302B (SASTM F23) and A533B (PNRLG23) material at reflector and in-core positions in the UBR and irradiating them to the same total fluences. The weld W8A (WMEA8A) from the MEA-AN experiment was also included in the study. 


\section{MOLBR3}

Irradiation Experiments in Support of the BR3 Reactor at Mol, Belgium

In order to investigate possible benefits of annealing for the BR3 reactor vessel several welds were irradiated in the UBR and subsequently annealed. The results are published in MEA 2218 and several CEN/SCK reports. The principal investigators were A. Fabry and J. R. Hawthorne. An independent evaluation was performed by D. Pachur.

MRI-1

Test of Hydrogen Influence in Steels performed at Materials Research, Idaho

The influence of Hydrogen on radiation embrittlement is studied in this report.

NRL-1

Exploratory Irradiation Studies of A533, A543, and A302 Steels at NRL

This study combines the results of several exploratory irradiation experiments to determine the radiation embrittlement of commonly used pressure vessel materials.

NRL-2

Irradiation Experiments with HSST Material at the Naval Research Laboratory

This study describes the results of irradiation experiments on the two HSST plates, HSST-1 (SHSS01) and HSST-2 (SHSS02), and a weld Cabricated by Combustion Engineering. One objective of this experiment was to compare dynamic tear tests to regular Charpy tests.

NRL-3

Test of Irradiation Sensitivity for Commercial and Improved Steels at NRL

This is a joint NRC-Combustion-Engineering program that was carried out at the NRL. The main objective was to determine the influence of copper, in particular, to compare newer improved low-alloy steels with older commercial steel samples.

NRL -4

Notch Ductility Degradation of Low-Alloy Steels with Low-to-Intermediate Fluence

This is another NRC-sponsored study of the radiation sensitivity of a variety of commercially produced steel plates and welds with varying copper content. Fluences range between 1.0E18 to $2.0 \mathrm{E} 19 \mathrm{n} / \mathrm{cm}^{2}(\mathrm{E}>1.0 \mathrm{MeV})$.

\section{NRL-AN}

Investigation of Cyclic Irradiation and Annealing Effects in A533-B Welds

This investigation is an annealing study on two commercially produced high-copper welds (Babcock \& Wilcox and Combustion Engineering, respectively) with up to two cycles of irradiation-annealing-re-irradiation and two different annealing temperatures $\left(650^{\circ}\right.$ and $750^{\circ} \mathrm{F}$, respectively). 
NRL-EP

NRL-EPRI Research Program (RP886-2)

This is a joint effort by EPRI and NRL to investigate the radiation embrittlement of typical reactor pressure vessel material. Plates (A533B and A302B), forgings (A5082) and associated welds were used in this program.

\section{ORRPSF}

Surveillance Dosimetry Improvement Program, ORR-PSF Metallurgical Irradiation

An essential part of the Pressure Vessel Surveillance Program was the PSF Benchmark Field which simulates the surveillance-cápsule-pressure-vessel configuration in the Poolside Facility (PSF) of the Oak Ridge Research Reactor (ORR). Six different materials consisting of two plates (SASTM F23 and SHSS03 PSF), two forgings (FKFA01 and FMOL01), and two welds (WEPR23 and WRRA_PSF), were each irradiated in two simulated surveillance capsules and three "block" capsules corresponding to the inner surface, $1 / 4 \mathrm{~T}$ and $1 / 2 \mathrm{~T}$ positions, respectively, of a pressure vessel in power reactors. The fluence spectra and relative fluence rates in these capsules are similar to the ones in fower reactors which provides some opportunity to validate surveillance programs.

\section{PR-EDB}

Experiments in Support of U.S. Power Reactor Surveillance

Data listed under this EXP_ID consist of power reactor surveillance materials that were

RRA irradiated in test reactors.

Series of Experiments Performed at Rolls Royce Associates, UK

The current data in the TR-EDB are taken from ASTM STP 782/343 which are from a joint study of Rolls Royce, Ass. and the Atomic Energy Research Establishment in Harwell, England.

\section{SM-1}

\section{Experiments with Demonstration Melt A533 Plates}

This is the first of a number of "Split Melt" experiments performed by J. R. Hawthorne at the Naval Research Laboratory and, later, at Materials Engineering Associates, in which one melt was divided into several parts, each of which received a different amount of alloys, such as copper, phosphorus, and nickel to determine the change of radiation sensitivity due to the alloying materials. In this experiment a 30-ton A533 heat was split four ways with two different copper contents $(0.13 \%$ and $0.03 \%)$, each of which received two different heat treatments corresponding to Class 1 and Class 2 designation. Several irradiation experiments were performed with these materials including annealing. 
Experiments with Split-Melts to Study the Influence of Residual Elements in A302-B Steels The study consisted of three 300-lb melts, each split three ways (PME38A to PME40C), and two 400-lb melts, split four ways (PMEV61, PMEV63,.., PMEV67, PMEV71,..,PMEV77). The different melts differ in copper and phosphorus content. Each was fabricated into 0.5-in. plates and heat treated in the usual way. The A302B reference plate was also included in the study for comparison. Some of the PMEVxx samples were annealed after irradiation.

SM-3

Experiments with Split-Melts to Study the Influence of Residual Elements in A543 Steels Similar to SM-2 two 300-lb melts were split three ways but are from A543 heats, with aluminum and nitrogen added in various amounts (PMEY2A to PMEY3C). Associated welds are also included in the study.

SM-4

Experiments with Split-Melts to Study Nickel-Copper Interactions

This study involves two 400-lb A302B melts split four ways (PME05A to PME06D), with varying amounts of copper and nickel added. The irradiation experiments include annealing.

SM-5

Experiments with Split-Melts to Study Copper-Phosphorus Interaction

This study involves seven melts, each split four ways, resulting in 28 materials of type A302B and A533B (PME66A to PME72D), with varying amounts of copper, phosphorus, and nickel. Some of the materials were used in the annealing study MEA-AN.

SRM

Irradiation of Standard Reference Materials in Power and Test Reactors

This study involves four steel plates provided by U.S. Steel to ASTM as Reference Correlation Monitor Materials (Standard Reference Material, SRM). One of these plates, the A302B reference material, has been used extensively in surveillance programs of older power reactors. Samples of the four plates were send to different organizations and irradiated in many different reactors to a variety of fluences and irradiation temperatures. The results have been collected and published by J. R. Hawthorne in ASTM DS54. Only changes between un-irradiated and irradiated data (shift values) are reported, not the baseline values themselves. Some of the baseline values were included in the MPC data base and have been transferred to the TR-EDB. There appears to be a large variation in baseline values for different sections of the plates, but these are not given, nor are the locations of the samples clearly identified. The HEAT_ID code reflects, wherever possible, the location of the sample, such as, SASTM S ${ }^{*}$, etc.; the plain code SASTM is reserved for surveillance material, SASTM X stands for material whose location could not be identified. The other plates are coded SASTMA, SASTMB, and SASTMC. SASTMD and further codes are used for other materials that were identified as "reference material" in the reports. 


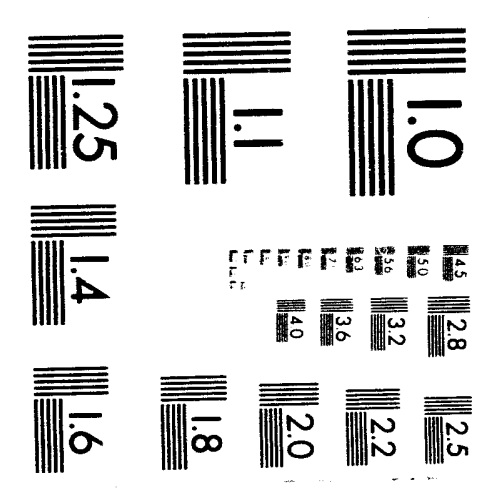

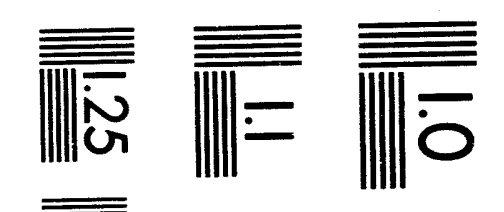

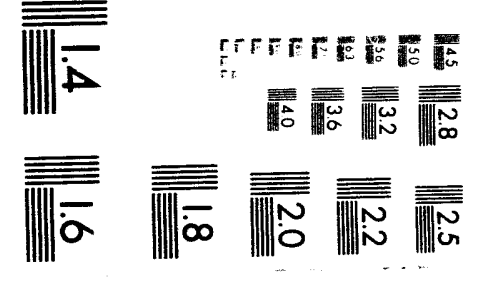

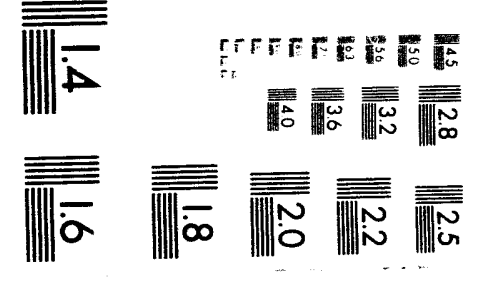

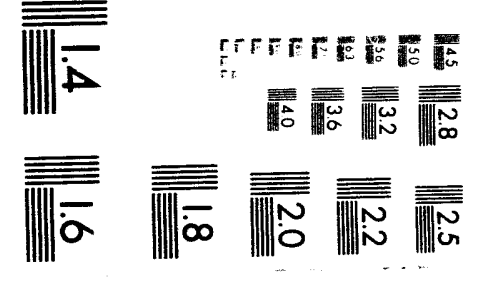



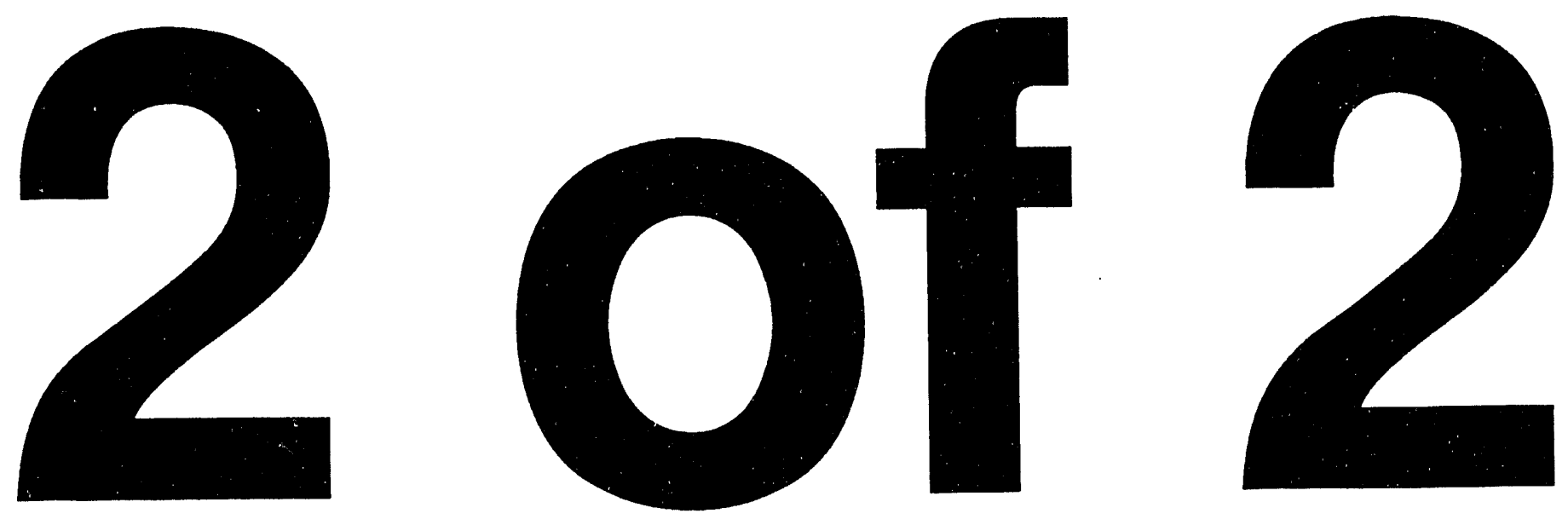
Steel Irradiation Program Sponsored by Verein Deutscher Eisenhüttenleute

This is an extensive irradiation program sponsored by the Verein Deutscher Eisenhüttenleute (VDE). Four different steels, coded A, B ,C , D, and associated welds with HAZ were irradiated in the FRJ-2 reactor, KFA, Jülich, to target fluences of $1.0 \mathrm{E} 19,5.0 \mathrm{E} 19$, and 1.0E20 ( $\mathrm{E}>1.0 \mathrm{MeV}$ ) at irradiation temperatures of 300 and $400^{\circ} \mathrm{C}$. The code A material is part of the HSST-2 plate (SHSSO2A, the associated weld and $\mathrm{HAZ}$ were fabricated from a piece of HSST-3), the others are MnNiCrMoV and NiCrMo alloys (PVDEOB, PVDE0C, and FVDE0D). Irradiations were performed in small batches, and detailed information is provided for each run (listed in REAC_TR.dbf, CV_RF_TR.dbf, and RAW_C_TR.dbf as individual physical capsules). Specimen from different capsules were then combined to determine the Charpy shift values for the target fluences and irradiation temperatures (the combined specimen sets are listed in RAW_C_FT.dbf and CV_RF_FT.dbf). All details are published in 24 "Berichten," plus a summary (Ābschlussbericht).

YR

Investigations in Support of the Yankee Rowe Reactor

The PV steel samples of the Yankee Rowe Reactor that were irradiated in surveillance capsules 1,2 , and 6 were not immediately tested but annealed for 168 hours, each capsule at a different temperature. The results of this program are reported in NRL 6616 and are included in the file SHFTA_TR.dbf of the TR-EDB. 


\section{Use of Units}

All data in the TR-EDB are given in the units of the original reports. (If reported in more than one unit, the data obtained directly from the test equipment are used, as indicated by whole numbers instead of fractions.) The ASTM recommends the use of the units given in the International System of Units (SI), as described in the ASTM Standard for Metric Practice. This standard provides also the guidance and constants for unit conversion. The basic units for this system are meter $(\mathrm{m})$ for length, seconds ( $\mathrm{sec}$ ) for time, and kilogram (kg) for mass. Prior to the adoption of the International System the customary engineering practice used units of force instead of mass as the third basic unit. Pound (lb) as unit of force, in addition to foot (ft), and inch (in) for length has been used in the U.S. and other English speaking countries and is still found in many U.S. reports (identified as US_Unit). Older European reports use kilogram (kg) or kilopond $(\mathrm{kp})$ as units of force, combined with meter and second. We shall identify this system of units as "other technical" (OT) units. The dual use of $\mathrm{kg}$ for force and mass is confusing, although the context makes it clear which meaning is attached to this symbol in a particular report. In the TR-EDB only one meaning is attached to any particular symbol as listed in the UNIT_TR.dbf in Table 35 and only the units listed in this file will appear in any unit field of the data files. Upper and lower cases are assigned to the unit symbols according to the ASTM Standard; this policy was not strictly followed in the PR-EDB but will be adopted in future releases. 


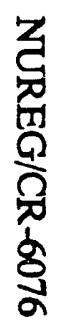

Table 35 Units used in TR-EDB files

\begin{tabular}{|c|c|c|c|c|c|c|}
\hline$\overline{\text { U_Name }}$ & U_Symbol & U_Type & U_System & SI_Unit & SI_Symbol & SI_Equiv \\
\hline $\begin{array}{l}\text { millimetre } \\
\text { inch } \\
\text { mil (1/1000 inch) } \\
\text { metre (basic SI unit) } \\
\text { joule } \\
\text { foot pound (pound force) } \\
\text { kilogram (force) metre } \\
\text { mega pascal } \\
\text { kip ( } 1000 \text { pounds)/square inch } \\
\text { kg (force)/square millimetre } \\
\text { degree Celsius (centigrade) } \\
\text { degree Fahrenheit } \\
\text { kelvin } \\
\text { second } \\
\text { day } \\
\text { hour } \\
\text { year ( } 365 \text { days) } \\
\text { metre per second } \\
\text { foot per second }\end{array}$ & $\begin{array}{l}\mathrm{mm} \\
\text { in } \\
\mathrm{mil} \\
\mathrm{m} \\
\mathrm{J} \\
\mathrm{ft}-\mathrm{lb} \\
\mathrm{kgm} \\
\mathrm{MPa} \\
\mathrm{ksi} \\
\mathrm{kg} / \mathrm{mm}^{2} \\
\mathrm{C} \\
\mathrm{F} \\
\mathrm{K} \\
\mathrm{S} \\
\mathrm{D} \\
\mathrm{H} \\
\mathrm{Y} \\
\mathrm{m} / \mathrm{s} \\
\mathrm{ft} / \mathrm{s}\end{array}$ & $\begin{array}{l}\text { length } \\
\text { length } \\
\text { length } \\
\text { length } \\
\text { energy } \\
\text { energy } \\
\text { energy } \\
\text { stress } \\
\text { stress } \\
\text { stress } \\
\text { temperature } \\
\text { temperature } \\
\text { temperature } \\
\text { time } \\
\text { time } \\
\text { time } \\
\text { time } \\
\text { velocity } \\
\text { velocity }\end{array}$ & $\begin{array}{l}\text { SI } \\
\text { US } \\
\text { US } \\
\text { SI } \\
\text { SI } \\
\text { US } \\
\text { OT } \\
\text { SI } \\
\text { US } \\
\text { OT } \\
\text { SI } \\
\text { US } \\
\text { SI }\end{array}$ & $\begin{array}{l}\text { metre } \\
\text { metre } \\
\text { metre } \\
\text { metre } \\
\text { joule } \\
\text { joule } \\
\text { joule } \\
\text { pascal } \\
\text { pascal } \\
\text { pascal } \\
\text { degree Celsius } \\
\text { degree Celsius } \\
\text { degree Celsius } \\
\text { second } \\
\text { second } \\
\text { second } \\
\text { second } \\
\text { metre per second } \\
\text { metre per second }\end{array}$ & $\begin{array}{l}\mathrm{m} \\
\mathrm{m} \\
\mathrm{m} \\
\mathrm{m} \\
\mathrm{J} \\
\mathrm{J} \\
\mathrm{J} \\
\mathrm{Pa} \\
\mathrm{Pa} \\
\mathrm{Pa} \\
\mathrm{C} \\
\mathrm{C} \\
\mathrm{C} \\
\mathrm{s} \\
\mathrm{s} \\
\mathrm{s} \\
\mathrm{s} \\
\mathrm{m} / \mathrm{s} \\
\mathrm{m} / \mathrm{s}\end{array}$ & $\begin{array}{l}0.001 \mathrm{~m} \\
0.0254 \mathrm{~m} \\
0.0000254 \mathrm{~m} \\
1.0 \mathrm{~m} \\
1.0 \mathrm{~J} \\
1.355818 \mathrm{~J} \\
9.806650 \mathrm{~J} \\
1,000,000 \mathrm{~Pa} \\
689,575.7 \mathrm{~Pa} \\
980,665 \mathrm{~Pa} \\
1.0 \mathrm{C} \\
1.8 \mathrm{C}+32 \\
1.0 \mathrm{C}+273.15 \\
1.0 \mathrm{~s} \\
86,400 \mathrm{~s} \\
3,600 \mathrm{~s} \\
3,153,600 \mathrm{~s} \\
1.0 \mathrm{~m} / \mathrm{s} \\
0.3048 \mathrm{~m} / \mathrm{s}\end{array}$ \\
\hline
\end{tabular}




\section{REFERENCES}

1. F. W. Stallmann,, F. B. K Kam, and B. J. Taylor, "PR-EDB: Power Reactor Embrittlement Data Base, Version 1," NUREG/CR-4816, June 1990.

2. "Radiation Embrittlement of Reactor Vessel Materials," Regulatory Guide 1.99, Revision 2, May 1988.

3. C. Z. Serpan, Jr., and J. R. Hawthorne, "Yankee Reactor Pressure-Vessel Surveillance: Notch Ductility Performance of Vessel Steel and Maximum Service Fluence Determined from Exposure During Cores II, III, and IV," NRL Report 6616, September 1967.

4. J. A. Wang, F. W. Stallmann, and F. B. K. Kam, "PR-EDB: Power Reactor Embrittlement Data Base, Version 2" NUREG/CR-4816, May 1993. 
APPENDIX A. CUSTOM SOFTWARE FOR PROCESSING OF THE TR-EDB 


\section{A.1 INTRODUCTION}

The software described in this appendix is the current implementation of a system that provides the user of the TR-EDB with the necessary tools to process the data and tc create a variety of tables, Charpy fits, and other graphs for reports and verification of irradiation embrittlement predictions. This software was originally created for the PR-EDB, and the current version remains compatible with this data base. Since that time, a large assortment of software tools for relational data bases has become commercially available so that the custom tools described in this appendix are now less crucial for the convenience of the user. For this reason, no effort is being made at this time for an extensive update of the custom software. However, the current version is still quite useful for many routine tasks. In particular, the processing of numerical data given in character format can be quite tedious and sometimes unreliable with commercial software. Many applications require some pre-processing to convert the dBASE files in the TR-EDB (or PR-EDB) to a form suitable for input to the more business-oriented procedures. The current version of the custom software has been thoroughly tested for several years and has provided reliable output for all tasks for which it was designed.

The current version of the software package EDB-Utilities has been written in the Clipper language, which allows compilation of dBASE procedures and has facilities for menu and help screens so that the user can usually run the program without additional instructions. The program package provides the means for a number of file-manipulation tasks, including the display of data on the computer screen and hard copy to a printer. The dBASE and related software, such as Clipper, lack the facility for extensive mathematics/statistics calculations and scientific graphs. Some plotting and fitting programs have been written in FORTRAN using the IMSL and GRAFMATIC libraries and require ASCII files as input. These ASCII files can be created through the EDB-Utilities file-manipulation feature. An ASCII file that contains all data that are available in the TR-EDB for fitting of raw Charpy data, RAW_C_TR.dat, is part of the TR-EDB set of diskettes. Also included are the files CV_RS_TR.sum, CV_RS_TR.dat, and CV_RS_TR.dbf, which contain the results of the Monte Carlo uncertainty analysis from $\mathrm{RA} \overline{\mathrm{W}} \_\overline{\mathrm{C}}$-TR.dat with 200 iterations. The file CV_RS_TR.dat can be used as auxiliary input file for the multiple fitting program.

The primary output device for graphic presentations by the EDB-Utilities is the monitor screen in EGA or VGA format which is selected automatically depending on what the graphic card can accommodate. A screen capture facility is needed to send the plot to the printer. It is assumed that the screen capture is activated by the <Shift-PrintScreen > command, which is given by the graph program, if selected.

\section{A.2 EDB-UTILITIES SOFTWARE PACKAGE}

The EDB-Utilities package has been designed to provide the end user of the Embrittlement Data Base with convenient means to manipulate, view, plot, and fit the data that are given in BBASE format. There are four major options that can be selected from the first menu. (See Figure A.1.) 
1. File-Manipulation Procedures. This option is not restricted to TR-EDB files; any file in dBASE format can be processed. Specifically, the following operations can be performed:

a. Retrieve a file for manipulation

b. Add or delete fields

c. Use numerical data for calculations and place results in user-defined fields

d. Add or delete records

e. Reorder records

f. Display or export data

g. Save working file

A detailed explanation of the different operations will be given in Sect. A.3.

2. Plot Data Exported from EDB files. Numerical data from dBASE files can be exported to ASCII files, as described in Sect. A.3.7, and can be represented in scatter plots with automatic scaling and labeling. Specific curves can be added to the graph as an option. Details are given in Sect. A.4.

3. Fit and Plot Charpy Impact Data from EDB files. Raw Charpy impact data from a file in ASCII format, created from a raw Charpy file such as RAW_C_TR.dat, can be fitted to a hyperbolic tangent curve and the results plotted. A Monte $\bar{C}$ arlo uncertainty analysis program is included which determines the uncertainties in the fitting parameters given the uncertainties in impact energy and test temperature of the original data. The following options are provided:

a. Single-curve fitting and plotting

b. Multiple-curve fitting and plotting

c. Monte Carlo uncertainty analysis

d. Extracting selected Charpy sets

Details are given in Sect. A.5.

4. Run dBASE III PLUS OR dBASE IV. This option allows the user to run the dBASE program without exiting EDB-Utilities, provided dBASE III PLUS OR dBASE IV has been properly installed. (It is assumed that the directory containing the dBASE program is in the path given in the autoexec.bat file.) The user can, in this manner, easily switch between different options and edit or perform other tasks in dBASE for which no provisions are given in the EDB-Utilities package. Note that all fields in the PR-EDB files are character fields, and any numerical manipulation of data must first use the VAL(...) function to obtain numbers, and convert the results back to character strings using $\operatorname{STR}(. .$.$) .$ 


\section{A.3 FILE-MANIPULATION PROCEDURES}

File-manipulation procedures are shown schematically in Fig. A.2.

\section{A.3.1 General Considerations}

The TR-EDB consists of a number of data files in dBASE format. Each file can be considered as a table of data; the columns of the table are called Data Fields and the rows, Records. Each data field has a given length FIELD_LEN, a unique identifier FIELD_NAME, and a FIELD_TYPE, which declares the data as either "character," or "numeric," or "date" fields, and this information is coded in a special manner at the head of the dBASE files. This information is used in the dBASE software for a variety of processing tasks. However, all data fields in the TR-EDB are of character type; this allows one to use blanks for missing data and also the introduction of scientific notation, for which dBASE III PLUS has no provisions. It requires, however, that the information about the actual data types must be provided in some other way to the processing codes in order to perform calculations, comparisons, and orderings. For this reason, a special "structure file" is assigned to each data file which has the same name but the extension .str instead of .dbf (e.g., REAC_PR.dbf has the structure file REAC_PR.str). This structure file has the same first five fields as the dBASE structure file, but in addition a field $F_{-} T$ for the actual field type, which can be $\mathrm{C}$ for character, $\mathrm{N}$ for numeric, $\mathrm{S}$ for scientific notation, and $\mathrm{D}$ for date. It also has a description field DESC which contains detailed information about the data contained in the field, plus the type of units used (enclosed in brackets [...]). This information is displayed in menu screens concerning data fields and is used to label the axes in the plots that are generated in the plotting option of EDB-Utilities. Also included in the structure files are tag fields that are used for temporary selections in display and printing.

All file-manipulation procedures, such as changing data fields or records, reordering, and displaying are never performed on the original data file; the input file is first copied to a "working file" WORK.dbf, and the associated structure file, to STRUCT.dbf. A dBASE-type structure file TMPS.dbf is also needed for some file-manipulation procedures. After performing the desired procedures, the working files may be saved to new files, or the old files may be overwritten. The working files remain in the directory and can be accessed again by the EDB-Utilities, even after the program has been temporarily terminated. The original files remain as they are unless overwritten by the user.

\section{A.3.2 Retrieval of Files for Manipulation}

Any dBASE file can be processed by the manipulation option of EDB, including the structure files. The input files need not be TR-EDB files (i.e., containing only character fields), but the working file WORK.dbf has this property. A new structure file is created if an associated structure file is not present or is incompatible with the input file. Field names used in the EDB files are listed in a file STR_ALL.dbf, and this file is used to put information in the new structure file for such field names. (This file, together with the associated index file STR_ALL.ndx, is part of the distribution of the TR-EDB.) Other information must be entered by the user, who can also change the information from STR_ALL.dbf, if necessary. The new structure file is saved if none was previously available, but old files are not automatically overwritten, even if they are incompatible. (Any structure file together with the dbf file may overwrite the original file at the 


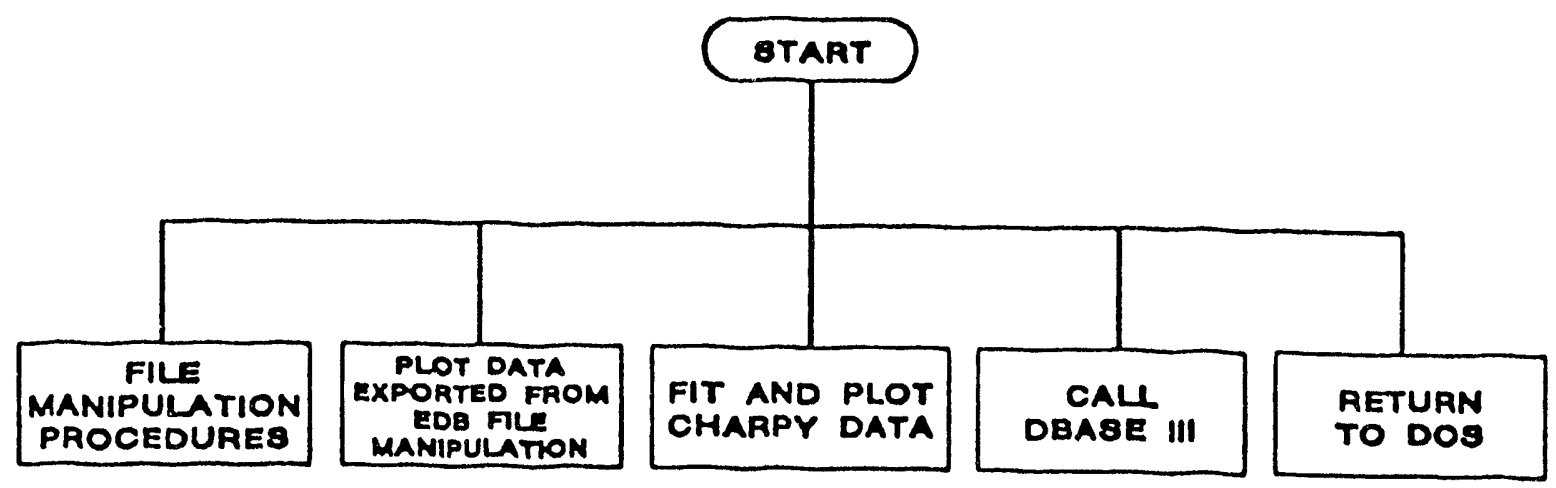

Fig. A.1 Major options selected from first menu

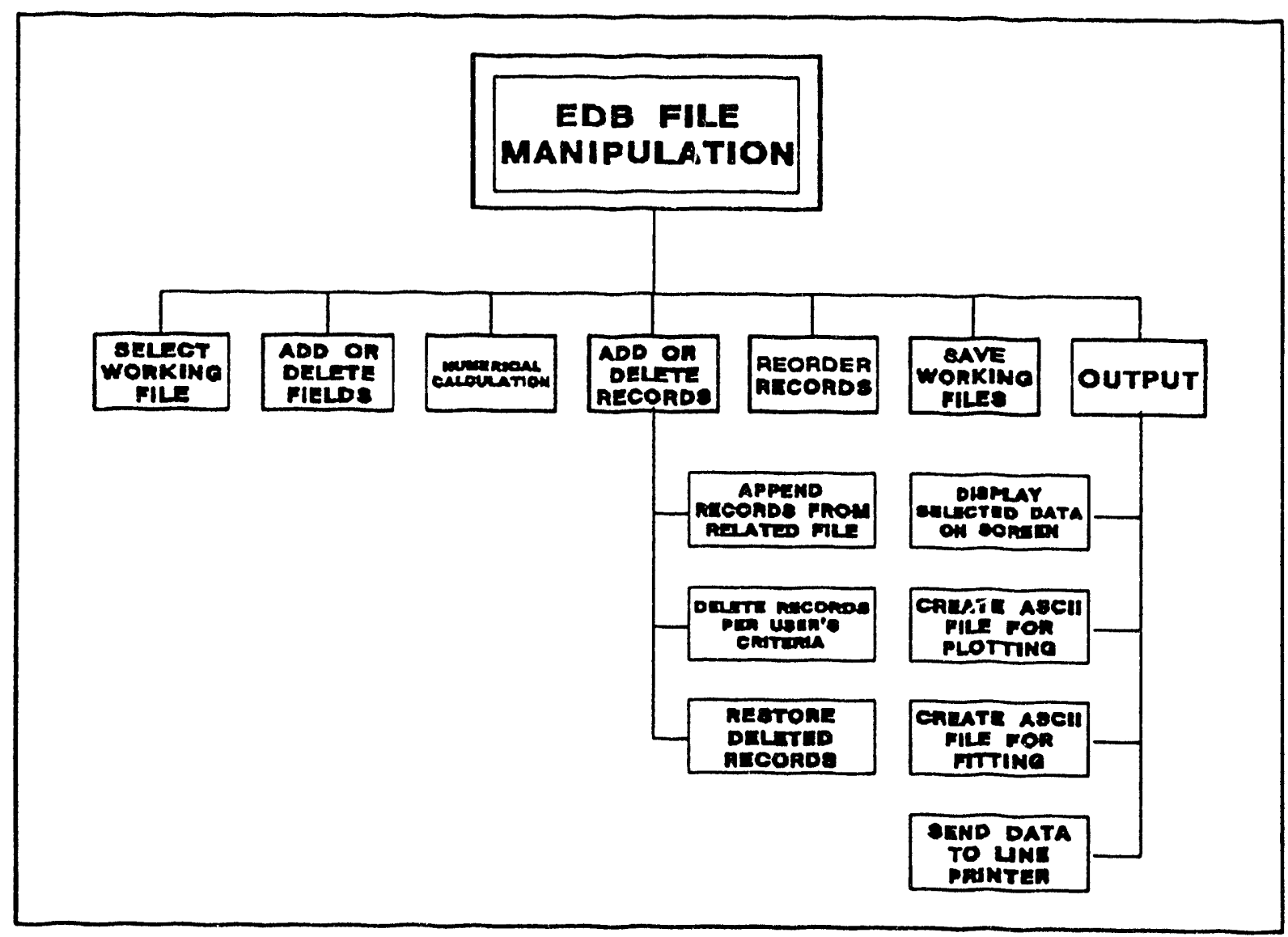

Fig. A.2 File-manipulation procedures 
user's option.) The working file WORK.dbf has no associated index file. However, an index file can be used with the input file to ensure the proper order in the working file.

\section{A.3.3 Addition or Deletion of Fields}

Fields can be added to the working file for storing the results of calculations, and only these fields can be used for this purpose. However, fields added in a previous run to a file that was subsequently saved can still be used for results after later retrieval of the file. Any field can also be deleted, including ones that had been added previously. Both additions and deletions become final only after the modification command is given; tentative additions and/or deletions can be aborted, if necessary.

\section{A.3.4 Addition and Deletion of Records}

Records can be deleted from the working file according to conditions entered by the user. This step is done using the option "Select Records From Working File." Note that the deletion of records in $\mathrm{dBASE}$ is a two-step procedure; first, records to be deleted are marked; following that step, the marked records are completely eliminated. The marked records can be restored as long as the final elimination step has not been executed. Consequently, there are two options in the selection procedure: deletion (marking) of records and restoring (unmarking). All records can be deleted if the restoration option is entered before deleting any records. Both procedures are done for records that satisfy conditions that are entered by the user in the menu screens provided. Using suitable sequences of deletions and restorations, practically all selection criteria can be satisfied (see Examples, Sect. A.6). After the selection procedure is completed, all deleted (i.e., marked) records are removed (eliminated) and can no longer be restored. Selections can also be aborted in case of an error.

Records can be added to the working file by appending them from another DBASE file. This file need not be a PR-EDB file or a saved working file and may have numerical or date fields. All data are again converted into character fields before appending. Data are appended according to the field names, which must be the same in the working and the added file.

\section{A.3.5 Calculations}

A variety of numerical operations can be performed on fields of numerical- or scientific-type data, with the results entered into user-defined scientific fields. Only one operation at a time can be performed, namely addition, subtraction, multiplication, division, exponentiation plus exponential function, and logarithm. More complicated formulas can be calculated in a properly chosen sequence of operations using, perhaps, some auxiliary fields for temporary storage. A warning is given for improper operations such as division by zero, and a blank record is given as a result. A blank is also given if one of the operations has a blank record, indicating missing data.

\section{A.3.6 Reordering}

No index files are associated with the working file, but records can be sorted in any manner by entering the ordering criteria in the menu screen provided. The chosen arrangement can be saved in an output file, if desired. 


\section{A.3.7 Display and Export}

The data in the working file can be displayed on the screen or printed. A menu is provided which allows the selection of fields to be displayed or printed in any desired order. For printing, the user must supply the number of characters per line and the number of lines per page. The fields will be distributed over several pages if the width of the output exceeds the number of lines permitted, and, of course, if there are more records than the number of lines per page. The data can also be saved in an output file that is formatted in a manner suitable for subsequent plotting with the EDB-Utilities plotting program. Another ASCII file can be created as input for the Charpy fitting programs from a raw Charpy data file, such as, RAW_C_TR.dbf or another file with the same structure. An empty file, RAW_C_DT.dbf, must be present to receive the data from the input file after the necessary unit conversions. An optional structure file RAW_C_PR.str can be used to assure that the input file has the proper data structure.

\section{A.3.8 Save Working File}

The working file and the associated structure file can be saved by copying them under a user-specified name. A warning will be given if a file under this name already exists, but overwriting an existing file is permitted, destroying the old file in the process.

\section{A.4 PLOTTING PROGRAM}

The data input for the plotting program (Fig. A.3) is prepared by the file-manipulation procedures and exported to special plot files as described in the previous Sect. A.2. Data from up to ten different files can be put in the same plot with different symbols assigned to each data set. Once the plotting program has been called from the main menu, the following information must be given:

1. The name of the structure file that was associated with the working file from which the data set was prepared. The sole purpose of this file is to provide the information about which data fields should be used for the $x$ - and $y$-coordinates, respectively. Thus, any structure file may be used which has the corresponding numerical data fields in it, even if another working file was used to create the plot input. The field names used for coordinates must be common to all plot files for the same plot, but other fields may differ.

2. The plot title. The title will appear in large letters on top of the plot.

3. Data fields for the coordinates. The user selects these fields from an input screen that shows the numerical fields in the structure file. The descriptions and units given in the structure file will be used for labeling the coordinate axes.

4. Names of the plot files and associated descriptions. The data descriptions will be used for (optional) legends that can be placed at any desired location in the plot and will appear in the same sequence as they are entered in the screen. Blanks as descriptions will be ignored in the legend. 
5. Curves. Certain types of curves can be placed on the plots in addition to the data points. The user selects the desired type of curves from the menu screen and may also enter legends for these curves.

6. Choice of a preset coordinate system. The default version of this option is a coordinate system that is automatically scaled to accommodate all data and curves in the smallest range possible. However, the user can select a predetermined range of coordinate values. The option includes also the choice of a logarithmic coordinate system in either or both coordinates. Points and curves that fall outside the range are eliminated.

7. Symbols and colors. An option is provided for selecting symbols and colors (for colc i monitors and printers) for the different data sets and the curves. Dashes of different densities can be selected for the curves.

Once the input is given, a picture of the plot will appear on the screen. Labeling of the axes is automatic, using the information from the input data and structure files. The user will be asked to place the legend at some location in the plot where it does not interfere with the data points and curves. The plot may then be sent to the printer if the necessary connections are in place.

All input data for the plot, including information about curves, symbols, and colors, are saved and can be used with subsequent plots. The user can choose to use the same plot data again, with a possible change in curves, symbols, colors, and the placement of the legend. The input information may also be changed selectively or completely erased (this applies only to the information that is generated during the plotting procedure, such as name of input files, title, and legends, but not to the data files which remain intact).

\section{A.5 CHARPY FITTING AND PLOTTING}

\section{A.5.1 General Considerations}

The EDB-Utilities software allows the creation of fits and plots for any given set of raw Charpy data using the hyperbolic tangent function. The program requires an input file in ASCII format that can be created by one of the options in the section for display and export discussed above. For convenience the file RAW_C_TR.dat that was created from RAW_C_TR.dbf is distributed with the TR-EDB data files. (This file contains some combination of sets from several physical capsules whenever there are too few specimen in anyone capsule. The dbf version of these combinations are found in RAW_C_FT.dbf and CV_RF_FT.dbf.) To be consistent with the PR-EDB software, all data are converted to U.S. units, the unit fields are removed, and a one-character field is added in front of SPEC_ID. If this field contains an asterisk, the record will be excluded from processing; this feature is useful for removing outliers. The program searches for the combination of PLANT_ID + CAPSULE + HEAT_ID + SPEC_ORI which are common to each set of raw Charpy data that are used for the determination of transition temperature and upper shelf energy. For some un-irradiated data (PLANT_ID and CAPSULE are blank) different sets were used for different experiments. Here, the only distinguishing identifier is EXP_ID which was, for this reason, added to the file RAW_C_TR.dbf but could not be retained in the ASCII file RAW_C_TR.dat. To permit the user to evaluate these sets 
separately additional set were added to the ASCII file in which the (blank) PLANT_ID was replaced by EXP_ID. Some evaluations were also performed from combinations of sets that come from different physical capsules but have similar fluences and irradiation temperatures. These sets with a different CAPSULE identification were also added to the ASCII file. All sets in the ASCII file that are not contained in RAW_C_TR.dbf are also placed in the dBASE file RAW_C_FT.dbf, which can be converted also to $\bar{A} \overline{S C I I}$ format.

The fitting procedure is completely automated. Upper and lower shelf values are restricted by adding a penalty proportional to the deviation from initial estimates to avoid unphysical fits. A first inspection of the points is made to obtain a rough estimate for the initial values of the curve parameters. (The starting value for the lower shelf is $3.0 \mathrm{~J}$ or $2.2 \mathrm{ft}-\mathrm{lb}$ ) A nonlinear least-squares-fitting program ZSSQ from the IMSL library is used to determine the best fit, which is then plotted and appears on the screen, including data points with automatic scaling and labeling of the axes in both U.S. and international units. The plots can be sent to the printer if a suitable screen capture program is active. All internal calculations are done in international units, centigrade and joule. The user has the option to select the range of temperature and energy values in the plot for convenient comparisons (e.g., overlays) of the curves. Points and curves that fall outside the range are ignored in the graph.

As stated in Sect. A.2, Item 3, there are four options for this part of the program.

\section{A.5.2 Single-Curve Fitting and Plotting}

In this option, the selected data sets are fitted and plotted, one at a time, with optional printing of the results. Titles and subtitles for the plots can be either given individually or at the start of the procedure, with the key identifiers serving as subtitles. The user has the option to skip any data set and to terminate the procedure without reading the whole input file.

\section{A.5.3 Multiple-Curve Fitting and Plotting}

With this option, up to ten different fits can be placed into one plot. This feature is useful for comparing data before and after irradiation. The user enters the overall title and legends for the individual fits. Default legends can be used which contain the name of the capsule and the total fluence $(>1.0 \mathrm{MeV})$. Legends can be placed by the user at a suitable free spot in the plot. An auxiliary file generated as dBASE output file from the Monte Carlo fitting procedure can be used to bypass the fitting procedure in favor of predetermined fitting parameters. The file CV_RS_TR.dat is distributed with the TR-EDB for this purpose. (See next Section A.5.4.)

\section{A.5.4 Monte Carlo Uncertainty Analysis}

Uncertainties for the fitting parameters are needed to determine accuracy and credibility of the transition temperature and upper shelf data. A covariance matrix of the fitting parameters is part of any least-squares procedure, but these covariances are not used for uncertainty analysis in the EDB-Utilities. The unavoidable linearization used for determining the covariances disregards second-order effects, and there is no possibility to account for uncertainties in test temperature. A more reliable procedure is the use of random variations of the input data (Monte Carlo procedure); such variations can be applied to both impact energy and test temperature, and the results reflect more accurately the influences of nonlinearities. The necessary computing time 
is, of course, increased by a large factor but remains manageable for today's computers. Because this option is completely automated, including printing the plots, a fairly large amount of data sets can be processed overnight or over a weekend. Nonphysical results and results that deviate substantially from the mean are eliminated from the sampling. This has the added advantage that fits can be obtained even after some tries have failed initially.

The user enters the (one-standard deviation) uncertainties for the impact energy and test temperature and the number of iterations. Unsuccessful iterations (i.e., the ones rejected by the program as nonphysical or inconsistent with the rest) are not counted; however, the total number of tries may not exceed five times the specified iteration number. Also needed is the number of sets to be skipped at the beginning of the input data file and the number to be processed. Processing is done, one set at a time, in sequence, starting after the specified number of sets have been skipped. A more specific selection can be obtained by using, as the input data file, the one created by the selection procedure (Sect. A.5.5). Continuous plotting and printing can be chosen as an option, with the user providing the common title and the key identifiers as a subtitle.

Three output files are created by the procedure, the names of which are either entered by the user or assigned by default. The "Summary Output File" (default name FORT15; the 15 in FORT15 is the unit number of the FORTRAN output file) is a list which contains the set number, key identifiers, fluence, irradiation temperature, transition temperature at $41 \mathrm{~J}$ and 68 $\mathrm{J}$ ( $30 \mathrm{ft}-\mathrm{lb}$ and $50 \mathrm{ft}-\mathrm{lb}$ ), upper and lower shelf energy (all in international units), the number of specimens in the set, and the number of successful iterations for each processed set. The "Covariance Output File" (default name FORT16) contains mean values, standard deviations, and correlations for all fitting parameters which include the transition temperature at the center of the curve and $1 /$ slope, which is one-half of the impact energy range of the transition region. The "EDB_dBASE Output File" (default name FORT17) is intended for conversion to a dBASE file whose data are an alternative to the file SHFT_PR. This file can also be used as an "auxiliary" input file in the multiple fitting option (Sect. 5.3). Its data are given in English units. A "status report" listing the results from all successful and unsuccessful iterations is placed on the screen during the procedure. The screen output can be redirected to a file as an option.

The complete file RAW_C_PR.dat has been processed with this program, with $10 \mathrm{~J}$ and $4^{\circ} \mathrm{C}$ as input uncertainties for impact energy and test temperature, respectively, and 200 iterations. The summary and dBASE output files, CV_RS_TR.sum and CV_RS_TR.dat, respectively, are included in the data disks. The dBASE version of CV_RS_TR.dat, CV_RS_TR.dbf is also included in the package. The covariance file, which is very large and of limited usefulness, is not included.

\section{A.5.5 Extracting Select d Charpy Sets}

The raw data files for individual Charpy sets are quite large and thus require long search times in sequential access. It is, therefore, convenient and saves time to copy small subsets from a larger file, if such subsets are processed repeatedly. This is accomplished through the data-selection option. The user specifies the selection criteria and may, in addition, skip certain sets and terminate the procedure without going through the rest of the input file. No processing is done during this option, but the user-specified output file (default FORT20) can now serve as an input file for any subsequent processing step. 


\section{A.5.6 Selection of Input Files and Data Sets}

The four options require essentially the same input information that is requested in several input screens:

1. Names of input data files, primary and auxiliary. The primary input file is RAW_C_PR.dat, which is included in the package and given as default at the menu. The user may change this name to that of any other data file that contains raw Charpy data in the same format (e.g., one obtained from the selection procedure described in Sect. A.5.5). The multiple-fitting option permits the use of an additional, "auxiliary" input file that contains the values of the fitting parameters as generated by the Monte Carlo uncertainty analysis as EDB-dBASE output file. The file RAW_C_RS.dat is included in the package and appears as default. Its use is optional and allows the user to bypass the least-squares fitting, speeding up the process and avoiding problems with convergence. The data sets in the primary and auxiliary files need not be identical or in the same sequence.

2. Selection criteria. Reactors and materials can be selected for processing by entering the selection criteria in the appropriate menu screen. These criteria are not used in Monte Carlo uncertainty analysis. The Monte Carlo uncertainty analysis is designed to process a large number of data sets in sequence without user intervention. Consequently, only the starting number and the number of sets to be processed can be given. The number associa' ed with each set can be found in the (ASCII) file RAW_CPY.SUM. These numbers are entered in the input screen as discussed in Sect. A.5.4.

3. Choice of a preset coordinate system. The default version of this option is a coordinate system that is automatically scaled to accommodate all data and curves in the smallest range possible. However, the user can select a predetermined range of coordinate values, which makes it easy to compare the Charpy curves from different sets. Points and curves that fall outside the range are eliminated.

4. Selection of symbols and colors. This is essentially the same procedure as for plots in Sect. A.4, Item 6. Data points that are excluded from the fitting procedure can be plotted using different symbols. Such points can also be completely eliminated from the plot by using the empty symbol (zero symbol) for rejected data points.

\section{A.6 INSTALLATION AND EXECUTION}

Running the EDB-Utilities with data files requires an IBM-compatible PC, preferably with 80286 (AT) or better processor, and a hard disk. At least $512 \mathrm{~kb}$ RAM is recommended. A matching co-processor 80287/80387 is also required. The graphics programs are written for an EGA screen with $640 \times 350$, or VGA, $640 \times 480$ pixel resolution. (The selection is automatic, depending on the active video card.) For a hardcopy of the graphics, a screen capture utility is needed that is activated by the Shift-PrtScr command. This command is part of the software and does not need be given externally. 
The TR-EDB plus software is being distributed on diskettes in compressed form. A directory with at least $5 \mathrm{Mb}$ free space must be prepared on the hard disk to receive the set of files. Place the distribution disk into the appropriate diskette drive " $D$ " ( $D$ being usually the drive A or $B$ ), and from the hard-disk directory give the command D:TR-EDB. This command will unpack the files and copy them to the hard disk. A list of data and program files is given in the file TR-EDB.lst and in Appendix C. After copying the files to a selected directory, the program is activated by typing "EDB." (Executing the file EDB.bat.) After a title screen the menus appear from which the user selects the various option by means of the arrow keys and the "Enter" button. The options are self-explanatory. No changes are made in the original input files, except if the overwrite option is explicitly chosen by the user. Thus, some experimentation or user errors will not result in destruction of the original files. All anticipated user errors will be displayed on the screen with suggestions for corrective action. However, in rare cases programs may be aborted, usually due to problems with the system, such as lack of memory. To retain the error message in these cases the executable file *.exe should be called directly and not the EDB.bat file. That is, type the name of the aborted file, in most cases PLNK, not EDB, to run the aborted program and obtain the error message.

No examples are included in the current release of the software. However, all necessary input files are provided with default values, whenever appropriate. 
APPENDIX B. DIFFERENCES BETWEEN CURRENT VERSIONS OF THE PR-EDB AND TR-EDB 


\section{B.1. DATA FILES}

1. The following new files were added that are not part of the PR-EDB:

1. E_LST_TR.dbf - List of experiments

2. SḦFTA-TR.dbf - Anneal data

3. SHFTX_TR.dbf - Charpy transition temperatures for non-standard criteria

2. Some files were renamed to distinguish between TR-EDB and PR-EDB versions:

1. SPEC_LST.dbf is renamed S_LST_TR.dbf

2. REAC_LST.dbf is renamed $\bar{R}_{-}$LST $\bar{T}_{-}$TR.dbf

3. HEAT_LST.dbf is renamed H_LST_TR.dbf

4. REF_TITL.dbf is renamed TITL_TR.dbf

5. REF LST.dbf is renamed REF TR.dbf

These files with the suffix PR will be introduced in future versions of the PR-EDB.

3. The field EXP_ID was added to all files, except R_LST_TR.dbf. It replaces the field PLANT_ID in HEAT_LST.dbf, HEAT_PR.dbf, CHEM_PR.dbf, WELD_PR.dbf, HAZ_PR.dbf, and REF_L̄ST.dbf.

4. The field SPEC_SIZE was removed from the TR version of SPEC_LST.dbf (i.e. S_LST_TR.dbf). A REPORT_TAG was added to this file, and the NO_OF_SPEC field increased to 3 characters.

5. A number of fields was added to the file SHFT_TR.dbf to make it more self-sufficient. The field FLU_TAG characterizes the fluence determination, EFP_TIME, TIME_U, and F1_RATE give information about the fluence rates (these data are part of the file REAC_TR.dbf). Also added is the specimen irradiation temperature CSP_TEMP and the fields $\bar{U}_{-}$TAG and I_TAG for information about the fitting procedures for un-irradiated and irradiated specimen, respectively. The width of the fields DUSE_ABS and DUSE_REL have been increased to 5 to make them consistent with the other numerical fields.

6. Information about the Charpy test machine was added in the file CV_RF_TR.dbf.

7. More detailed information about the dimensions of the tensile specimen was added to the file TEN_TR.dbf. This information - in reduced form - is located in the file SPEC_LST.dbf of the current version of the PR-EDB. The number of fields for units has been reduced to one each for temperature and stress (in addition to the unit for length for the specimen dimensions). It can be assumed that the same units are used for the data in each individual test.

8. Three new fields were added to the file R_LST_TR.dbf (formerly REAC_LST.dbf), namely, two fields for the energy output both thermal and electric, and a NOTES field, which is part of most other files.

9. Several fields have been added to the files REAC_TR.dbf. Specific for test reactors is the information about "fission" fluence. This term refers to a method of fluence determination that was quite common in the early days of irradiation experiments. The fluence $(E>1.0 \mathrm{MeV})$ is determined from an activation dosimeter, usually ${ }^{54} \mathrm{Fe}(\mathrm{n}, \mathrm{p})$, whose 
cross-section relative to the $\mathrm{E}>1.0 \mathrm{MeV}$ portion of a fission spectrum is known (68 mb for ${ }^{54} \mathrm{Fe}(\mathrm{n}, \mathrm{p})$ ). This cross section multiplied with the measured activity is defined as the "fission equivalent fluence", or, fission fluence, for short. Often a ratio between fission fluence and calculated fluence is reported, based on comparison between the spectrum in the capsule obtained from a neutron transport calculation and the fission spectrum. Fields for the fission spectrum, CAP_FISS, and the ratio F1_TO_FISS are now in the reactor file. Also added are fields for the ratios of fluence $(E>0.1 \mathrm{MeV})$ and dpa to fluence (E > 1.0 MeV), FP1_TO_F1 and DPA_TO_F1, respectively. These ratios are useful for determining damage exposure parameters for individual specimen if specimen fluences are different from capsule fluences. A further addition is that of a nominal (or target) irradiation temperature, if only one temperature value is reported, which may be neither a minimum or maximum value. The meaning of the field TEMP_TAG has been changed somewhat from that used for surveillance capsules; here, the characters " $C$ ", " $T$ ", or " $\mathrm{M}$ " are used, depending whether the temperature was only calculated, determined by thermocouples (the most frequent and reliable method for test reactors), or melt wires. A corresponding field for fluence determination methods, FLU_TAG, has also been added.

10. Fields for nominal temperature, NOMTEMP $\mathrm{x}$, have been added to each heat treatment run. In the PR-EDB file single temperature (target) values were relegated to the minimum temperature, leaving the maximum temperature blank. This procedure reduces the size of the file but is inappropriate and confusing.

11. Separate fields for authors have been added to the reference file, TITL_TR.dbf (formerly REF_TITL.dbf), for easy retrieval of publications of a specific author. Any number of authors for the same paper can be accommodated, using the continuation record, if necessary. The same procedure makes it possible to list more than one EXP_ID for the same paper. Also added is a field for alternative references, ALT_REF; this can be useful if a report is published under the sponsorship of more than one organization (e.g., as NUREG report and ORNL-TM). However, only one designation is used as REF_ID.

12. A field for MPC number, MPC_ID, was added to the file REF_TR (formerly REF_LST). The field PLANT_ID was replaced by EXP_ID, as in other files mentioned above. 


\section{B. 2 SOFTWARE}

In addition to the removal of some bugs, the following changes have been made in the EDB software since it was distributed with the first version of the PR-EDB. These changes should make the software more useful while leaving all features of the previous version intact. Any user familiar with the old software will have no difficulty to use the new one, even without any additional explanation. The modified description is given in Appendix A. The new software has also been distributed with the Version 2 of the PR-EDB. The following changes were made:

1. An option is provided to convert the raw Charpy file RAW_C_PR.dbf or any other file with the same structure to a corresponding ASCII file that can be used in the Charpy fitting programs. An empty file RAW_C_DT.dbf and the file RAW_C_PIR.str should be present. This file is optional but useful to establish that the input file has the correct structure. The input file is WORK.dbf (i.e., RAW_C_PR.dbf) must be retrieved in the same manner as any other file used for processing with the EDB software. The program performs all the necessary conversions and checking automatically, informs the user of any problems and provides appropriate options. This program eliminates the need for including the ASCII data in the distribution of the TR-EDB (but this may still be done as a convenience to the user).

2. The graphic output for both plotting and Charpy fitting programs has been extended to accommodate the VGA in addition to the EGA display. The choice is automatic, the VGA display is more aesthetically pleasing and will be used whenever possible.

3. Some choice of parameters that have been previously lost after exiting the program will be retained for subsequent runs. A typical example is the number of characters in a line and number of lines on a page for the printing program. Any setting used for one printout will be retained as default for future runs until changed instead of reverting to the initial default setting after exit. The same is true for the user settings in the Charpy fitting programs.

4. Both the plotting and the Charpy fitting programs have an additional option that allows the user to define the boundaries of the coordinates in the plotting window. For the plotting program, this option includes a choice of logarithmic coordinates in either or both coordinate axes. The affected axis has to start and end with an integer power of ten with a range not to exceed 8 decades. For the Charpy fitting program the range of test temperatures (in ${ }^{\circ} \mathrm{C}$ ) and the maximum impact energy (in joules) may be specified. All data points and pieces of the curves that fall outside the specified ranges will not be displayed. This feature is especially useful for creating overlays that must be plotted in the same scale.

5. The printing of text next to the graphs of Charpy fitting containing transition temperature and upper shelf data has been eliminated. It has been difficult to place the text correctly because it depends on the printer and font size used and may also cause problems in some color printers such as HP Desk Jet 500C. The same information can be obtained through the Monte Carlo fitting program and is also displayed on the screen in the other fitting programs. 
6. The format of the dBASE output of the Monte Carlo program has been changed slightly, providing the same room for the uncertainties as for the other data. (In addition, the program puts a blank instead of a -1 into the uncertainties if no information can be obtained.) The program for multiple fits on the same graph that uses this output as auxiliary file has been adjusted accordingly. Consequently the program will not run correctly with an auxiliary file that has been created with the old version of the EDB software. The file CV_RS_TR.dat that is being distributed with the TR_EDB has the correct format. 
APPENDIX C. LIST OF FILES INCLUDED IN THE TR-EDB AND SOFTWARE 
C.1 Data Files:

E LST TR.dbf

ELST TR.str

S LST TR.dbf

SIST TR.str

SHFT_TR.dbf

SHFT TR.str

SHFTX_TR.dbf

SHFTX TR.str

SHFTA TR.dbf

SHFTA_TR.str

RAW_C_TR.dbf

RAW C TR.str

CV_RF_TR.dbf

CV_RF_TR.str

TEN _TR.dbf

TEN_TR.str

R_LSTT_TR.dbf

R_LST_TR.str

REAC TR.dbf

REAC_TR.str

H_LST_TR.dbf

H_LST_TR.str

CHEM_TR.dbf

CHEM_TR.str

HEAT_TR.dbf

HEAT_TR.str

WELD_TR.dbf

WELD TR.str

HAZ_TR.dbf

HAZ_TR.str

TITL TR.dbf

TITL_TR.str

REF_TR.dbf

REF_TR.str 
C.2 Auxiliary files:

RAW_C_TR.dat

RAW_C_FT.dbf

input file for fitting programs

r abinations and modification of RAW_C_TR.dbf for use in RAW_C_TR.dat

CV RF FT.dbf

CV RS TR.dat companion file to RAW_C_FT.dbf

CV RSTR.dbf

CV_RS_TR.str

CV_RS_TR.sum

dBASE output file from Monte Carlo fitting (US units)

dbf file created from CV_RS_TR.dat with references

summary output file in international units from

Monte Carlo fitting

RAW_C_DT.dbf

RAWCCPR.str

STR A A L $\bar{L} \cdot d b f$

empty file for creating ASCII file for fitting programs

file to verify correct structure of input file for fits

collection of all records used in structure $\left({ }^{*}\right.$.str) files

STR_ALL.ndx

index file used for constructing structure files

\section{C.3 Program files:}

EDB.bat

INTRO.exe

PLNK.exe

FITIN.exe

PLTIN.exe

PPLOT2.exe

STFIT2.exe

MTFIT2.exe

UTFIT2.exe

SELSYM.exe

C.4 Supplementary input files for the EDB software:

SYMDATA

SYMPLOT

SYMUSER

PLCOORD.dat

FTCOORD.dat

PROG.rbm

PLINFO.rbm

IDINFO.rbm

CUINFO.rbm

STINFO.rbm

MTINFO.rbm

UTINFO.rbm

MASTER.mem

MVSCR.mem

FILES.mem

PLOT.mem 


\section{INTERNAL DISTRIBUTION}

$\begin{aligned} 1 . & \text { B. R. Appleton } \\ 2 . & \text { C. A. Baldwin } \\ 3 . & \text { B. R. Bass } \\ 4 . & \text { J. A. Bucholz } \\ 5 . & \text { R. D. Cheverton } \\ 6 . & \text { W. R. Corwin } \\ 7 . & \text { F. M. Haggag } \\ 8 . & \text { S. K. Iskander } \\ 9-25 . & \text { F. B. K. Kam } \\ 26 . & \text { J. G. Merkle } \\ 27 . & \text { R. K. Nanstad } \\ 28 . & \text { W. E. Pennell } \\ 29 . & \text { C. E. Pugh }\end{aligned}$

\author{
30-32. C. H. Shappert \\ 33-37. F. W. Stallmann \\ 38. R. E. Stoller \\ 39-42. J. A. Wang \\ 43. R. M. Westfall \\ 44. G. E. Whitesides \\ 45. Central Research Library \\ 46. ORNL Y-12 Research Library \\ Document Reference Section \\ 47-48. Laboratory Records Department \\ 49. Laboratory Records, ORNL (RC) \\ 50. ORNL Patent Office
}

\section{EXTERNAL DISTRIBUTION}

51. E. D. Eason, Modeling and Comp. Services, 39675 Cedar Blvd. Suite 290, Newark, California 94560

52. T. J. Griesbach, EPRI, 3412 Hillview Avenue, P.O. Box 10412, Palo Alto, California 94393

53. J. Helms, Department of Applied Physics and Nuclear Engineering, 202 Mudd, Columbia University, New York, New York 10027

54. A. Hiser, U.S. Nuclear Regulatory Commission, Division of Engineering, Mail Stop NL S 217C, Washington, D. C. 20555

55. Erno Sajo, Louisiana State University, Nuclear Science Center, Baton Rouge, Louisiana 70803

56. C. Z. Serpan, Jr., U.S. Nuclear Regulatory Commission, Division of Engineering, Mail Stop NL S 217C, Washington, D. C. 20555

57. Al Taboada, U.S. Nuclear Regulatory Commission, Division of Engineering, Mail Stop NL S 217C, Washington, D. C. 20555

58. Office of the Deputy Assistant Manager for Energy, Research and Development, Department of Energy Oak Ridge Operations, Oak Ridge (DOE-ORO), P.O. Box 2001, Oak Ridge, Tennessee 37831-6269

59-60. Office of Scientific and Technical Information, P.O. Box 62, Oak Ridge, Tennessee 37831 

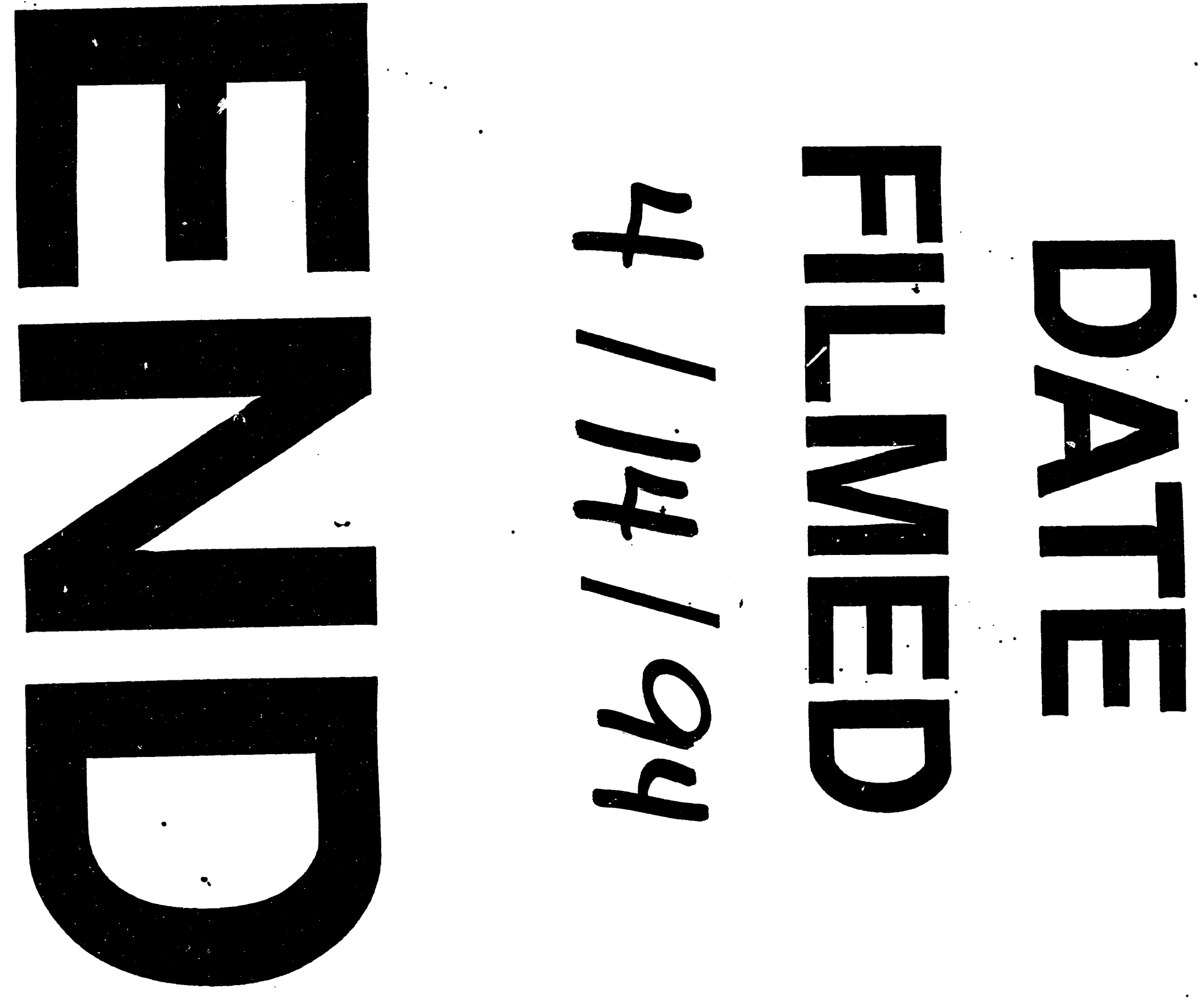


$$
\text { - }
$$

